\title{
Active Tectonics in Southern Xinjiang, China: Analysis of Terrace Riser and Normal Fault Scarp Degradation Along the Hotan-Qira Fault System
}

\author{
JEAN-PHILIPPE AVOUAC, 1 \\ Institut de Physique du Globe de Paris \\ GILLES PELTZER, 2 \\ Jet Propulsion Laboratory, California Institute of Technology, Pasadena
}

\begin{abstract}
The northern piedmont of the western Kunlun mountains (Xinjiang, China) is marked at its easternmost extremity, south of the Hotan-Qira oases, by a set of normal faults trending N50E for nearly $70 \mathrm{~km}$. Conspicuous on Landsat and SPOT images, these faults follow the southeastern border of a deep flexural basin and may be related to the subsidence of the Tarim platform loaded by the western Kunlun northward overthrust. The Hotan-Qira normal fault system vertically offsets the piedmont slope by $70 \mathrm{~m}$. Highest fault scarps reach $20 \mathrm{~m}$ and often display evidence for recent reactivations about $2 \mathrm{~m}$ high. Successive stream entrenchments in uplifted footwalls have formed inset terraces. We have leveled topographic profiles across fault scarps and transverse abandoned terrace risers. The state of degradation of each terrace edge has been characterized by a degradation coefficient $\tau$, derived by comparison with analytical erosion models. Edges of highest abandoned terraces yield a degradation coefficient of $33 \pm 4 \mathrm{~m}^{2}$. Profiles of cumulative fault scarps have been analyzed in a similar way using synthetic profiles generated with a simple incremental fault scarp model. The analysis shows that (1) rate of fault slip remained essentially constant since the aggradation of the piedmont surface and (2) the occurrence of inset terraces was synchronous at all studied sites, suggesting a climate-driven terrace formation. Observation of glacial and periglacial geomorphic features along the northern front of the western Kunlun range indicates that the Qira glaciofluvial fan emplaced after the last glacial maximum, during the retreat of the Kunlun glaciers $(12-22 \mathrm{ka})$. The age of the most developed inset terrace in uplifted valleys is inferred to be $10 \pm 3 \mathrm{ka}$, coeval with humid climate pulses of the last deglaciation. The mass diffusivity constant $\left(k=\tau / T, T\right.$ being time B.P.) in the Hotan region is determined to be $3.3 \pm 1.4 \mathrm{~m}^{2} / 10^{3}$ years, consistent with other estimates in similar climatic and geologic environments of western China. These results imply a minimum rate for the Tarim subsidence of $3.5 \pm 2 \mathrm{~mm} / \mathrm{yr}$. If Western Kunlun overthrusts the Tarim platform on a crustal ramp dipping $40^{\circ}-45^{\circ}$ to the south, it would absorb at least $4.5 \pm 3 \mathrm{~mm} / \mathrm{yr}$ of convergence between western Tibet and Tarim.
\end{abstract}

\section{INTRODUCTION}

The western Kunlun Shan (Xinjiang, China) is an east-west mountain range marking the limit between the Tarim basin and the high Tibetan plateau (Figure 1). Formed in the late Paleozoic, the western Kunlun belt has been reactivated since the India-Eurasia collision [Tapponnier and Molnar, 1977]. Its young morphology and the existence of large folds in the Quaternary piedmont formations at the northern front of the range [Norin, 1946] (also visible on Landsat images Figures 2a and $2 b$ ) suggest that the western Kunlun presently absorbs north-south crustal shortening by underthrusting the Tarim basin to the south. South of the range, the westernmost segment of the Altyn Tagh fault (Figure 1) is left-lateral, strike slip [Molnar and Tapponnier, 1975; Tapponnier and Molnar, 1977] with a Holocene average rate of slip of $1-2 \mathrm{~cm} / \mathrm{yr}$

\footnotetext{
${ }^{1}$ Now at Laboratoire de Détection Géophysique, CEA, Bruyère le Châtel, France.

${ }^{2}$ Also at Observatoire Midi-Pyrénées, Toulouse, France.
}

Copyright 1993 by the American Geophysical Union.
[Peltzer et al., 1989a]. How crustal movements combine between the northern and southern sides of the western Kunlun belt is important to understand the kinematics of present deformations north of Tibet. However, very little is known or published about the neotectonics of this region. The historical and instrumental seismic record is scanty [Institute of Geophysics, 1976] and there is no published report of geologic field expeditions in this region since Norin [1946], except a recent report on the 1986-Sino German Kunlun expedition [Jakel and $Z h u, 1991$ ], which does not include any tectonic studies.

Landsat images have revealed a system of right-stepping en échelon normal faults, at the eastern extremity of the Western Kunlun north piedmont (Figure 1). The fault system is formed of 2 to $10-\mathrm{km}$-long fault scarps and trends N5OE for nearly 70 $\mathrm{km}$ between the oases of Hotan and Qira. During an expedition in 1988, we carried out field studies in the region of Hotan and performed detailed topographic leveling at several sites along the fault system. We proposed earlier that the Hotan-Qira fault system could represent the surficial expression of a basement left-lateral strike-slip fault [Peltzer et al., 1989b]. We present here a slightly different interpretation based on the observation that the main component of displacement across the fault system is vertical, lowering the Tarim basin with respect to the western Kunlun mountains. Although it may have a small component of left-lateral movement, the fault 


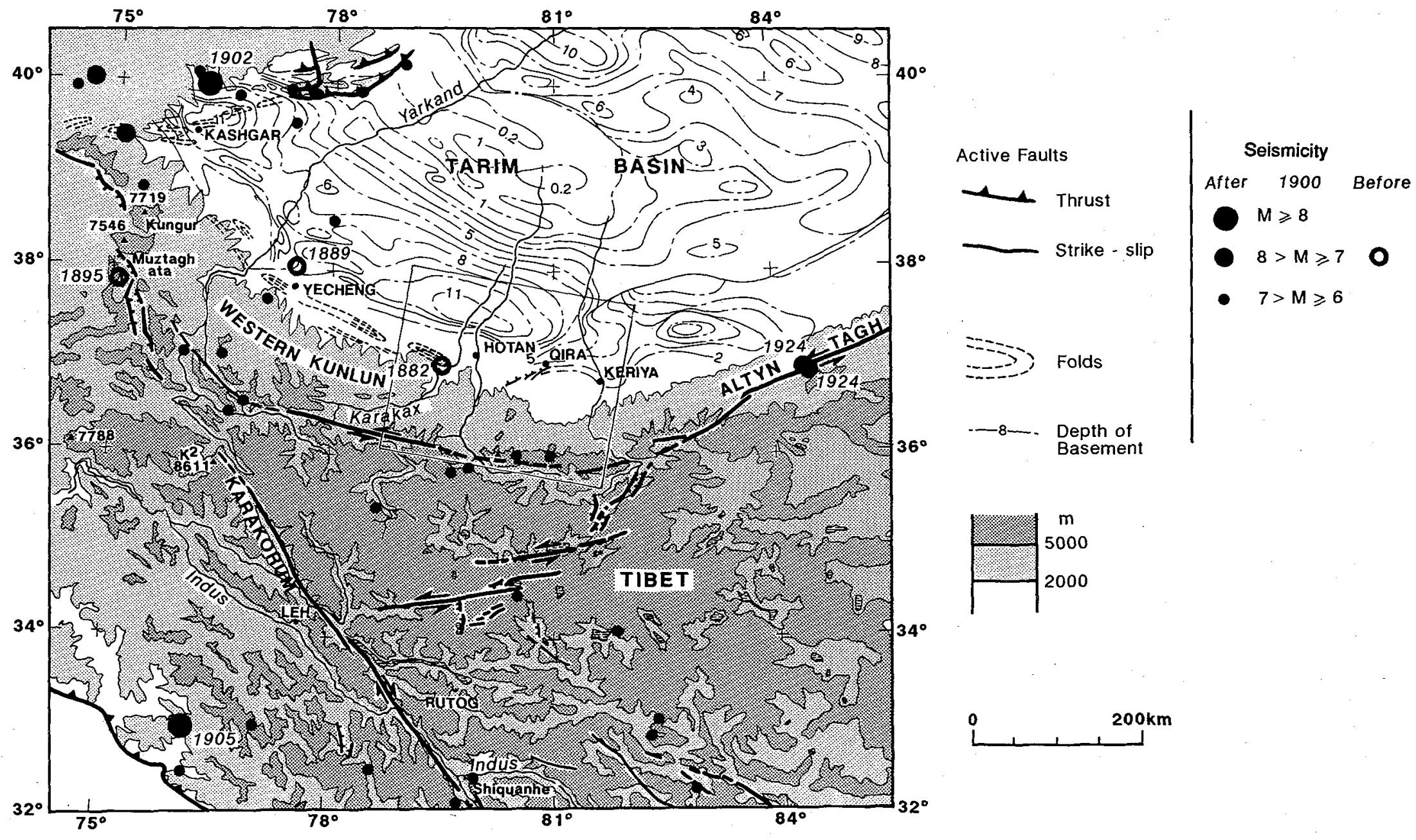

Fig. 1. Simplified map of Quaternary tectonics of Tarim basin and western Tibet. Active faults and folds are from analysis of SPOT and Landsat images, topographic contours from Times Atlas of the World [1978], isopachs of Mesozoic and Cenozoic sediments from Bureau of Geology and Mineral Resources of Xinjiang [1985]. Seismicity is from China Cartographic Publishing House [1989]. Box depicts area shown in Figure 2. 


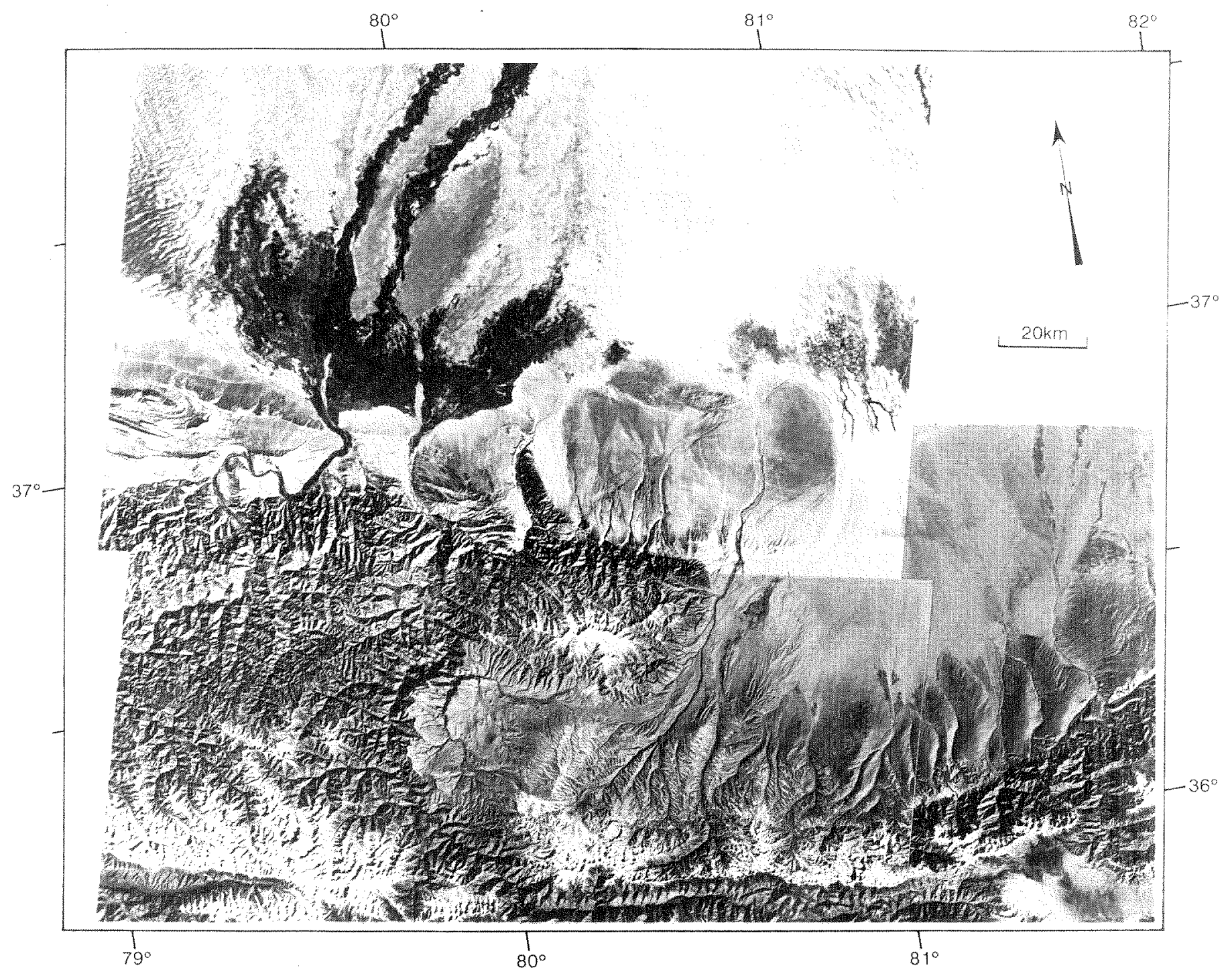

Fig. 2 a. Mosaic of three Landsat images of southern Tarim and western Kunlun (World Reference System: 157-34, 156-34, 156-35).

system is essentially normal and may be related to the flexural subsidence of the Tarim platform loaded by the western Kunlun overthrusts. The Hotan-Qira fault can be interpreted as a crustal tear fault following the southeastern edge of the Hotan flexural basin.

Our goals in this study were to characterize the deformation taking place on the fault system and to estimate the resulting movement integrated across the faulted zone and the rate at which this deformation occurs. In order to place time constraints on offset measurements, our approach involves the morphologic analysis of terrace risers and fault scarps degradation using techniques similar to those pioneered by Wallace [1977], Andrews and Hanks [1985] and Andrews and Bucknam [1987]. The analyses presented below rely on best adjustments of topographic profiles of scarp with synthetic profiles generated using a simple scarp evolution model [Avouac, 1991, 1993]. An advantage of this approach is to allow us to analyze a variety of scarp types including cumulative fault scarps formed by multiple seismic events (Appendix A).
TECTONICS OF SOUTHWESTERN XinJIANG

Analysis of satellite imagery, field investigations and the distribution of seismicity in Asia indicate that intracontinental deformation resulting from the collision with India takes place over a region exceeding 10 million square kilometers le.g. Molnar and Tapponnier, 1975; York et al., 1976; Tapponnier and Molnar, 1977, 1979]. North of Tibet, although deformation extends as far as in the Tien Shan and in the Altai, the Tarim basin seems to have remained relatively undeformed. Molnar and Tapponnier [1981] noticed that regions where little deformation occurs in Asia correspond to old and strong Precambrian shields.

Along the edges of the Tarim basin, the most prominent tectonic feature is the Altyn Tagh fault, which follows its southern rim for nearly $2000 \mathrm{~km}$ (Figure 1). Satellite images have revealed that the fault is active, left-lateral [Molnar and Tapponnier, 1975; Tapponnier and Molnar,1977] with a slip rate between 20 and $30 \mathrm{~mm} / \mathrm{yr}$ [Peltzer et al., 1989a]. West of longitude $82^{\circ} \mathrm{E}$, the Altyn Tagh Fault bends about $25^{\circ}$ and 


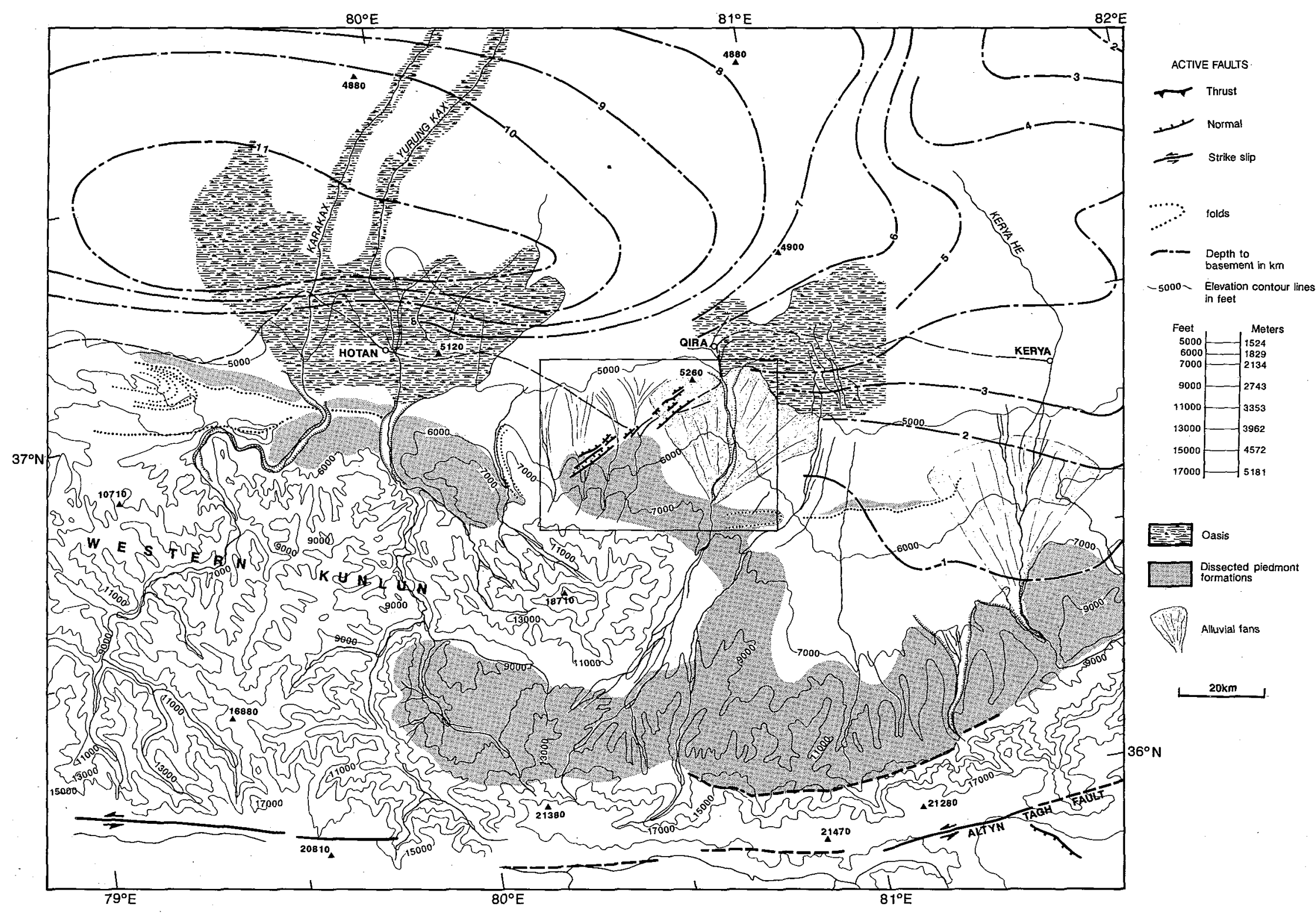

Fig. 2b. Morphotectonic interpretation. Sediment isopachs are from same source as in Figure 1 and elevation contours from

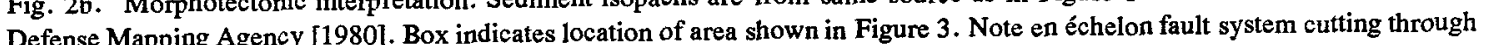
Defense Mapping Agency [1980]. Box indicates location of area shown in Fiedmont southwest of Hotan and Qira oases and large E-W flexural basin formed by western Kunlun overthrusts. 
become westerly oriented (Figure 1). This bend occurs where the Gozha Co-Longmu Co fault system, which traverses western Tibet, merges with the Altyn Tagh Fault through a series of north-south normal faults (Figure 1). The two branches of the Altyn Tagh Fault thus form a fault triple junction with the Gozha Co - Longmu Co fault system. Deformation around the Tarim basin also occurs in the Tien Shan, to the north and in the Western Kunlun, to the southwest. These mountain ranges are late Paleozoic and have been reactivated during the Cenozoic [Tapponnier and Molnar, 1979]. On the Tarim side, both are flanked by sedimentary troughs more than $10 \mathrm{~km}$ deep, filled with Cenozoic sediments $[M a, 1987$; Bally et al., 1986]. The asymmetric and elongated shape of these basins [Bureau of Geology and Mineral Resources of Xinjiang, 1985] suggests that they have originated from underthrusting of the Tarim basement beneath the Tien Shan to the north and beneath the Western Kunlun to the southwest (Figure 1). This process has induced the detachment and folding of the sedimentary cover along the fronts of both ranges [Tapponnier and Molnar, 1979]. Gravity anomalies show a pattern of coupled mass deficit and mass excess typical of flexural basins under the Tien Shan [Burov et al., 1990] and under the western Kunlun [Lyon-Caen and Molnar, 1984]. Fault plane solutions [e.g., Ni, 1978; Nelson et al., 1987] provide evidence that underthrusting is presently occurring under the Tien Shan. Similarly, using gravity measurements collected during the Sino-Swedish Expedition (1929-1933), Lyon-Caen and Molnar [1984] concluded that the Tarim basement has underthrust the western Kunlun by at least $80 \mathrm{~km}$. Geological observations also suggest that this process may be still active. Norin [1946] described folds in the Cenozoic sedimentary cover along the north front of the range. Erosion of these folds has formed questas prominent on Landsat images, south and west of the Hotan oasis (Figure 2a). These folds are similar but less developed than the folds observed along the southern and northern piedmonts of the Tien Shan [Avouac et al., 1993], suggesting that the rate of crustal shortening in the Western Kunlun range is probably lower than the estimate of 6 to 19 $\mathrm{mm} / \mathrm{yr}$ proposed for crustal shortening in the Tien Shan by Molnar and Deng [1984].

The Hotan-Qira fault may be related to the subsidence of the southern Tarim platform. The fault system borders to the southeast the flexural basin and appears to coincide with an abrupt step in the basement (Figure 1). The thickness of the sedimentary cover reaches $11,000 \mathrm{~m}$, including $7000 \mathrm{~m}$ of Neogene sediments, on the northwestern side of the HotanQira fault system and only about $2000 \mathrm{~m}$ on the other side [China Cartographic Publishing House, 1989]. This suggests that the formation of the Hotan basin is mostly Cenozoic. The isopach contours also suggest that this basement scarp extends to the northeast, nearly parallel to the Altyn Tagh Fault for a few hundred kilometers (Figure 1). Piedmont folds also appear to be better developed west of the Hotan-Qira fault than east of it (Figures $2 \mathrm{a}$ and $2 \mathrm{~b}$ ). East of $81^{\circ} \mathrm{E}$, no such folds are observed on satellite images. Since folding of piedmont sediments is associated with subsidence and underthrusting of the Tarim basement, such observations suggest that the Hotan-Qira fault system may mark the southeastern limit of the subsiding part of the Tarim basin. Therefore an estimate of the vertical throw rate on the fault may be used to estimate the rate of Tarim subsidence.

\section{MORPHOLOGY AND GEOMETRY OF THE HOTAN-QIRA FAULT SYSTEM}

The Hotan-Qira fault system cuts through and offsets vertically the north piedmont alluvium of the Western Kunlun mountains and the 30-km-wide alluvial fan of the Qira River (Figures 3 and 4). The fault system extends for nearly $70 \mathrm{~km}$ and consists of right-stepping en echelon normal faults of 2-10 $\mathrm{km}$ in length. The $10-\mathrm{m}$ resolution SPOT image reveals in detail prominent linear fault scarps, distinct from river-cut terrace risers because they are generally perpendicular to the local drainage pattern (Figure 3). The fault system involves several antithetic faults forming horsts and grabens, characteristic of an extensive stress regime. North facing scarps are generally more developed and higher than south facing scarps, suggesting that the total movement across the fault system results in a net lowering of the northwestern block. However, the en échelon geometry attests to a small component of left-lateral movement which is difficult to quantify. The pattern of faulting appears to be more complex in the northeastern part of the system, probably because the Tertiary and Quaternary sedimentary sequence thickens away from the front of the range. Farther northeast, fault scarps gradually disappear under sand dunes and the Qira oasis.

A careful analysis of drainage patterns using the SPOT image (Figure 3a) shows that entrenchment of large rivers and reincision of depositional surfaces are controlled by tectonic deformation. South of the faults, four large rivers flowing down from the Kunlun mountains are deeply entrenched and have formed successive inset terrace levels. North of the faults, these rivers are not entrenched and develop modern alluvial fans. This observation confirms that the compartment south of the faults is uplifted, and the northern compartment is lowered, with respect to the level of river equilibrium.

The Qira alluvial fan does not display a uniformly dissected surface. Streams appear to have developed headwards from the fault scarps in the northwest distal part of the fan, and from the terrace edge on the west bank of the Qira river (Figures $3 a$ and $3 b$ ). The low degree of dissection observed in other parts of the fan probably results from the fact that the fan surface is poorly supplied with water runoff. Water originates mainly from springtime ice and snow melting from the mountains, and most of the runoff is channeled by major entrenched rivers before reaching the piedmont. Near the apex of the Qira fan, more intense surface dissection outlines an east-west trending fold in the sediments (Figure $3 \mathrm{a}$ and $3 \mathrm{~b}$ ). This zone extends to the west and connects a larger zone of dissected piedmont, extending from the front of the range to the faults. In this zone, dissection is probably due to headward erosion which has progressed upslope from the fault scarps. It thus appears that the degree of stream dissection does not reflect different ages of deposition but rather results from tectonic movements and irregular distribution of water runoff from the mountains.

In the field, piedmont alluvium is capped with stone pavement. Pebbles collected on terrace surfaces are coated with desert varnish. Pavement is generally less developed on inset terraces compared to that found on the uppermost surface, consistent with a decreasing age for decreasing terrace levels.

The topographic contours in Figure $3 b$ outlines the conical shape of the Qira alluvial fan. West of the Qira fan, the piedmont slope is nearly planar and dips to the north about $1^{\circ}$. 


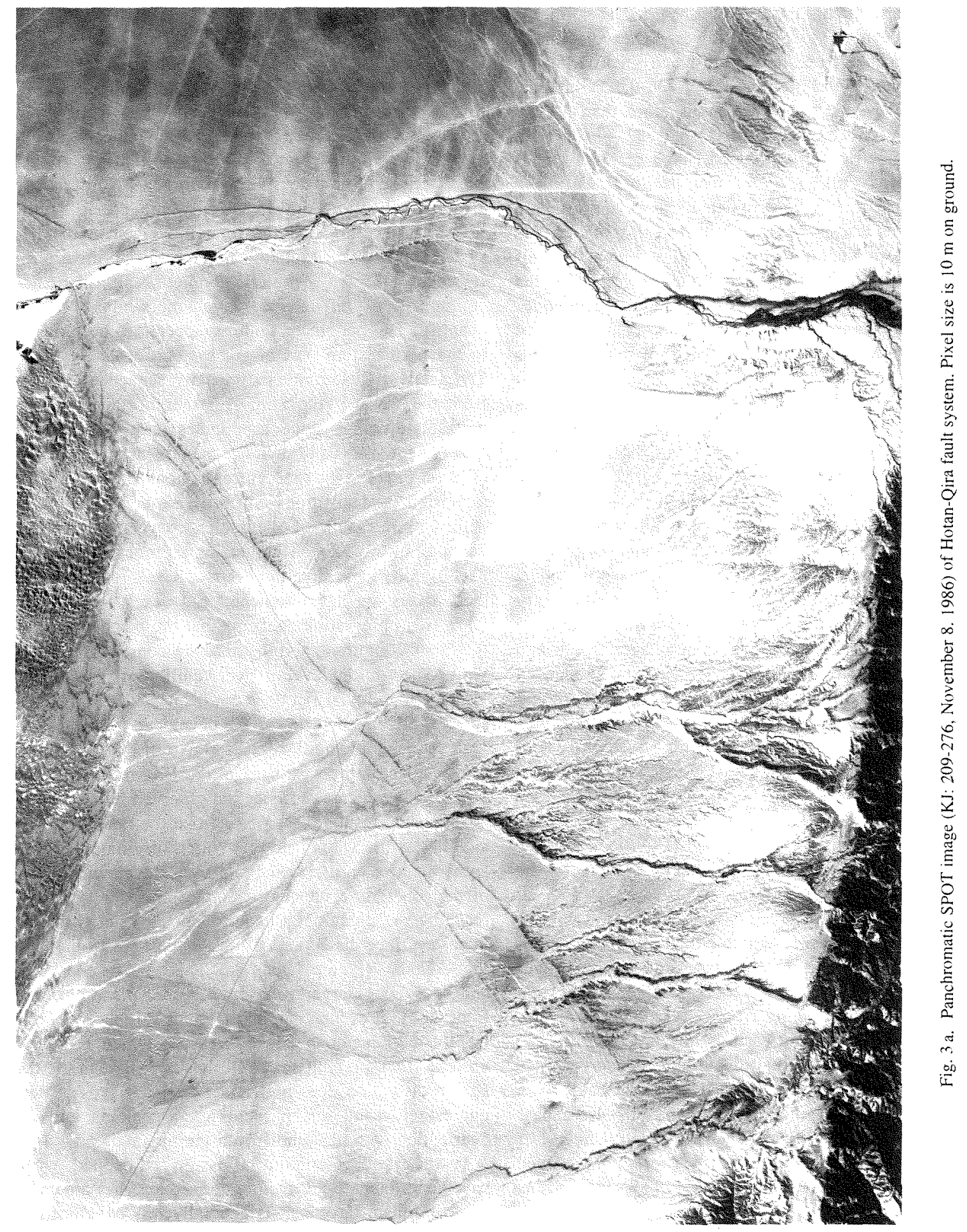




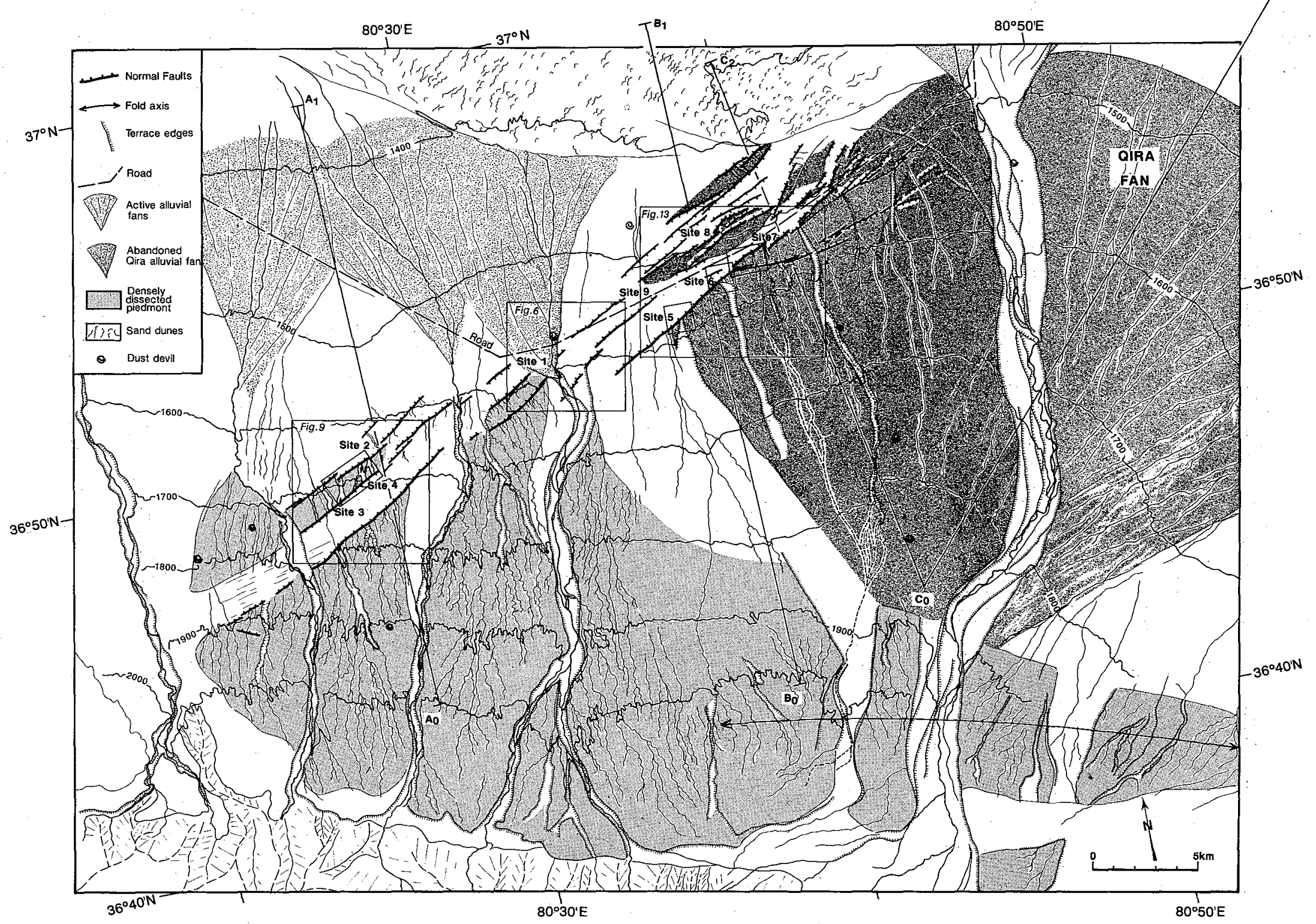

Fig. 3b. Morphotectonic interpretation. Fault morphology is typical of normal faults. Normal fault segments form right-stepping helons, suggesting a left-lateral component of movement. Sites were topographic measurement were conducted are indicated, and. boxes refer to corresponding figures. Elevation contour lines are from $1 / 100,000$ topographic maps of Xinjiang. Note nearly planar piedmont surface, west of faults and conical shape of the Qira alluvial fan. 

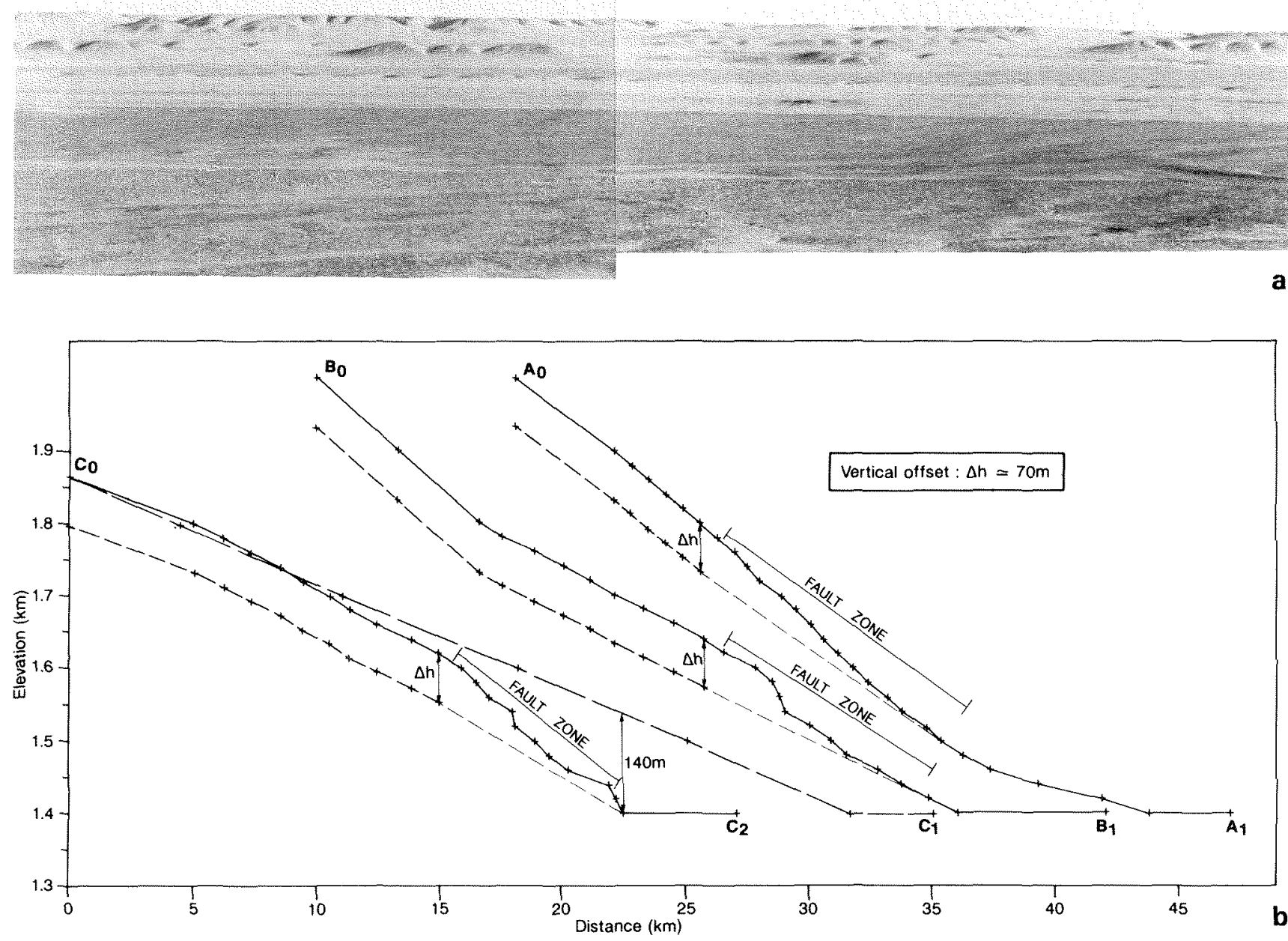

Fig. 4. (a) South looking view of multiple faults offsetting the Qira alluvial fan. (b) Topographic cross sections of Figure $3 \mathrm{~b}$. $\mathrm{C}_{0} \mathrm{C}_{1}$ and $\mathrm{C}_{0} \mathrm{C}_{2}$ are radial cross sections of the Qira alluvial fan. Piedmont surface appears to be offset by approximately $70 \mathrm{~m}$ across fault zone.

South of the faults, the sinuosity of the topographic contour lines results from the denser stream dissection of the surface. The bending of the contour lines crossing the fault zone confirms that the southern compartment has been uplifted with respect to the Tarim basin. As seen on the SPOT image (Figure $3 a$ and in the field, from a point located north of the fault system, the Qira fan offset results from offsets on multiple fault scarps with heights ranging from a few tens of centimeters to more than $20 \mathrm{~m}$ (Figure $4 \mathrm{a}$ ). Figure $4 \mathrm{~b}$ shows four topographic cross-sections of the piedmont slopes corresponding to the straight lines in Figure $3 \mathrm{~b}$. Profiles $\mathrm{A}_{0} \mathrm{~A}_{1}, \mathrm{~B}_{0} \mathrm{~B}_{1}$ and $\mathrm{C}_{0} \mathrm{C}_{1}$ show clear disruptions of the piedmont slope across the fault. $A$ total vertical offset of approximately $70 \mathrm{~m}$ can be estimated from profiles $A_{0} A_{1}$ and $B_{0} B_{1}$, assuming that both profiles were linear prior faulting. Profiles $\mathrm{C}_{0} \mathrm{C}_{1}$ and $\mathrm{C}_{0} \mathrm{C}_{2}$ follow diverging lines of maximum slope of the Qira alluvial fan. As profiles $A_{0} A_{1}$ and $B_{0} B_{1}$, profile $C_{0} C_{2}$ shows a disruption of the fan surface across the fault system, but the lower part of the profile reaches the base level of the Qira oasis, preventing us from constraining the fan slope north of the faults. Restoring the top and bottom parts of profile $\mathrm{C}_{0} \mathrm{C}_{2}$ according to profile $\mathrm{C}_{0} \mathrm{C}_{1}$, which does not cross the faults, would imply a total vertical offset of approximately $140 \mathrm{~m}$ for the fault system. However, this estimate would be correct only if the original shape of the Qira fan was perfectly conical before faulting. Fan surfaces are in general not conical and have steeper lateral slopes. The original slope of the fan was probably steeper along profile $\mathrm{C}_{0} \mathrm{C}_{2}$ than along profile $\mathrm{C}_{0} \mathrm{C}_{1}$, and the $140-\mathrm{m}$ offset of the fan surface may thus be a large overestimate of the actual offset. $A 70-\mathrm{m}$ offset on profile $\mathrm{C}_{0} \mathrm{C}_{2}$, as measured on profiles $\mathrm{A}_{0} \mathrm{~A}_{1}$ and $\mathrm{B}_{0} \mathrm{~B}_{1}$, would be consistent with steeper lateral slopes on the Qira fan (Figure $4 b$ ). 


\section{QUANTITATIVE STUDY OF TERRACE RIȘERS AND FAULT SCARPS}

The sités we have surveyed along the Hotan-Qira faults show clear records of the interaction between tectonic and channel incision processes. This interaction has resulted in the formation of characteristic landforms such as fill-cut terraces in uplifted valleys, fault scarps and terrace risers of various heights. Terraces are formed of loose fan gravels, derived mainly from black schists and granite, and a few large boulders, mixed with finer minerals probably of eolian origin, or due to in situ rock weathering. Scarps formed in such erodible materials are known to degrade starting with a rapid phase of gravitational collapse of the free face, bringing the scarp slope at the angle of repose of the material, followed by a slower phase of diffusive erosion [e.g., Hanks et al., 1984; Andrews and Hanks, 1985].

By measuring the height of fault scarps and terrace risers, and by analyzing the degree of degradation of these features under the action of erosion, our goals were to estimate the amount and rate of vertical movement on various fault segments of the Hotan-Qira system. Using a Wild total station (digital theodolite coupled with an infrared distance meter) we have leveled 150 topographic profiles across fault scarps and terrace risers along the fault system. Details of measuring technique and measurement precision are discussed by Peltzer et al. [1988]. For each profile, we determine the vertical offset $(2 a)$, the maximum scarp slope $(\tan \alpha)$ and the regional slope $(\tan \beta)$ (Figure 5). Parameters of all measured profiles are reported in Table 1 for fault scarps and in Table 2 for terrace risers. Profiles are referred by original field log numbers.

We have analyzed the state of degradation of river-cut terrace risers and fault scarps using a Gaussian model of erosion [Andrews and Hanks, 1985; Avouac, 1991, 1993]. Our approach consists in adjusting measured profiles to synthetic profiles generated using a scarp evolution model in order to determine a coefficient of degradation, $\tau$, characteristic of the degree of erosion of the scarp. For high fault scarps, the model involves a progressive scarp formation by small increments (Appendix A). Degradation coefficient $\tau$ depends on the age of the scarp and the rate of erosion of alluvium materials in a given climatic environment. This approach is consistent with previous studies of scarp degradation based on the diffusion

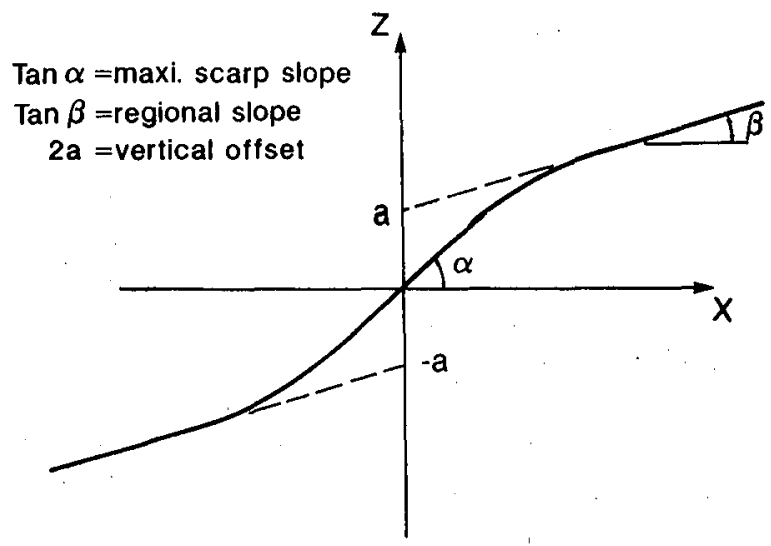

Fig. 5. Symmetric scarp profile and geometric parameters used in our analysis (Tables 1 and 2). We measured vertical offset as defined by Hanks et al. [1984]. For cases where upper and lower regional slopes are different, $\tan \beta$ is computed as the mean value of both slope measurements.
TABLE 1. Values of Geometric Parameters Derived From Fault Scarp Profiles.

\begin{tabular}{cccccc}
\hline Profile & $\begin{array}{c}\text { Offset, } \\
\mathrm{m}\end{array}$ & Scarp & Regional \\
& Slope, $\%$ & Slope, $\%$ & Orientation & Terrace
\end{tabular}

\begin{tabular}{|c|c|c|c|c|c|}
\hline \multicolumn{6}{|c|}{ Site 1} \\
\hline P118 & 9.6 & 54 & 1.1 & NW & T0 \\
\hline P121 & 11.1 & 50 & 2.5 & NW & T0 \\
\hline \multicolumn{6}{|c|}{ Site 2} \\
\hline P98 & 10.8 & 43 & 3 & NW & T0 \\
\hline P99. & 11.6 & 49.5 & 3 & NW & T0 \\
\hline P100 & 9.3 & 46 & 4 & NW & T0 \\
\hline P101 & 10.3 & 47 & 3 & NW & T0 \\
\hline \multicolumn{6}{|c|}{ Site 3} \\
\hline P85 & 9.8 & 45.5 & 0.5 & SE & T0 \\
\hline P87 & 5.3 & 32 & 2 & SE & $\mathrm{T} 1$ \\
\hline P88 & 3.5 & 32.5 & 0. & SE & $\mathrm{T} 2$ \\
\hline P89 & 5.4 & 36.5 & 0.4 & SE & T1 \\
\hline P96 & 8.6 & 25.5 & 0. & SE & T0 \\
\hline P97 & 8.3 & 31.5 & 1 & $\mathrm{SE}$ & T0 \\
\hline \multicolumn{6}{|c|}{ Site 4} \\
\hline P140 & 5.8 & 20.5 & 0 & $\mathrm{SE}$ & T0 \\
\hline P141 & 5.4 & 17 & 0 & SE & T0 \\
\hline P142 & 4.8 & 17 & 0 & SE & T0 \\
\hline \multicolumn{6}{|c|}{ Site 5} \\
\hline P66 & 16.5 & 51 & 7 & NW & T0 \\
\hline P67 & 17.5 & 53 & 7 & NW & T0 \\
\hline P67 & 1.80 & 50 & 17.5 & NW & $\mathrm{R}$ \\
\hline P68 & 17.0 & 54.5 & 7 & NW & T0 \\
\hline P68 & 1.65 & 54 & 18 & NW & $\mathrm{R}$ \\
\hline P69 & 15.5 & 39.5 & 8 & NW & T0 \\
\hline P69 & 1.46 & 38 & 14.5 & NW & $\mathrm{R}$ \\
\hline P71 & 1.55 & 56 & 17 & NW & $\mathrm{R}$ \\
\hline P73 & 18.5 & 48 & 8 & NW & T0 \\
\hline P74 & 15.4 & 42 & 7 & NW & T0 \\
\hline P75 & 5.5 & 47.5 & 6.5 & NW & T1 \\
\hline P76 & 4.7 & 57.5 & 8 & NW & $\mathrm{T} 1$ \\
\hline P77 & 4.3 & 48.5 & 6 & NW & $\mathrm{T} 1$ \\
\hline P78 & 9.5 & 44 & 5 & NW & T1 \\
\hline P79 & 5.9 & 34.5 & 3.5 & NW & $\mathrm{T} 2$ \\
\hline P80 & 5.7 & 29 & 4 & NW & $\mathrm{T} 2$ \\
\hline P84 & 14.2 & 59 & 2 & NW & T0 \\
\hline P109 & 13.8 & 59 & 2 & NW & T0 \\
\hline \multicolumn{6}{|c|}{ Site 6} \\
\hline P25 & 11.9 & 50 & 6.5 & NW & T1 \\
\hline P26 & 12.4 & 46 & 6 & NW & $\mathrm{T} 1$ \\
\hline P30 & 19.7 & 60.5 & 7 & NW & $\mathrm{T} 1$ \\
\hline P30 & 17.3 & 60.5 & 7 & NW & T0 \\
\hline P32 & 22.3 & 50.5 & 7 & NW & T0 \\
\hline P35 & 21.2 & 48 & 9.5 & NW & T0 \\
\hline P36 & 19.8 & 62 & 5.5 & NW & T0 \\
\hline P37 & 20.5 & 54 & 6 & NW & T0 \\
\hline P38 & 1.26 & 18.1 & 9 & NW & $\mathrm{R}$ \\
\hline P39 & 2.04 & 19. & 7.5 & NW & R \\
\hline P40 & 5.9 & 40.5 & 8 & NW & $\mathrm{T} 2$ \\
\hline P41 & 6.9 & 35 & 6.5 & NW & $\mathrm{T} 2$ \\
\hline P42 & 8.5 & 48 & 8 & NW & $\mathrm{T} 2$ \\
\hline P43 & 1.44 & 21.1 & 8.7 & NW & $\mathrm{T} 2$ \\
\hline P44 & 21.3 & 62 & 5.5 & NW & T0 \\
\hline P45 & 13.7 & 57 & 5 & NW & $\mathrm{Tl}$ \\
\hline P46 & 7.1 & 39 & 7.5 & NW & $\mathrm{T} 2$ \\
\hline P47 & 21 & 0.2 & 5 & NW & T0 \\
\hline \multicolumn{6}{|c|}{ Site7 } \\
\hline P1 & 11.0 & 44.5 & 3 & $\mathrm{~N}$ & T0 \\
\hline $\mathrm{P} 2$ & 9.9 & 46 & 2 & $\mathrm{~N}$ & T0 \\
\hline P3 & 8.7 & 35 & 2.5 & $\mathrm{~N}$ & T0 \\
\hline P1la & 9.3 & 45 & 4 & $\mathrm{~N}$ & T0 \\
\hline P1lb & 2.7 & 19 & -2 & $S$ & T0 \\
\hline P14 & 10.8 & 50.5 & 4 & $\mathrm{~N}$ & $\mathrm{TO}$ \\
\hline P19a & 6.6 & 36.5 & 8 & $\mathrm{~N}$ & TO \\
\hline P19b & 1.97 & 14 & -2.5 & $S$ & T0 \\
\hline P20a & 5.5 & 28 & 5.5 & $\mathrm{~N}$ & T0 \\
\hline $\mathrm{P} 20 \mathrm{~b}$ & 2.56 & 15.5 & -0.5 & $S$ & $\mathrm{TO}$ \\
\hline P22a & 7.7 & 47 & 7 & $\mathrm{~N}$ & T0 \\
\hline P22b & 4.65 & 29 & -1 & $S$ & T0 \\
\hline
\end{tabular}


TABLE 1. (continued)

\begin{tabular}{cccccc}
\hline Profile & $\begin{array}{c}\text { Offset, } \\
\mathrm{m}\end{array}$ & $\begin{array}{c}\text { Scarp } \\
\text { Slope, } \%\end{array}$ & $\begin{array}{c}\text { Regional } \\
\text { Slope, } \%\end{array}$ & Orientation & Terrace \\
& & &
\end{tabular}

\begin{tabular}{|c|c|c|c|c|c|}
\hline P23a & 14.9 & 58 & 5 & $N$ & T0 \\
\hline $\mathrm{P} 23 \mathrm{~b}$ & 6.2 & 29 & -1 & $S$ & T0 \\
\hline P24 & 19.5 & 54.5 & 4.5 & $\mathrm{~N}-\mathrm{NW}$ & T0 \\
\hline P32 & 19.3 & 50.5 & 7 & N-NW & T0 \\
\hline P48 & 12.6 & 50.5 & 3 & NW & T0 \\
\hline P49 & 12.9 & 50 & 5 & NW & T0 \\
\hline P50 & 13.9 & 40 & 5.5 & NW & T0 \\
\hline P51 & 10.7 & 36.5 & $\begin{array}{l}6 \\
8\end{array}$ & NW & Т0 \\
\hline P52 & 7.5 & 39 & 4 & NW & \\
\hline P53 & 7.5 & 38.5 & 4 & NW & \\
\hline P54 & 6.3 & 31 & 3.5 & NW & \\
\hline P55 & 6.5 & 42 & 4 & NW & \\
\hline P56 & 2.7 & 29.5 & 2.2 & NW & \\
\hline P57 & 1.9 & 27 & 4 & NW & \\
\hline P58 & 2.8 & 16 & 2 & NW & \\
\hline $\mathrm{P} 60$ & 2.5 & 14.5 & 3.5 & $\mathrm{NW}$ & \\
\hline P61 & 2.7 & 16 & 3. & NW & \\
\hline P62a & 1.8 & 17 & 4 & NW & \\
\hline P62b & 1.1 & 13 & 4 & NW & \\
\hline P63a & 1.95 & 20 & 3 & $\mathrm{NW}$ & \\
\hline P63b & .47 & 10.5 & 3 & NW & \\
\hline P64 & 2.45 & 27.5 & 3 & NW & \\
\hline P65 & 1.95 & 19 & 3 & NW & \\
\hline \multicolumn{6}{|c|}{ Site 9} \\
\hline P111 & 2.3 & 25.9 & 1.7 & NW & \\
\hline P112 & 2.5 & 25.6 & 2 & NW & \\
\hline P113 & 3.25 & 30.2 & 1.8 & NW & \\
\hline P114 & 2.6 & 29.8 & 3. & NW & \\
\hline P117 & 2.8 & 28.4 & 1.8 & NW & \\
\hline
\end{tabular}

For site 5 , " $\mathrm{R}$ " in the terrace level column indicates secondary scarp resulting from reactivation of older scarp.

model [e.g., Nash, 1980; Hanks et al., 1984]. Under the assumption that the erosion rate is constant through time, $\tau$ is proportional to the age, $t$, of the scarp and the coefficient $k$ given by $\tau=k t$ is the mass diffusivity constant [Andrews and Hanks, 1985; Avouac, 1993]. For a given set of climatic and geologic (soil material) conditions, coefficient $k$ needs to be determined in order to estimate the age of the degraded scarps. Based on analysis of fault scarps related to a historical earthquake, Tapponnier et al. [1990] have determined a value of $3.3 \mathrm{~m}^{2} / 10^{3}$ years for the mass diffusivity constant on the northern front of the Qilian Shan, Gansu province. Similar analyses of terrace riser degradation along the northern front of the Tien Shan, Xinjiang province, have led Avouac et al. [1993] to propose a value of $k=5.5 \mathrm{~m}^{2} / 10^{3}$ years for this region. Because of the geologic and climatic similarities of these two regions with the northern piedmont of Western Kunlun, it is likely that a calibration of the analysis technique in the region of Hotan would lead to similar values for the mass diffusivity constant.

\section{Topographic Profile, Measurements and Analyses}

West of the Qira alluvial fan, four large rivers, spaced 5 to 7 $\mathrm{km}$ apart, have deeply entrenched the piedmont between the mountain front and the fault zone (Figure $3 \mathrm{a}$ and $3 \mathrm{~b}$ ). At site 1 , where one river crosses the fault, the present channel is entrenched by more than $10 \mathrm{~m}$ into the uplifted footwall and its flat floor does not appear to be offset by the fault (Figures 6 and 7). This means that the river is competent enough to maintain its longitudinal profile of equilibrium at the base level of erosion. Because of the deep stream entrenchment, upper surface $\mathrm{TO}$ is preserved from erosion and is vertically offset 9.6-11.1 $\mathrm{m}$ by the major fault scarp on the western side of the river (profiles P118 and P121, Figure 8 and Table 1). The lighter zone in the lower part of the scarp outlines loess accumulation and the development of small alluvial fans (Figure 8a). The amount of eolian sediments accumulated at the base of scarps depends on their orientation with respect to dominant winds. East facing scarps have generally more sediments accumulated at their base than others, consistent

TABLE 2. Values of Geometric Parameters Derived From Terrace Riser Profiles.

\begin{tabular}{|c|c|c|c|c|c|}
\hline Profile & $\begin{array}{l}\text { Offset, } \\
\text { m }\end{array}$ & $\begin{array}{c}\text { Scarp } \\
\text { Slope, \% }\end{array}$ & $\begin{array}{l}\text { Regional } \\
\text { SLope, \% }\end{array}$ & Orientation & Terrace \\
\hline
\end{tabular}

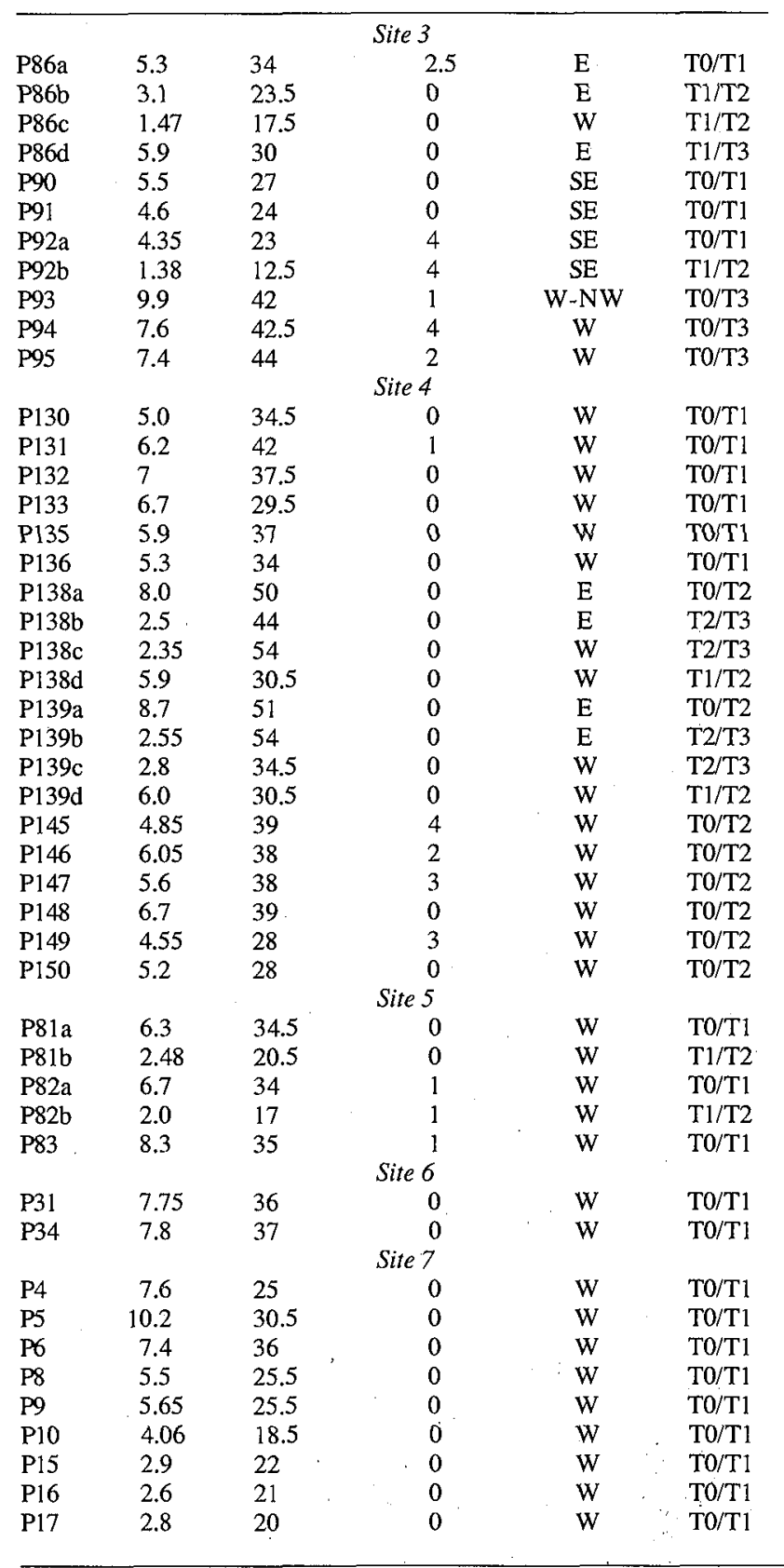



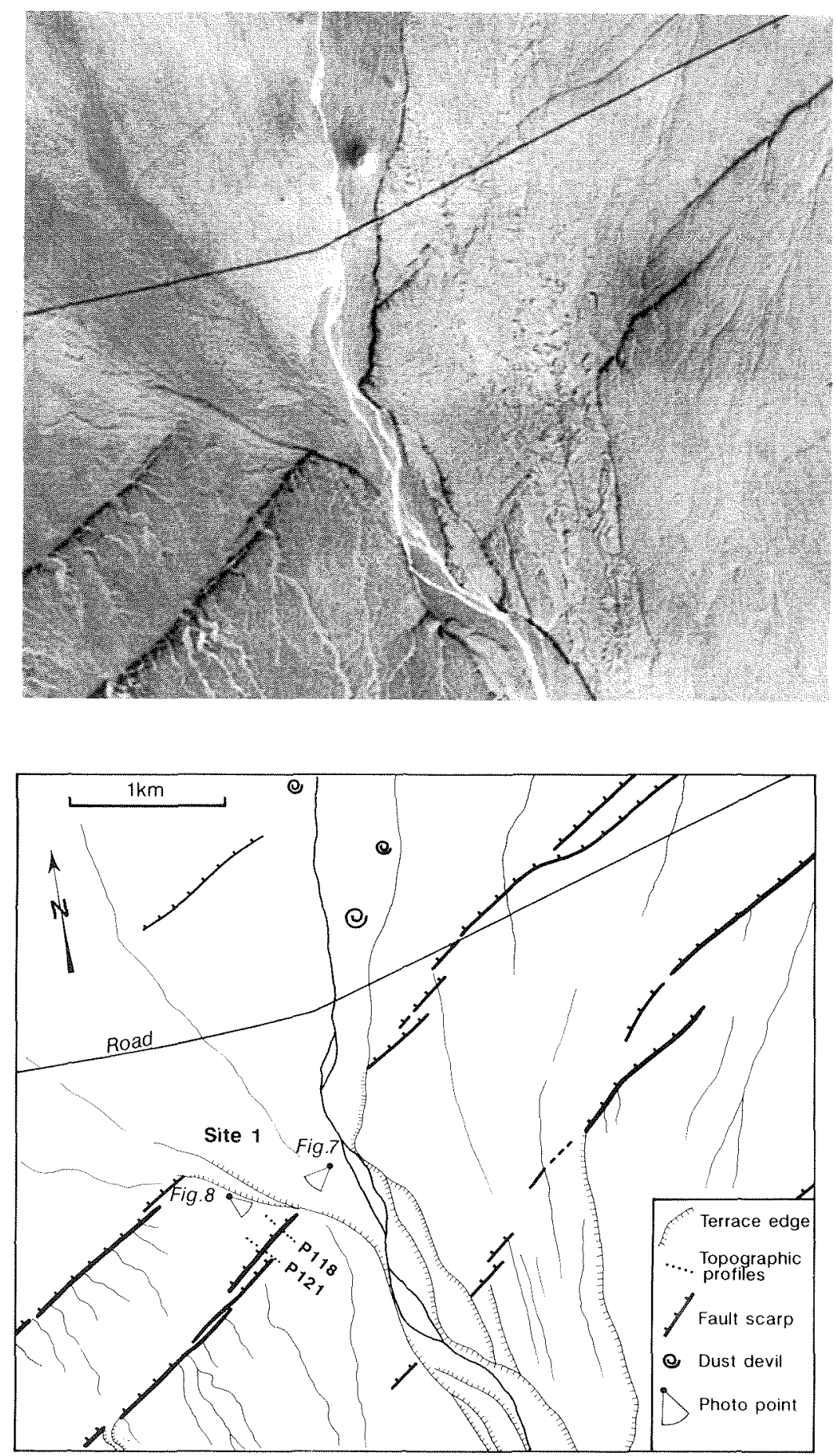

Fig. 6. (a) SPOT close-up view of site 1 in contral zone of the Hotan-Qira fault system where a major river crosses the faults. (b) Interpretative sketch map of Figure 6a. Note four levels of terrace on left and right banks of river, upstream of the faults, denoted by lines with teeth on the riser side. Solid circles indicate location of leveling profiles at site 1 .

with dominant northwesterly winds in southwestern Tarim [Zhu, 1984]. This example also shows that scarps degrade not only under the action of diffusion type processes but also undergo rill erosion and gullying. Profile Pl18 was leveled between two gullies which have fed two small fans at the base of the scarp (Figure 8a). Elevation and slope profiles of Figure $8 \mathrm{~b}$ illustrate how actual fault scarp profiles may depart from error function and Gaussian curves such as those produced by ideally diffusive scarp models. Basal accumulation of sediments due to colian deposits and adjacent fans produces the characteristic bump in segment D of slope profile (Figure 8b). A characteristic feature of high fault scarps, resulting from several seismic events, is a zone where the slope is significantly steeper than in the rest of the scarp (segment $A$ in Figure 8b). We interpret this as evidence of the most recent activation of the fault whose effect is to rejuvenate a steep slope over a part of the scarp (see Appendix A). Remnants of the older scarp slope are visible on both sides of the steeper segment $A$, 


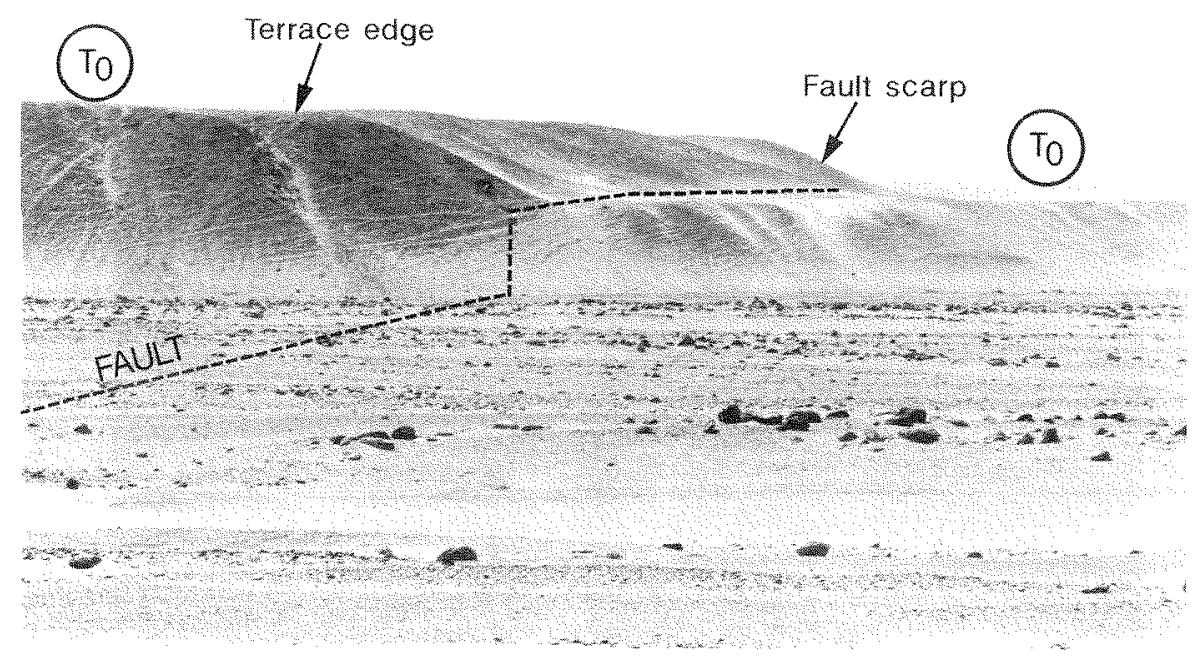

Fig. 7. Southwest looking view of river cut cross section of major fault scarp at site 1 (see Figure $6 b$ for location). Uppermost surface $\mathrm{TO}$ is offset by $9.7-11.1 \mathrm{~m}$.

making the characteristic shoulders on the slope profile (segments B in Figure 8b).

At the southwestern end of the fault system, antithetic faults have formed a graben and horst structure (Figure 9a and $9 \mathrm{~b}$ ). Streams have been uplifted on footwalls with respect to the local base level of erosion. The resulting stream channel downcutting has produced deep valleys which have then widened by lateral erosion once streams have achieved and maintained a dynamic equilibrium longitudinal profile. A slight northward tilt of the horst upper surface is probably responsible for the abandonment of the $N 10-20^{\circ} \mathrm{E}$ entrenched channels where modern drainage develops closer to the faultstrike perpendicular direction (Figure 9b). Sketches of Figure 10 show a likely sequence of events which could have resulted in the geomorphic features observed at this site. After an episode of aggradation, rivers entrench their terraces (A, Figure 10). Each faulting event produces the uplift of the central compartment, deviating the rivers laterally (B), until they can cut through the horst and recover a profile of equilibrium (C). Sequences of entrenchment and equilibrium phases result in the formation of inset terraces in uplifted valleys (C). Subsequent episodes of faulting eventually start the process again. We have observed that some river segments were perched and abandoned on the top of the horst (D), whereas other rivers had cut through the horst, entrenching their valley down to the base level of erosion ( $\left.\mathrm{D}^{\prime}\right)$. According to such a scenario, processes and timing of terrace formation would be controlled by climatic variations, whereas amounts and rates of river entrenchment would rather record tectonic movements.

Profiles leveled across the northern border of the horst (P98 to P101, Figure $9 \mathrm{~b}$ ) yield offsets ranging between $9.2 \mathrm{~m}$ and $11.6 \mathrm{~m}$ (Table 1). Along the southern edge of the horst, the measured profiles indicate that the height of terrace To decreases from 8.3-9.8 $\mathrm{m}$ (P96, P97 and P85) at site 3 to 4.8-5.8 $\mathrm{m}$ (P140-P142) at site 4 (Table 1). Such an eastward decrease is consistent with the observation that the scarp vanishes approximately a kilometer east of site 4 . At site 3, two inset terrace levels ( $\mathrm{T} 1$ and $\mathrm{T} 2$ ) can be distinguished and are offset by $5.4 \mathrm{~m}$ (P87 and P89) and $3.5 \mathrm{~m}$ (P88), respectively (Table 1). The present floor of the perched valleys at this site is slightly higher than the graben floor, to the south, so that streams are deviated into the graben and forced to flow along the fault scarp until the next valley (Figures $9 a$ and $9 b$ ).

At sites 3 and 4 , we observed that modern streams have entrenched into the flat floor of the valleys by $1.2 \mathrm{~m}$, although this recent progression of rivers does not cross the southern scarp at site 3. We interpret this small and most recent entrenchment as the result of the last, or the two last seismic events on the faults. At site 3, we measured an entrenchment of 1.4-1.5 $\mathrm{m}$ on profiles P92b and P86c (Table 2). In the western valley of site 4 , we measured $2.3-2.8 \mathrm{~m}$ on profiles $\mathrm{P} 138 \mathrm{~b}$ and P138c, and P139b and P139c (Table 2). This last value could more likely represent two single events of $1.3 \mathrm{~m}$ each.

We have analyzed the degradation of profiles leveled across the terrace risers between T0 and T1 (P86a, P90, P91 a, P92a) and between $\mathrm{T} 1$ and $\mathrm{T} 2$ (P86b, P92b) (Figures 9b, $11 \mathrm{a}$ and 11b). Profile adjustments are shown in Figure 12 and the derived parameters are listed in Table 3. Terrace riser To/T1 begins to degrade when level $\mathrm{T} 1$ is abandoned and incised by the river. Similarly, terrace riser T1/T2 starts degrading when level T2 is abandoned. The analyses indicate that the abandonment of terrace $\mathrm{T} 1$ corresponds to a degradation coefficient of approximately $32.5 \mathrm{~m}^{2}$, and the abandonment of $\mathrm{T} 2$, to a coefficient of $17.5 \mathrm{~m}^{2}$. These results are consistent with a younger age for $\mathrm{T} 2$ compared to $\mathrm{T} 1$.

Sites 5 to 8 are located along the northeast segments of the Hotan-Qira fault system, where the western corner of the Qira alluvial fan is offset and partly disappears under recent sediments (Figures $3 \mathrm{~b}$ and 13 ). During our field investigation we focused on sites where large stream channels (about $150 \mathrm{~m}$ wide) have been perched on uplifted footwalls. These channels are regularly spaced and are similar in size and shape (Figure 


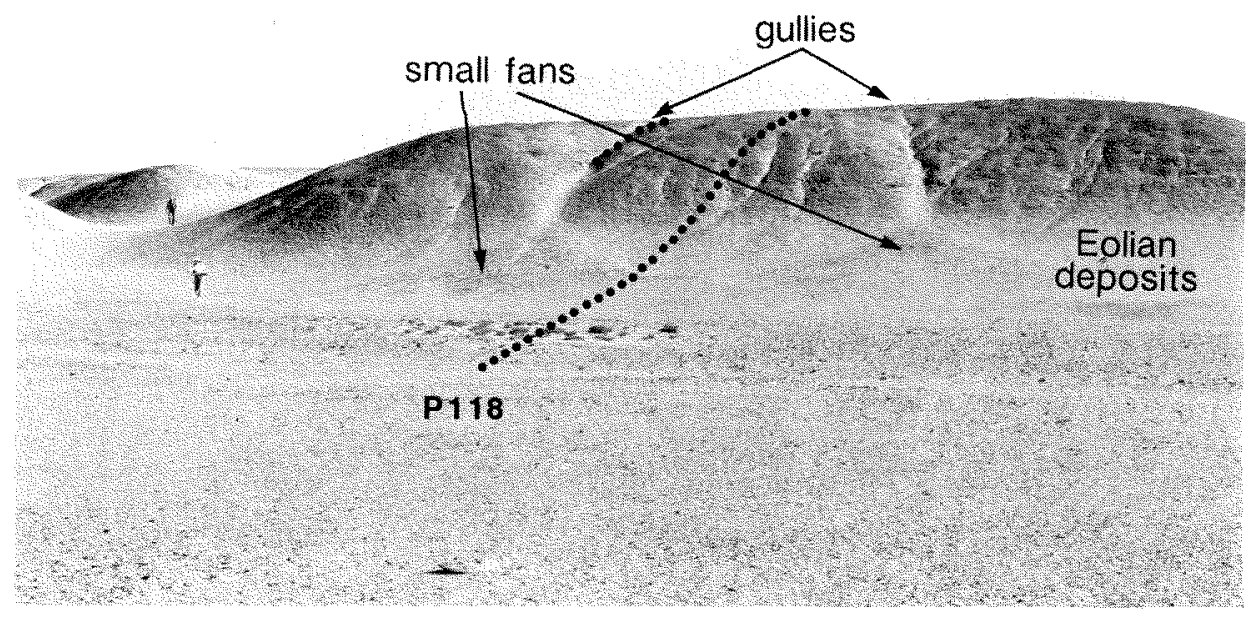

Fig. 8 a. South looking view of same fault scarp as in Figure 7 (see Figure $6 \mathrm{~b}$ for location). SOlid circles indicate location of profile P118. Note rill erosion, small fans fed by gullies and eolian deposits at base of scarp.

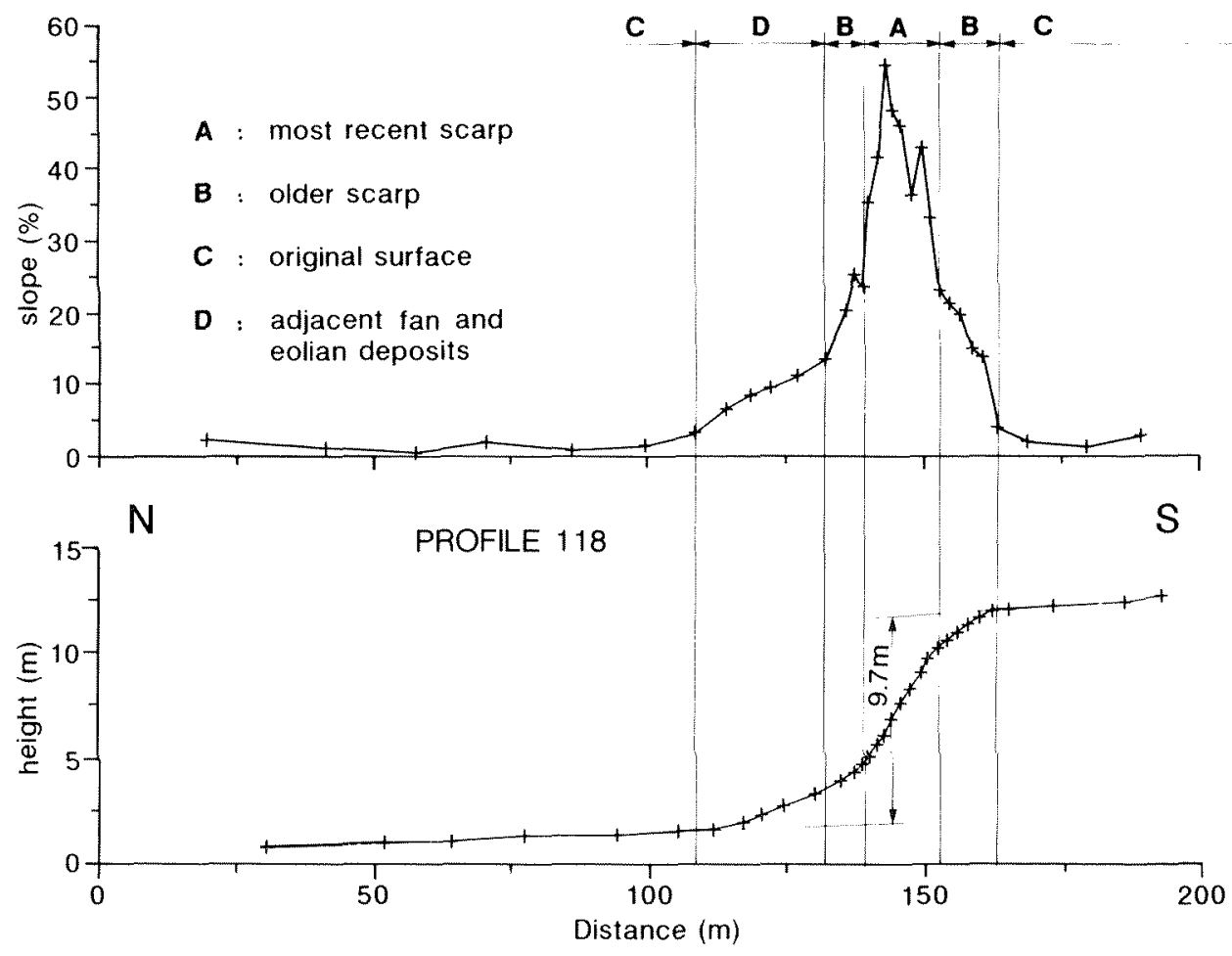

Fig. 8 b. Elevation and slope distribution along profile P118. This example is typical of most fault scarp profiles of average height. Central segment $A$ is steepest and most recent scarp, upper and lower parts B are remnants of more eroded, older scarp, $\mathrm{D}$ is zone of basal deposits, and $\mathrm{C}$ far field.

13). Most of them can be traced on the SPOT image over a distance of more than $5 \mathrm{~km}$ upstream from the faults (Figure 3a). The Qira river has now reached a lower level of equilibrium, preventing these channels from being supplied with water. Only during occasional spring floods do these channels collect some surface runoff. Therefore stream erosion in these valleys is unable to incise as fast as uplift is occurring.

The height of the major, north facing scarp appears to increase towards the east between sites 5 and 6 . Uppermost surface To, which refers here to the top surface of the Qira alluvial fan, is offset by approximately $16 \mathrm{~m}$ at site 5 west (Figures 14 and 15), $17 \mathrm{~m}$ at site 5 east (P66 and P67, Table 1), 


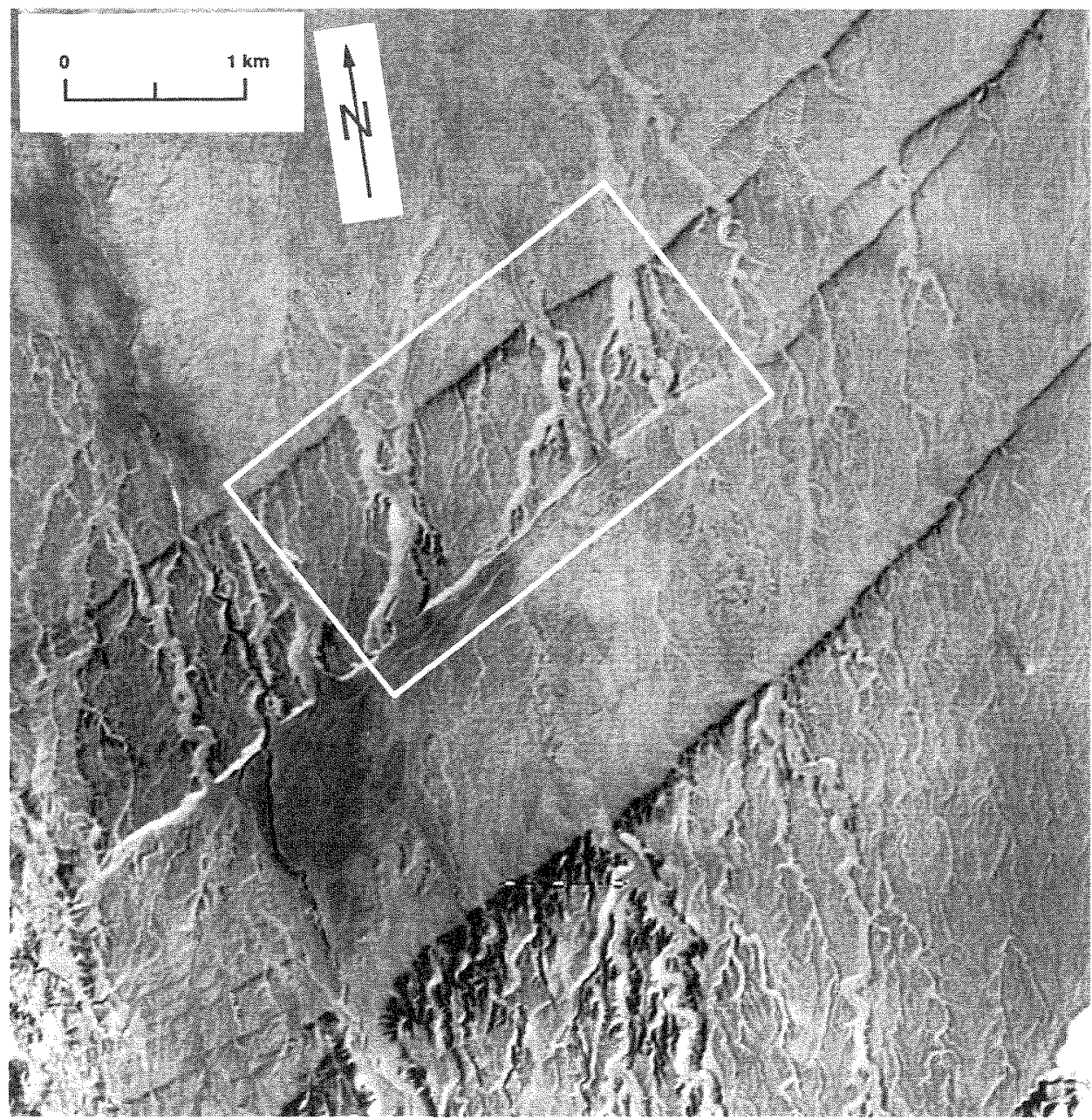

b

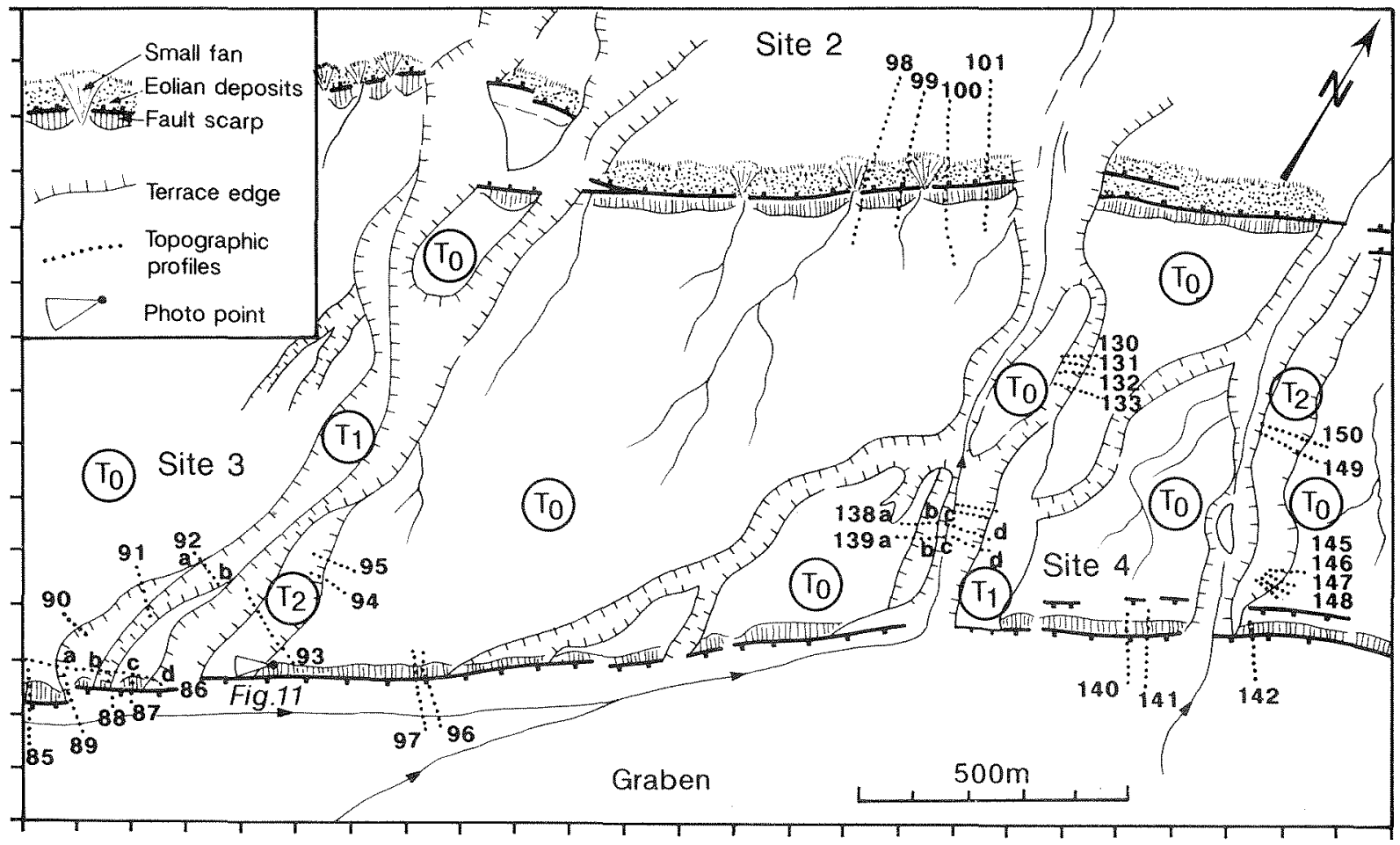

Fig. 9. (a) SPOT close-up view of southwestem part of Hotan-Qira fault systen. (b) Sketch map of zone in box in Figure 9a. Uplifted compartment between north and south faults bears entrenched flat floor valleys now abandoned due to uplift. Solid circles indicate location of leveling profiles at sites 2,3 , and 4 . 

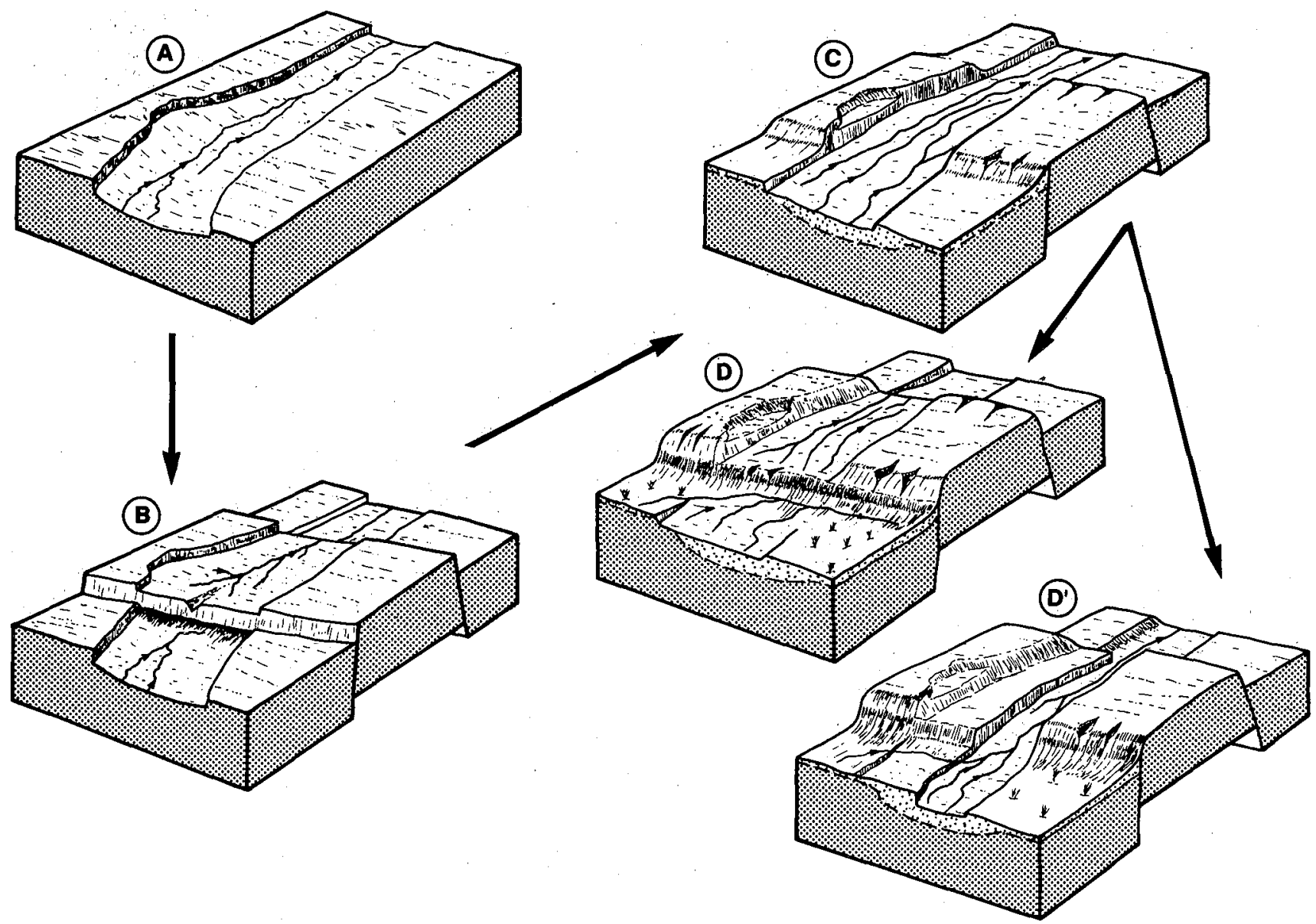

Fig. 10. Bloc diagrams showing sequence of faulting events and river entrenchment. (a) Aggradation of piedmont alluvium at time of large sedimentary discharge covers existing fault scarps. (b) Basement faults are reactivated. Ruptures propagate through sedimentary cover and reach surface. River channels are uplifted in fault footwalls. (c) Return of energetic river episode. Rivers recover longitudinal profile of equilibrium, cutting into fill terrace in uplifted compartment. Abandoned terrace risers degrade under action of erosion. Subsequent faulting events repeat scenario. (d) Small rivers are deviated and uplifted channel segments are abandoned. (d') Energetic rivers maintain profile of equilibrium.

and 19-22 $\mathrm{m}$ at site 6 (Figures 16, 17, 18 and Table 1). Farther east, the fault splits into three branches forming a graben and a horst (Figures 13 and 19). West of the junction, profile P24 and P32 indicate that surface T0 has been uplifted by approximately $19.4 \mathrm{~m}$ (Table 1). East of the junction, profiles $\mathrm{P} 22 \mathrm{a}, \mathrm{P} 22 \mathrm{~b}$ and P50 can be used to estimate the cumulative offset across the graben and horst, indicating that surface T0 is uplifted by approximately $17 \mathrm{~m}$ (Table 1). Given the uncertainty on these estimates due to the relatively poor constraints of the far field slope on profiles P22 and P24, it is likely that the total offset of the Qira fan surface is conserved across the fault junction. This suggests that the three branches probably merge at depth into a single fault plane. Along the southern branch of the fault, the easternmost profiles we have measured at site 7 indicate an offset of $13.5 \mathrm{~m}$ for upper surface T0 (Figures 20 and 21).

Offsets of lower levels T1 and T2 (where T2 is observed), appear to follow similar variations along the fault strike. At site 5 west, two inset terraces $\mathrm{T} 1$ and $\mathrm{T} 2$ are clearly identified and show offsets of $9.4 \mathrm{~m}$ and $6.5 \mathrm{~m}$, respectively (Figure 15). At site 6 west, the offsets of the corresponding levels increase to 13.7 $\mathrm{m}$ and $8.5 \mathrm{~m}$, respectively (Figure 17b). Note that at site 6 west the fault makes a right-stepping echelon, and that terrace levels are offset by both north and south fault branches (Figure $17 \mathrm{~b}$ ). The offsets indicated above are the total offsets recorded by these levels. At site 6 east, only upper level T1 can be identified and is offset by $13.5 \pm 1.0 \mathrm{~m}$ (Figure 18). Finally at site 7 , terrace level $\mathrm{T} 1$, which we interpret to correspond to the flat floor of the eastern valley (Figures 19 and 20a), appears to have been offset by two north dipping faults, approximately $140 \mathrm{~m}$ apart. The cumulative offset recorded by the valley floor is $7.9 \mathrm{~m}$ (Figure 20b).

At sites 5 and 6, west facing terrace risers have been well preserved from loess accumulation and other nondiffusive erosion processes, allowing us to estimate their degree of degradation. We have leveled two profiles across the edge of terrace $\mathrm{T} 0$ on eastern side of the valley V2, site 6 east (P31a and P34a, Figure 16). Analysis of profile 31 a by best adjustment of synthetic profile yields a well-defined estimate of the degradation coefficient of $34 \pm 6 \mathrm{~m}^{2}$ (Figure 21a). The base of profile P34a barely shows the intermediate level $\mathrm{T} 1$ as on profile P31a. However, if we assume that offset on profile P34a has the same amplitude as in profile P31a, the analysis of profile p3la yields the same degradation coefficient $\left(33 \pm 6 \mathrm{~m}^{2}\right)$ with a good quality fit (Figure 21a). An attempt at adjusting the entire profile with a synthetic profile indicates an 
a
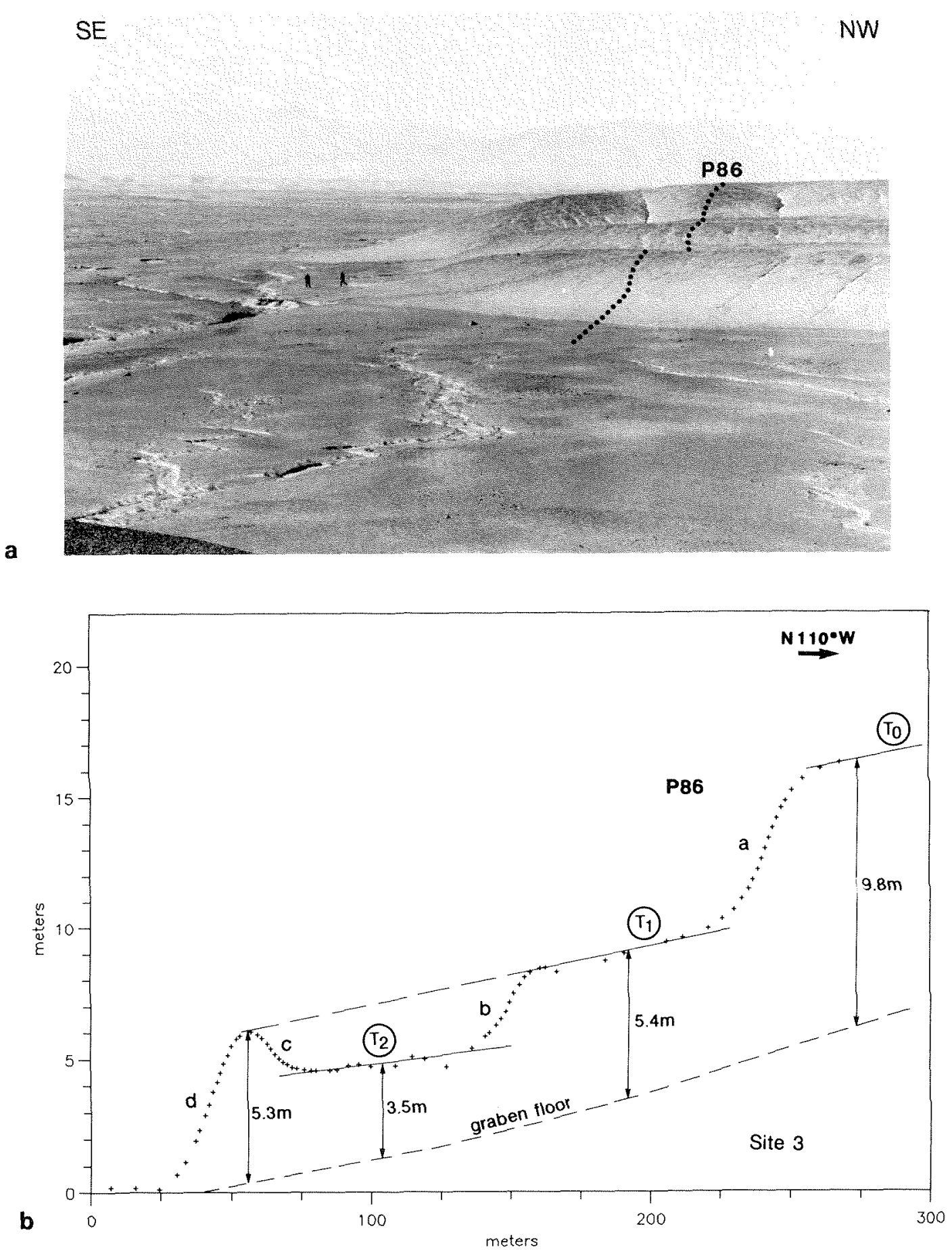

Fig. 11. (a) West looking view of terrace risers and south fault scarp at site 3 (see Figure 9b). (b) Profile P86 projected on a Nil $10 \mathrm{~W}$ plane. Heights of terraces T0, T1, and T2 with respect to base level in graben south of fault are from profiles P85, P89, and P88.

extremely poor fit and a degradation coefficient of $82 \mathrm{~m}^{2}$, inconsistent with all our other estimates at the studied sites (Table 3). We thus interpret this profile as a compound profile, similar to profile P31a. Profiles P81b and P82b have been measured across terrace riser T1-T2, $100 \mathrm{~m}$ south of the fault, at site 5 west (Figure 16). Morphologic analysis of these two profiles provides good adjustments with synthetic profiles and indicates degradation coefficients of $13 \pm 5 \mathrm{~m}^{2}$ for $P 81 \mathrm{~b}$, and $16.5 \pm 8 \mathrm{~m}^{2}$ for P82b (Figure $2 \mathrm{lb}$, Table 3 ). These values appear to be consistent with the values determined for corresponding levels at site 3 (Table 3 ).

\section{Example of Recent Fault Rupture}

At site 5 east, a clear mark of recent reactivation is visible at the base of the scarp (Figure 22a). This reactivation is particularly prominent between profiles $\mathrm{P} 67$ and $\mathrm{P} 73$, because it affects the colluvial toe of the cumulative fault scarp. We 
have measured the offset related to this reactivation on these profiles and have obtained $1.65 \pm 0.15 \mathrm{~m}$ (P67r, P68r, P69r, P71r and P73r in Table 1). The reactivation scarp merges laterally with the steeper part of the cumulative scarp and therefore cannot be distinguished easily in the scarp elevation and slope profiles (compare for example P66 and P68 in Figures $22 \mathrm{~b}$ and $22 \mathrm{c}$ ). At profile $\mathrm{P} 66$, it seems that reactivation of the scarp has rejuvenated most of the scarp slope forming a linear central segment with a steep slope close to the equilibrium slope of the colluvium. This is clear on the scarp slope profile which displays a plateau at $51 \%$ (Figure 22c). The nonreactivated part of profile P68 also displays a central linear segment but with a less steep slope of $43 \%$ (Figure $22 \mathrm{~b}$ ). Morphologic analyses of profiles across the reactivated scarp yields degradation coefficients of $1.6-4 \mathrm{~m}^{2}$ (Table 3 ). In Figure $22 \mathrm{~b}$, the original geometry of profile P68 has been restored by subtracting from the total scarp profile the best adjusted synthetic profile corresponding to the reactivation only. The good adjustment between measured and synthetic profiles and the consistency of the various degradation coefficient estimates suggest that the reactivation could be related to a single faulting event with a vertical slip of about $1.65 \mathrm{~m}$. If we take the value $\mathrm{k}=3.3 \mathrm{~m}^{2} / 10^{3}$ years for the mass diffusivity constant in the region of Hotan [Tapponnier et al., 1990], we derive an age of 360-1500 years for the last rupture on this fault. This estimate has to be corrected by adding the duration of the gravitational phase. In low-cohesion fanglomerates and for small scarps, the free face generally last for a few decades to a century [Wallace, 1977].
According to the seismicity map of Xinjiang [China Cartographic Publishing House, 1989], no large earthquake has been reported in the region of Hotan, except a $M=7$ earthquake, in 1882, whose epicenter is located approximately $50 \mathrm{~km}$ southwest of the city of Hotan (Figure 1). Given the sparsity of the population in this area, it might be possible that the epicenter of such an event would have been mislocated and that the earthquake would have occurred on the Hotan fault system. However, a $M=7$ earthquake on this fault system would have certainly ruptured significantly a large number of the fault scarps we have surveyed. It seems unlikely that the rupture observed at site 5 could correspond to the 1882 earthquake because our analysis of the reactivation scarp yields an age of 360-1500 years, i.e., significantly older than the 1882 earthquake. Alternative fault candidates for this earthquake would be the northern Kunlun frontal thrust, or, farther south, the western branch of the Altyn Tagh fault, in the Karakax valley. In this later case, this earthquake could have been responsible for the surface rupture of more than $100 \mathrm{~km}$ along this fault, with a coseismic displacement of several meters, ouserved by Tapponnier and others, and reported by Avouac [1991], in the Karakax valley.

\section{GEOMORPHIC CONSTRAinTS ON THE AGE OF TERRACE LEVELS}

\section{Terrace Riser. Degradation}

Analysis of SPOT images and field observations have shown that two abandoned terrace levels can be distinguished in large
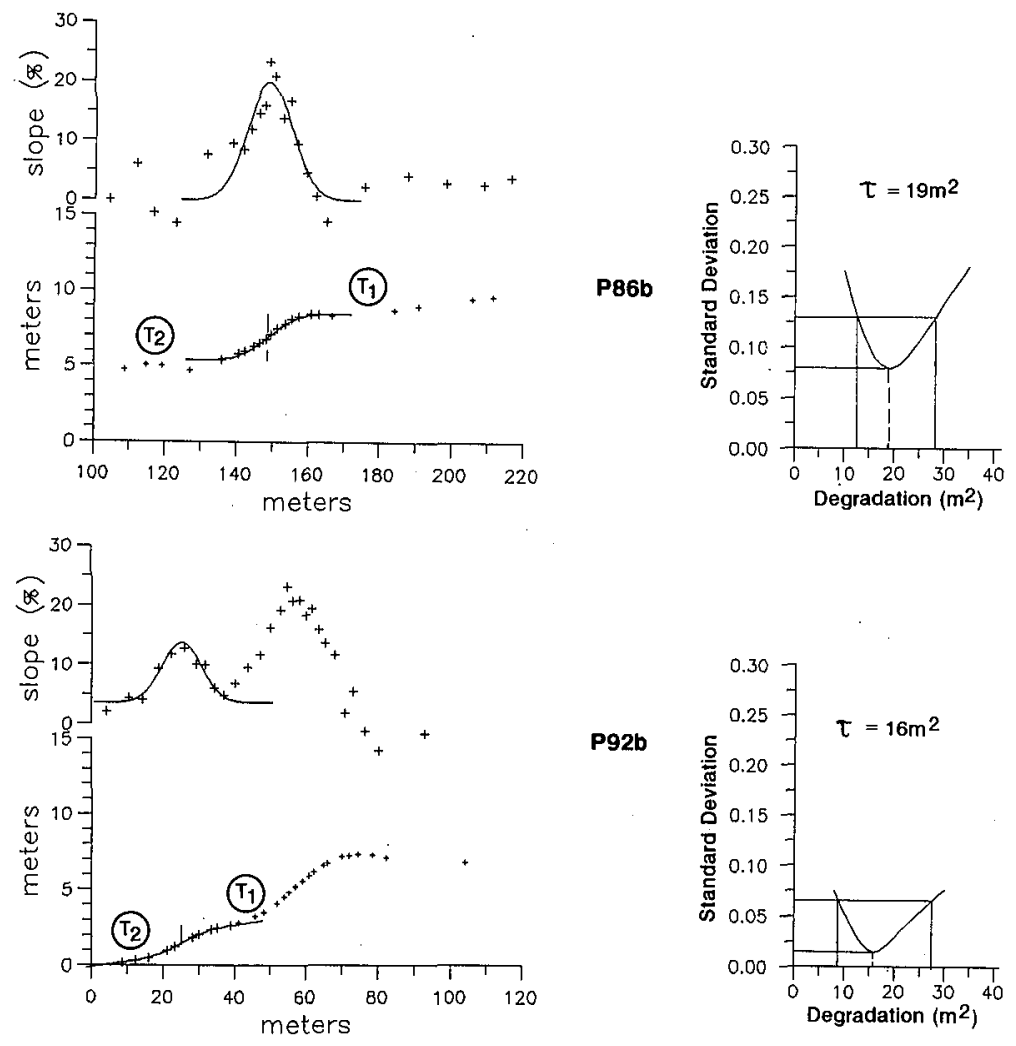

Fig. 12. Analyses of terrace risers degradation at site 3. For each profile, pluses are measurement points of elevation and slope distribution. Curves are best adjusted synthetic profiles. Standard deviation of vertical misadjustments between data points and synthetic profiles is plotted against degradation coefficient $\tau$. Values of $\tau$ corresponding to minimum standard deviation is indicated, and error bars are based on 5-cm uncertainty on vertical measurements. 

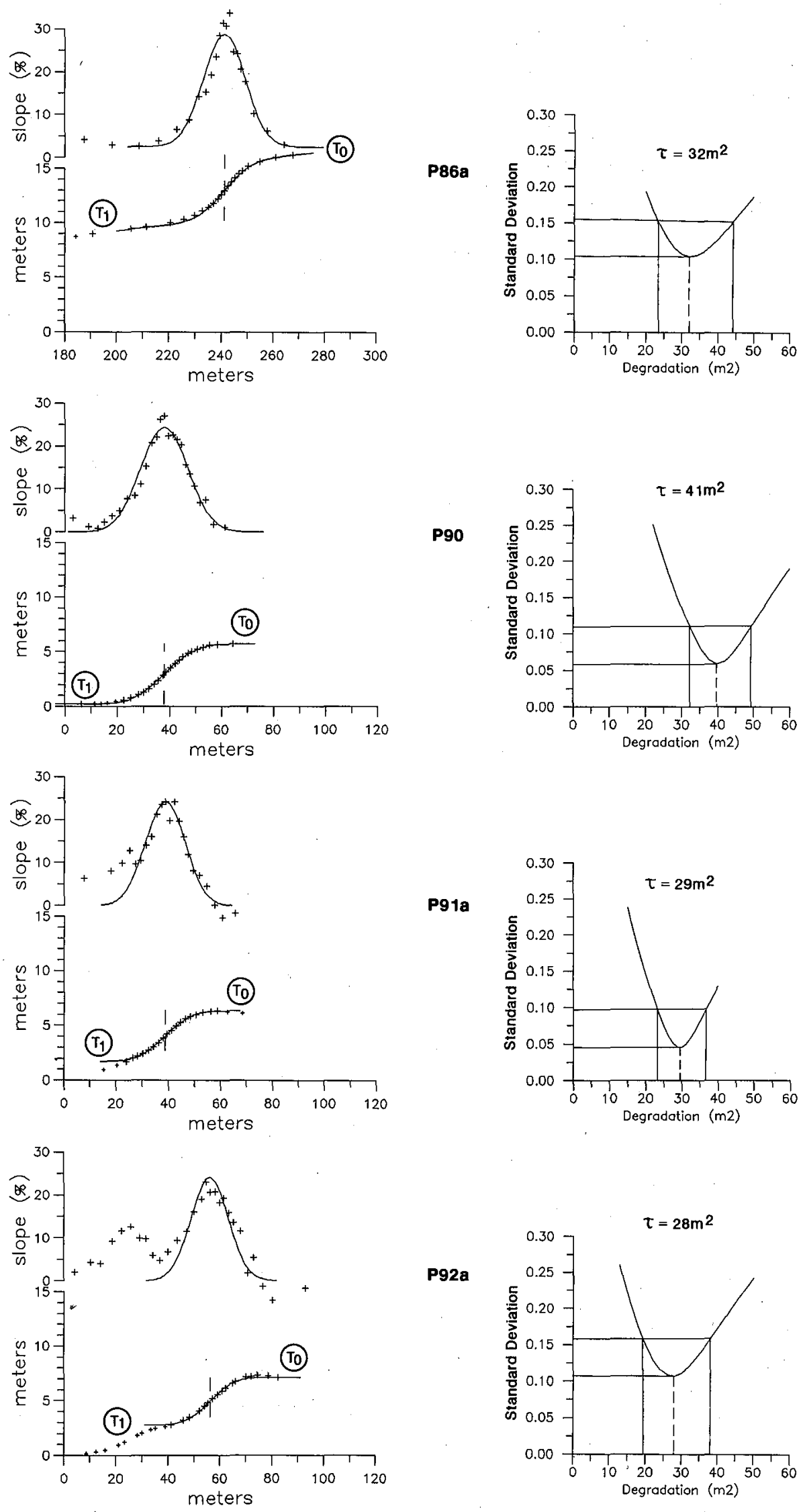

Fig. 12. (continued) 
TABLE 3. Morphologic Parameters Derived by Best Adjustment of Synthetic Profiles to Terrace Risers and Single Event Fault Scarps.

\begin{tabular}{|c|c|c|c|c|c|}
\hline Profile & $\begin{array}{c}\text { Offset } \\
\mathrm{m}\end{array}$ & $\begin{array}{l}\text { Regional } \\
\text { Slope, \% }\end{array}$ & $\begin{array}{l}\text { Terrace } \\
\text { Levels }\end{array}$ & $\begin{array}{c}\text { Standard. } \\
\text { Deviation, } \mathrm{cm}\end{array}$ & $m \frac{\text { Degradation, }}{m^{2}}$ \\
\hline & & & Site 3 & & \\
\hline P86a & 5.3 & 2.5 & $\mathrm{~T} 0 / \mathrm{Tl}$ & 8.9 & $22<32<42$ \\
\hline P86b & 3.1 & 0 & $\mathrm{~T} 1 / \mathrm{T} 2$ & 7.9 & $12.5<19<28$ \\
\hline P90 & 5.5 & 0 & $\mathrm{~T} 0 / \mathrm{T} 1$ & 6.0 & $33<41<49$ \\
\hline P9la & 4.6 & 0 & TO/T! & 4.6 & $23 .<29<37$ \\
\hline P92a & 4.35 & 0 & TO/T1 & 10.7 & $18<28<38$ \\
\hline P)2b & 1.38 & 3.5 & $\begin{array}{l}\mathrm{T} 1 / \mathrm{T} 2 \\
\text { Site } 5\end{array}$ & 1.4 & $8.5<16<27$ \\
\hline P8lb & 2.48 & 0 & $\mathrm{~T} 1 / \mathrm{T} 2$ & 4.1 & $8<13<18$ \\
\hline P82b & 1.99 & 1 & $\mathrm{~T} 1 / \mathrm{T} 2$ & 3.0 & $10<16.5<26$ \\
\hline$P 67$ & 1.80 & 17.5 & reactivation & 2.5 & $1.2<2.3<3.9$ \\
\hline P68 & 1.65 & 16.5 & reactivation & 3.9 & $1.0<2.1<4.7$ \\
\hline P69 & 1.46 & 14.5 & reactivation & 5.0 & $1.6<4<8.5$ \\
\hline P71 & 1.55 & 17 & $\begin{array}{l}\text { reactivation } \\
\text { Site } 4\end{array}$ & 5.0 & $0.5<1.6<4.0$ \\
\hline P31a & 7.75 & 0 & $\mathrm{~T} 0 / \mathrm{Tl}$ & 13.0 & $28<34<40$ \\
\hline P34a & 7.80 & 0 & $\mathrm{~T} 0 / \mathrm{T} 1$ & 14.5 & $26<33<39$ \\
\hline P34a & 10.2 & 0 & $\mathrm{TO} / \mathrm{Tl}$ & 43.3 & $62<82<112$ \\
\hline
\end{tabular}

Standard deviation indicates quality of profile adjustment.

valleys below the uppermost surface level (TO) which forms essentially all the Western Kunlun piedmont in the region of Hotan. These inset teraces are particularly well developed in flat-floored valleys in uplifted footwalls, south of large northfacing normal fault searps. As noted before, the entrenchment of rivers in fault footwalls is the result of vertical movement on these faults. Hence vertical offsets of terraces above the present level of river equilibrium provide information about the amplitude of fault slip since terrace formation. Constraints on the age of such terraces would inform us on the rate of faulting along the fault system.

We have measured total offsets of terrace levels $\mathrm{T} 0$ and $\mathrm{Tl}$ at 6 sites along the fault system (Table 2). Although the amount these terraces have been uplifted varies from one site to the next, the mean values at all sites, indicate that the of fset of terrace $\mathrm{T} 1$ is approximately $55-60 \%$ of that of uppermost surface To (Table 4 and Figure 23a). Assuming that the rate of fault slip has remained essentially constant since the deposition of piedmont surface TO, this suggests that the formation of terrace $\mathrm{T}$ l occurred synchronously at all these sites, presumably during a major morphogenic episode. Our analyses of terrace riser degradation seem to confirm this inference. Recall that the degradation of terrace riser TO-Tl starts when the formation of $\mathrm{Tl}$ is completed. Its state of degradation is thus an indicator of the age of $\mathrm{Tl}$. The degradation coefficients derived for all profiles leveled across terrace riser T0-Tl cluster between 29 and $41 \mathrm{~m}^{2}$, with a mean value of $33.3 \pm 4 \mathrm{~m}^{2}$ (Table 2 and Figure 23b). Since, in a given environment, the state of degradation of a scarp is a function of its age, such a cluster also indicates a synchronous occurrence for terrace $\mathrm{Tl}$ at all sites.

We have made similar observations for the lower terrace level $\mathrm{T} 2$, although $\mathrm{T} 2$ could not be clearly identified in all valleys. At sites 3, 4, and 5, where level T2 has been observed, measurements show that its vertical of fset is approximately 35$40 \%$ of that of upper level To (Figure 23a). Analyses of the state of degradation of terrace riser T1-T2, which is an indicator of the age of level T2, yield degradation coefficients of 13-19 $\mathrm{m}^{2}$, consistent with a younger age for $T 2$ compared to $\mathrm{T} 1$ (Figure 23b).

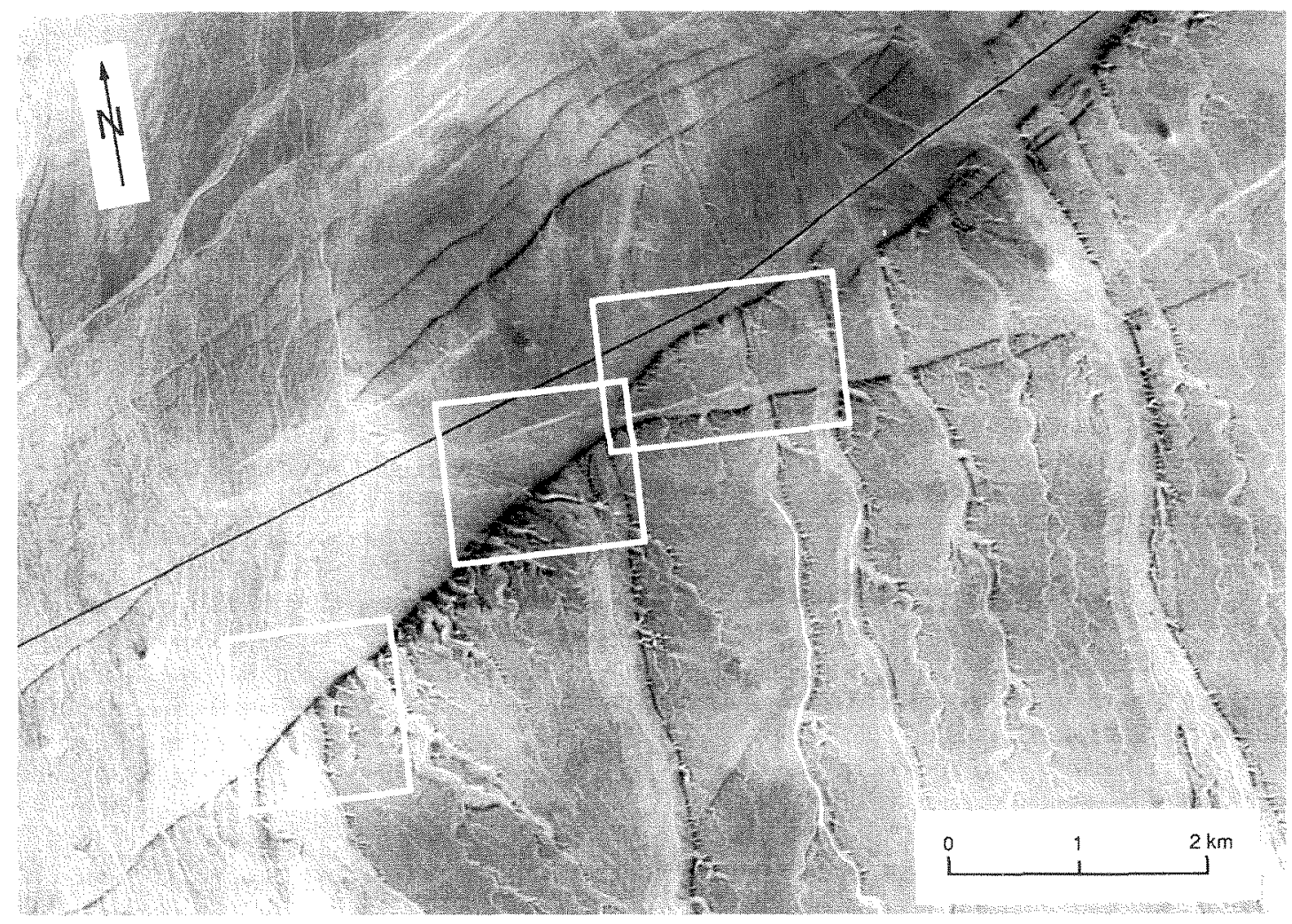

Fig. 13. SPOT close-up view of northeastern part of the Hotan-Qira fault system. Boxes depict areas shown in Figures 14, 16, and 19 , and correspond to sites 5,6 , and 7 , respectively. 


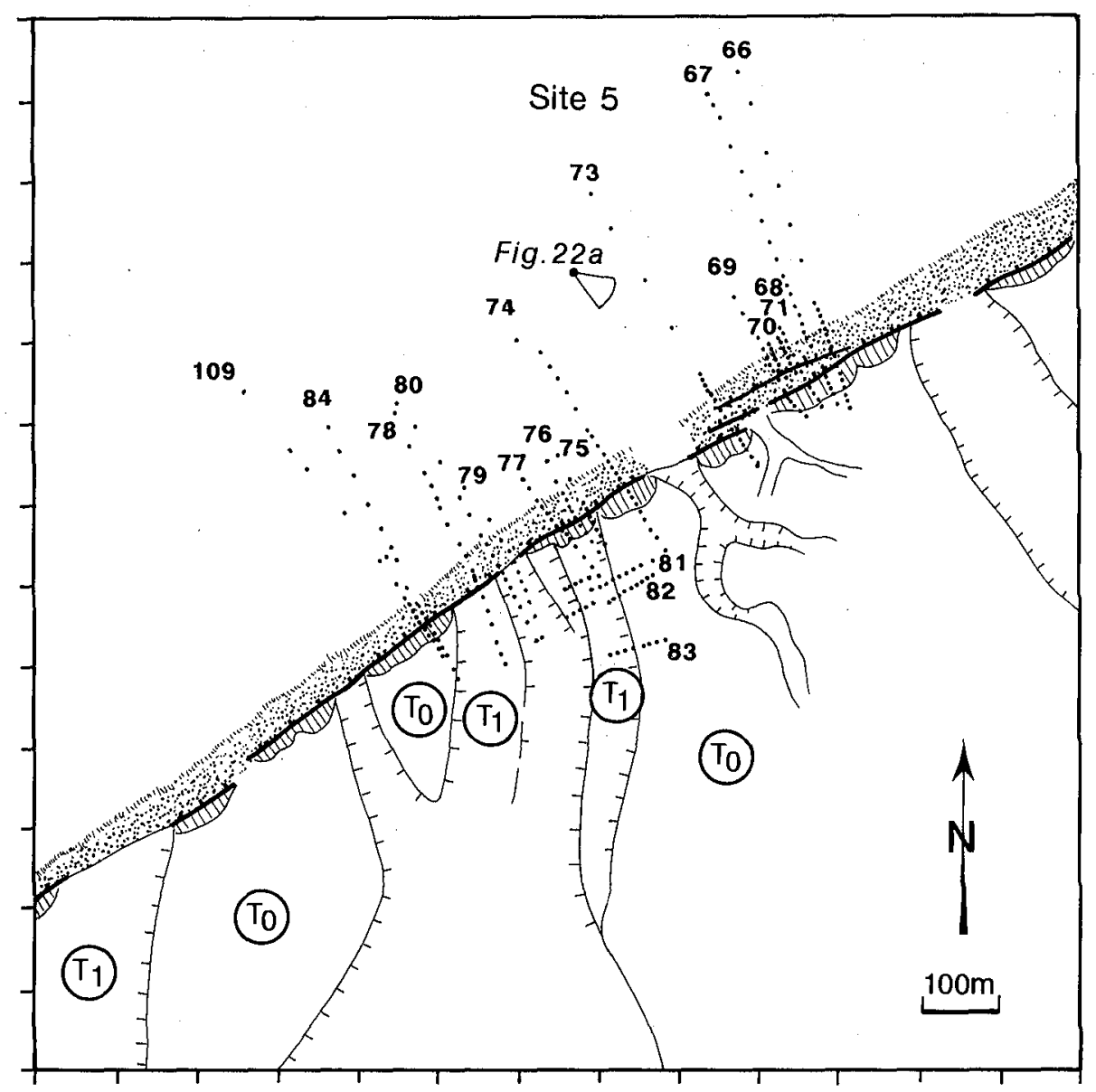

Fig. 14. Sketch map of morphology at site 5. See box in Figure 13 for location. Solid circles indicate leveling profiles.

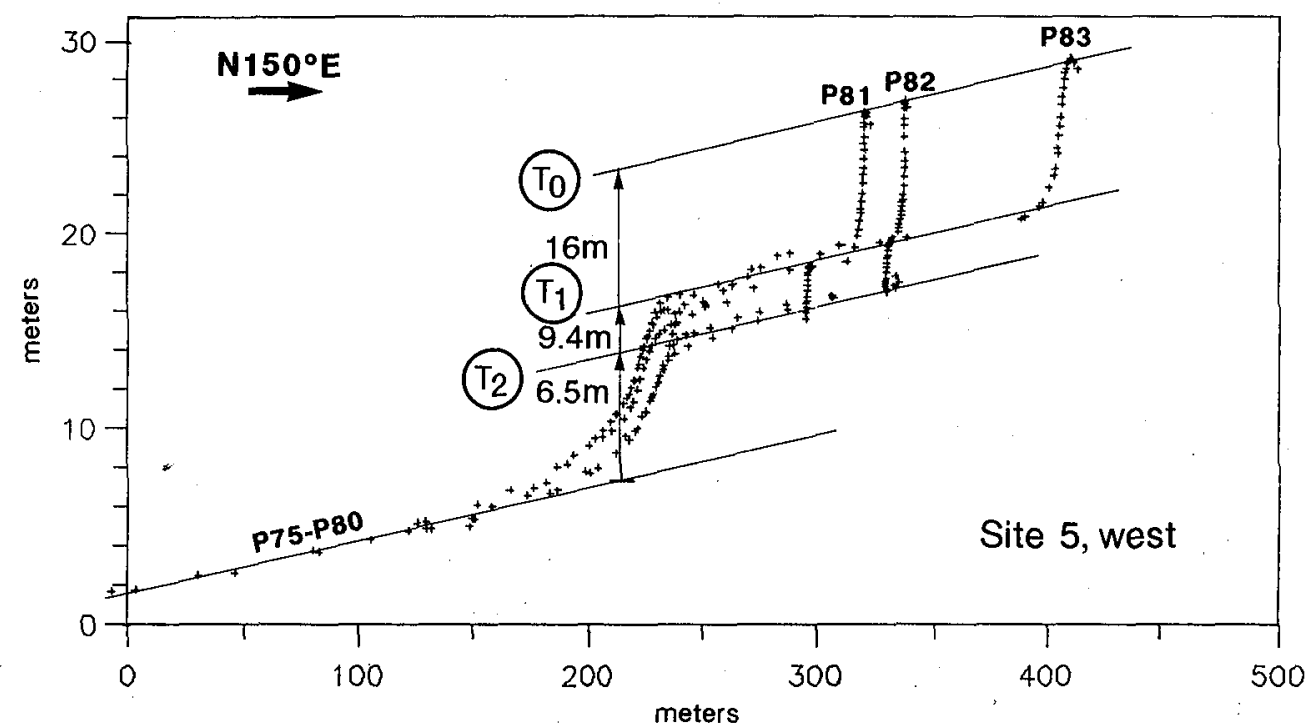

Fig. 15. Projection of profiles P75, P80, P81, P82 and P83 on a vertical plane striking N150 ${ }^{\circ}$. Vertical offset of terraces T0; T1, and $\mathrm{T} 2$ refer to surface slope at base of scarp. 


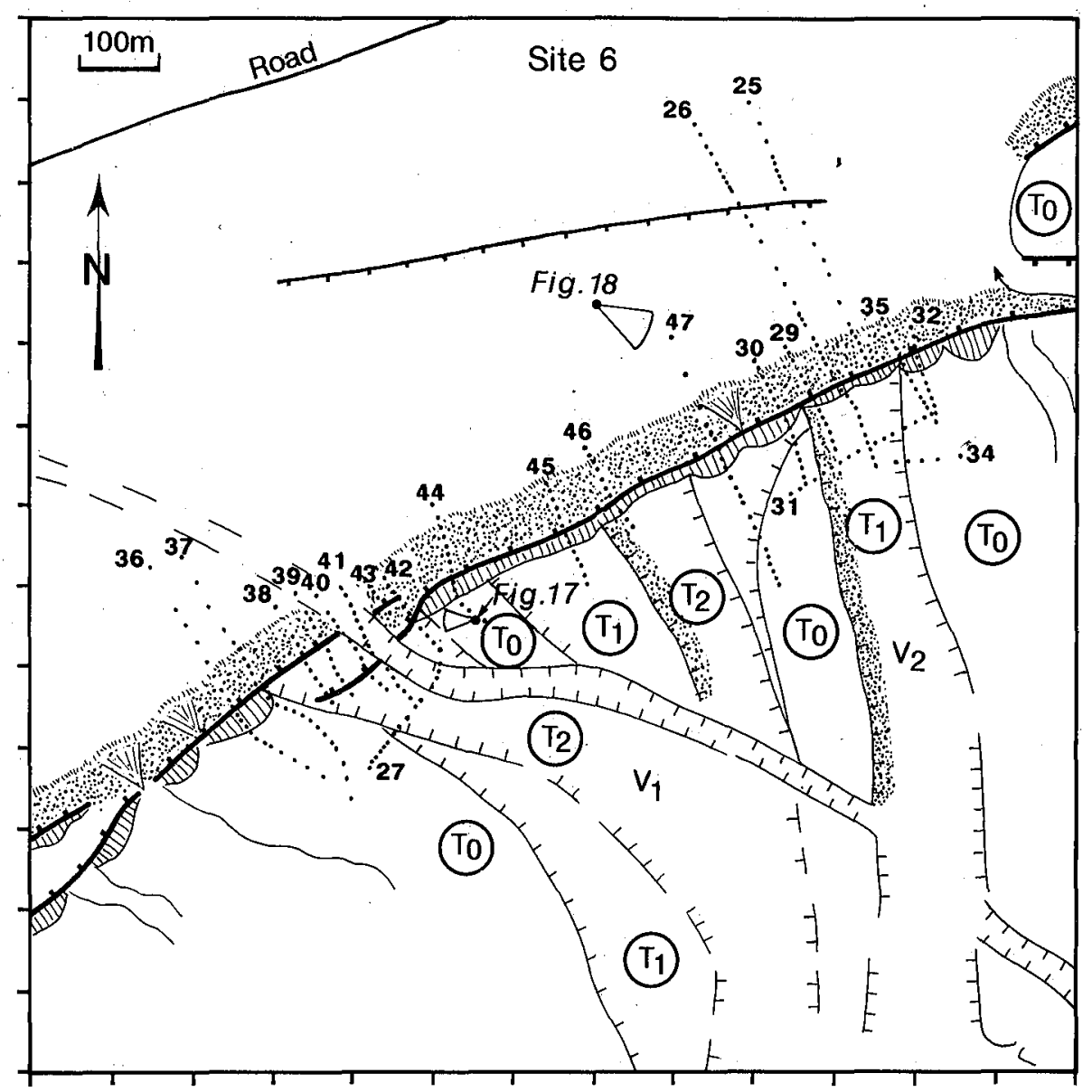

Fig. 16. Sketch map of morphology at site 6 (box in Figure 13). Symbols are as in Figure $9 \mathrm{~b}$.

For many of our profiles leveled across terrace risers, analysis by best adjustment with synthetic profiles was not possible, or would have led to erroneous results. As discussed previously, the main reason for this is that our model does not take into account effects such as deposition of eolian sediments at the base of scarps. Large accumulation of eolian sediments makes scarp profiles too asymmetrical to be reliably adjusted to a symmetric, synthetic profile (e.g., Figure $8 \mathrm{~b}$ ). However, for such asymmetrical scarps, since eolian sediments were concentrated at their base, the maximum slope could still be measured with good confidence. Following Hanks and Andrews [1989], we have plotted the reduced scarp slope $(\tan \alpha-\tan \beta)$ as a function of the scarp height for all our profiles of terrace risers (Figure 24a). According to the Hanks and Andrews [1989] approach, terrace risers of same age should fall on, or near the same error function curve corresponding to their degradation coefficient. Figure $24 \mathrm{a}$ shows that most points corresponding to terrace riser T0- T1 fall between the curves $20 \mathrm{~m}^{2}$ and $40 \mathrm{~m}^{2}$, and those corresponding to riser $\mathrm{T} 1$ $\mathrm{T} 2$, between the curves $10 \mathrm{~m}^{2}$ and $20 \mathrm{~m}^{2}$. The mean values of $33.3 \pm 4 \mathrm{~m}^{2}$ and $16 \pm 1 \mathrm{~m}^{2}$ determined by degradation analysis of terrace risers $\mathrm{T} 0-\mathrm{T} 1$ and $\mathrm{T} 1-\mathrm{T} 2$, respectively, appear to be in good agreement with these brackets.

\section{Cumulative Fault Scarp. Degradation}

The analysis of fault scarps resulting from cumulative displacements is generally more difficult than that of scarps resulting from a single event, such as a single-rupture fault scarp or a river-cut terrace riser [e.g., Mayer; 1984]. The number of parameters involved in a cumulative fault scarp model renders the analysis by best adjustment of individual profiles ill adapted to the problem. However, the forward modeling approach described in Appendix $\mathrm{A}$ allows us to assess the influence of various parameters involved in the model on the resulting scarp geometry. Comparing model predictions with our profile measurements yields some constraints on fault slip rates. As we did for terrace risers in Figure 24a, we have displayed parameters derived from fault scarp profiles measured along the Hotan-Qira fault system on a reduced slope versus offset graph (Figure 24b). Since fault scarps are high and result from several seismic events, they cannot be compared with simple functions obtained with the diffusion model as in Figure 24a. The curves displayed in Figure 24b have been computed from a series of synthetic scarps generated using a simple scarp incremental model (Appendix A). Each scarp is the result of a sequence of elementary vertical offsets of amplitude $\Delta h$ inserted between dormancy intervals of duration $\Delta t$, during which erosion degrades the scarp as a Gaussian smoothing. The overall shape of the scarp is mostly controlled by the dip of the fault and the two parameters $\Delta h$ and $\Delta \tau, \Delta \tau$ being equal to $k \Delta t$, where $k$ is the mass diffusivity constant. $\Delta \tau$ represents the scarp degradation during a dormancy interval. In Appendix A we show that the maximum slope of synthetic profiles is most sensitive to the ratio $\Delta h / \Delta \tau$, i.e., the slip rate on the fault, and the fault dip. High fault slip rate and large fault 
Site 6, west
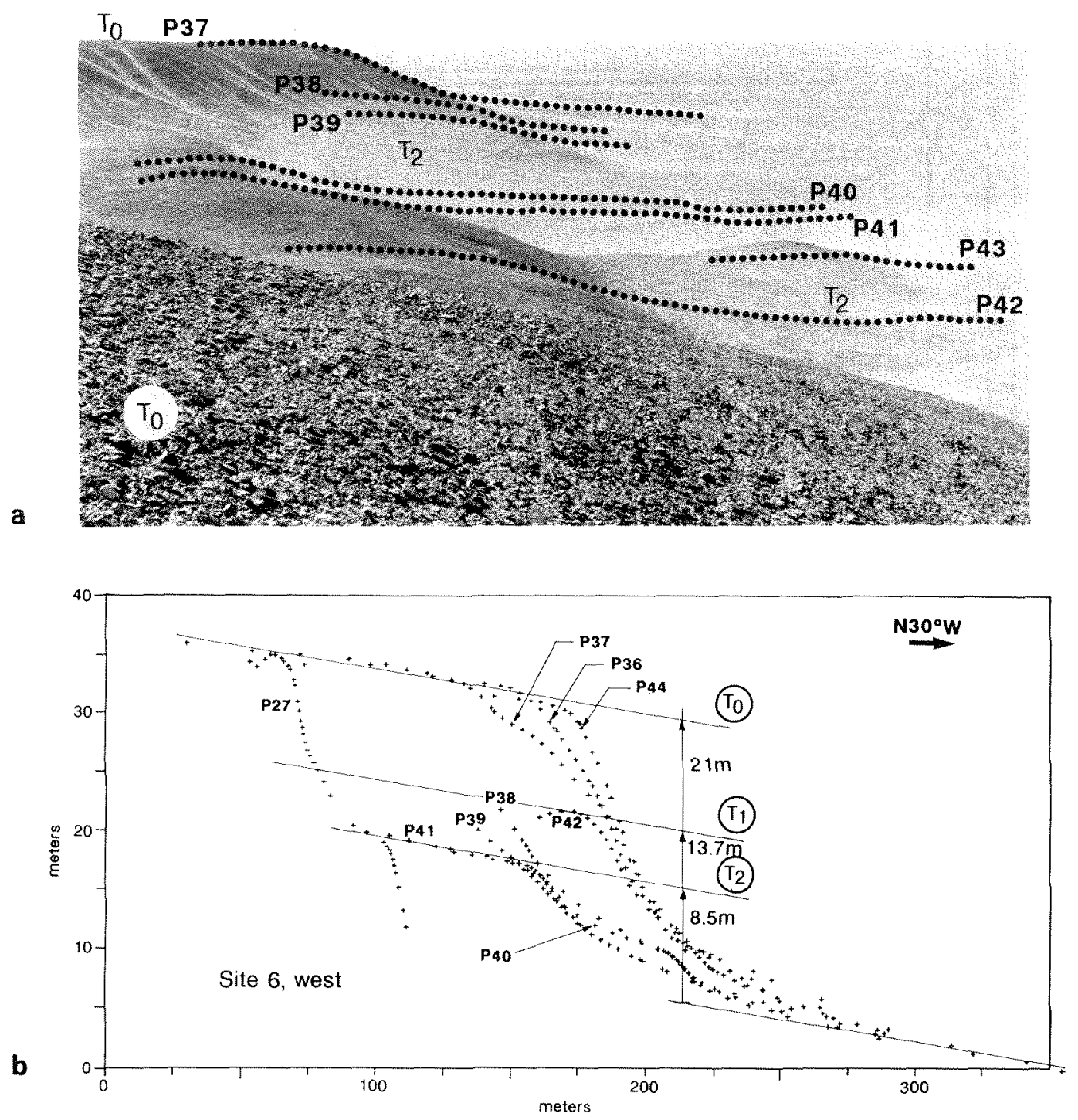

Fig. 17. (a) West looking view of right-stepping echelon on fault across valley $V I$ at site 6. (b) Vertical projection of profiles P27, P36, P37, P38, P39, P40, P41, P43, and P44 at site 6.

dip both produce steep scarps, whereas low rates and small dips make less steep scarps. A trade-off exists between these two parameters. Our measurements in the field show that scarps as small as $1.6 \pm 0.3 \mathrm{~m}$ could have occurred during individual fault ruptures (Table 1). The curves displayed in Figure $24 \mathrm{~b}$ are the slope offset distributions of populations of ideal scarps defined by $\Delta h=1.5 \mathrm{~m}$ and $\Delta \tau=6,8$ and $10 \mathrm{~m}^{2}$, for faults dipping $31^{\circ}, 45^{\circ}$ and $56^{\circ}$. Our measurements clearly indicate a departure from such ideal distributions. Two main reasons can be advocated to explain such a departure. First, the assumption that all scarps have been formed by elementary offsets of equal heights with a constant return period may not be strictly valid for all the scarps considered in this analysis. Second, and more important, is the observation that elementary scarps are likely to return at different places along the scarp profile, whereas in our model, elementary ruptures all occur at the same abscissa.
The primary effect of distributing the elementary ruptures over a finite length is to reduce the maximum slope of the scarp and increase its length by the same factor. According to this second interpretation, and if the fault rate was uniform along the fault system, all the scarps displayed on the slope offset graph of Figure $24 \mathrm{~b}$ should fall on or below a given curve. The curve best matching the upper envelope of our measurement distribution can be used to constrain the set of parameters $\Delta h$, $\Delta \tau$ and fault dip best describing the fault characteristics along the Hotan-Qira system. With throw increments of $\Delta h=1.5 \mathrm{~m}$, consistent with heights of smallest scarps measured in the field (Table 1), Figure $24 \mathrm{~b}$ shows that at least for scarps higher than $5 \mathrm{~m}$, the curve corresponding to a fault dip of $45^{\circ}$ and intervals $\Delta \tau$ of $8 \mathrm{~m}^{2}$ matches satisfactorily the data. Although this is an approximate figure, based on an average fault slip rate for all sites, it appears to be consistent with our analysis of terrace riser 

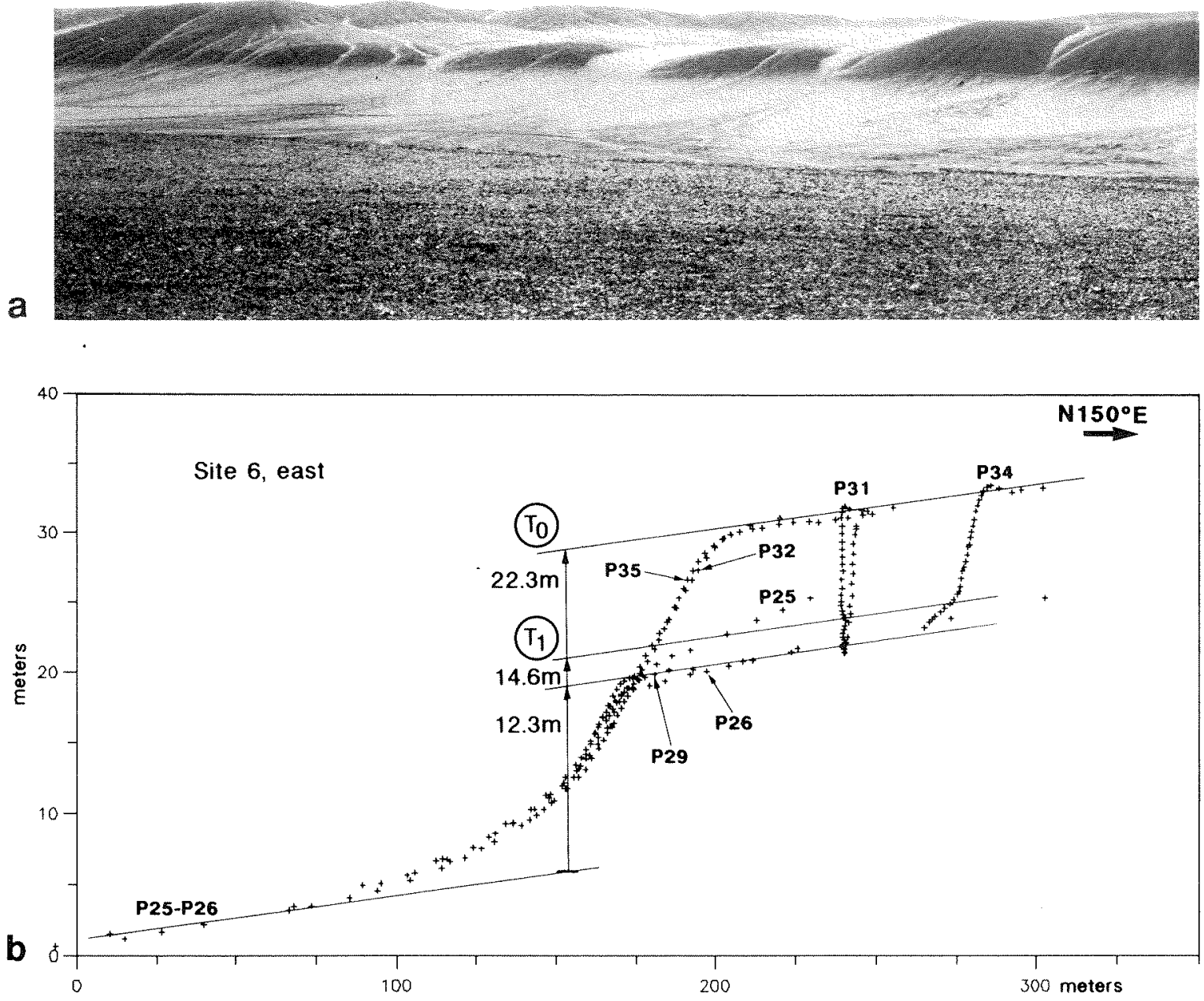

Fig. 18. (a) Southeast looking view of fault across valley V2 at site 6. (b) Vertical projection of profiles P25, P26, P29, P31, P32, $P 34$, and $P 35$ at site 6.

degradation. If one excepts site 6 , where terrace offsets appear to be particularly high, and thus fault slip rates probably higher than at other sites, the average offset of terrace T1 is $6.45 \pm 2.8 \mathrm{~m}$ (Table 4). If this offset is the result of vertical increments of $1.5 \mathrm{~m}$ separated by intervals corresponding to $\Delta \tau=8 \mathrm{~m}^{2}$, the age of terrace $\mathrm{Tl}$ would correspond to a degradation coefficient of $34.4 \pm 12 \mathrm{~m}^{2}$, consistent with the value of $33.3 \pm 4 \mathrm{~m}^{2}$ derived from our analysis of terrace riser degradation. Our estimate of scarp vertical slip rate appears to be larger than the estimate derived using the continuous offset scarp model of Hanks et al. [1984]. Using Hanks et al. [1984] equation (14) and our data of Figure 24, one can estimate the ratio $2 A / k=0.05 \mathrm{~m}^{-1}$, where $2 A$ is the vertical slip rate and $k$ the mass diffusivity constant. Our estimate of the same quantity is $\Delta h / \Delta \tau=0.19 \mathrm{~m}^{-1}$, approximately 4 times larger than the value obtained with the continuous offset model. This large discrepancy is mainly due to the fact that the continuous offset model does not involve any gravitational phase. The gravitational collapse of incremental free faces makes the central segment of the scarp rest at the angle of repose of the material when the diffusive phases begins (Appendix A). Therefore for a given vertical slip rate, the continuous of fset model would predict scarp slopes steeper than the incremental model. Conversely, the rate derived from the analysis of a given scarp is smaller when using the continuous model than when using the incremental model.

\section{Possible Correlation Between the Last Glacial REtreat and Fan AGGRADATION}

The studied area, along the Hotan-Qira fault system is located $80-100 \mathrm{~km}$ north of the highest peaks in the Kunlun 


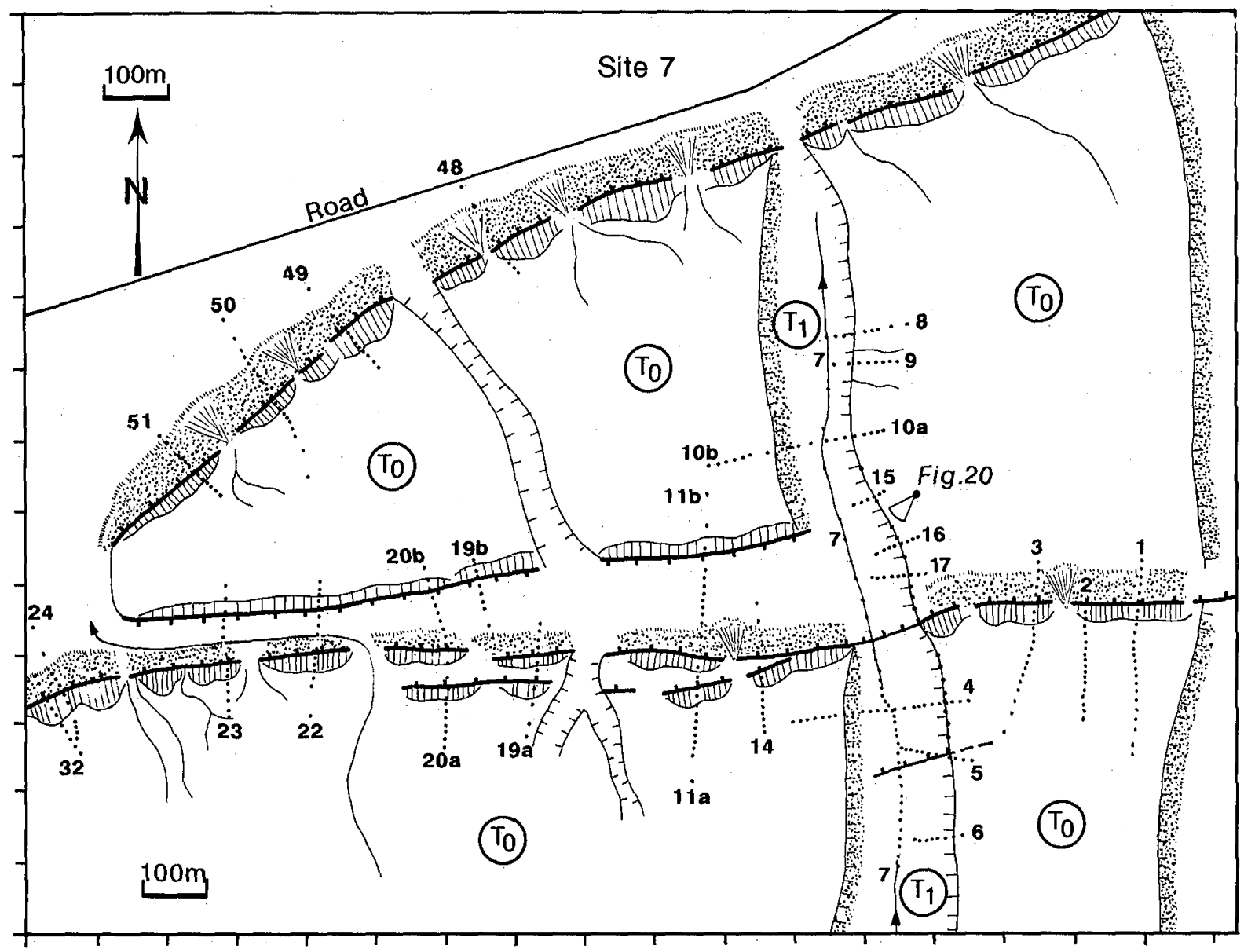

Fig. 19. Sketch map of surface morphology at site 7 (Figure 13). Symbols are as in Figure $9 \mathrm{~b}$.

mountains, with elevations in excess of $6000 \mathrm{~m}$ (Figure $2 \mathrm{~b}$ ). Rivers like the Qira River, the Yurung Kax and the Keriya River have their source at the foot of these high peaks and have probably channeled large amounts of meltwater during the successive glacier retreats of the last glacial age. A detailed study of glacial and periglacial features in the Keriya River basin, $60 \mathrm{~km}$ east of Qira, is reported by Jakel and Hofmann [1991] and Hovermann and Hovermann [1991]. Because the Qira fan (1) appears to be composed of similar coarse gravels and (2) rests at the same elevation and about the same distance from the Kunlun front as the Keriya fan, it seems reasonable to assume that both fans are contemporaneous. The results of Jakel and Hofmann [1991] show in particular that the Keriya fan is of glaciofluvial origin, connected to the terminal moraines of the last major glacial stade (Pulu stade). Based on ${ }^{14} \mathrm{C}$ age determination of charcoal found in moraines and loess, they infer that the end of the Pulu stade took place between 25,000 and 5,000 years. Because alluvial fans aggradation generally takes place during major episodes of river outwash and sediment discharge such as those produced by glacier retreats, we can reasonably assume that the Keriya and the Qira fans emplaced when the Kunlun glaciers retreated after the last glacial maximum, dated at 19,000 years $\left({ }^{14} \mathrm{C}\right.$ age) according to oxygen isotope record in marine sediments (SPECMAP [Martinson et al., 1987]). Hovermann and Hovermann [1991] further report polygons soil formed by permafrost on the Qira fan surface, at an elevation of $1800 \mathrm{~m}$ above sea level.
This suggests that the surface of the fan has been exposed to a periglacial environment after its aggradation, which might thus predate the end of the glaciation. From the analysis of sediment cores collected in lakes of western Tibet, Gasse et al. [1991] infer that the end of the glacial period took place in two stages, at 12,500 and 10,000 years $\left({ }^{14} \mathrm{C}\right.$ age). This result corroborates those inferred from the sea level record, which shows two increase pulses followed by stabilization after 9,000 years [Fairbanks, 1989]. If we correct the ages above according to the ${ }^{14} \mathrm{C}$ age scale calibration of Bard et al. [1990], the ${ }^{14} \mathrm{C}$ age brackets of $10-19,000$ years for the aggradation of the Qira fan would become $12.5-22,000$ years $(\approx 17 \pm 5 \mathrm{ka})$. In the absence of more precise age determination of terrace surfaces in the studied region, we feel confident in these ages and discuss below some consequences of this assumption and its consistency with other observations.

\section{Estimation of Mass Diffusivity Constant $k$ in Southern Tarim}

The degree of degradation of abandoned terrace risers and amplitude of cumulative uplift of terrace levels both increase with age. Although the amounts of uplift of terrace levels T0, $\mathrm{T} 1$ and $\mathrm{T} 2$ vary significantly from one site to the next, we have observed that their ratios remain essentially constant along the fault system (Figure 23a). We have displayed synthetically the results of our morphologic analyses in Figure 25. For each 

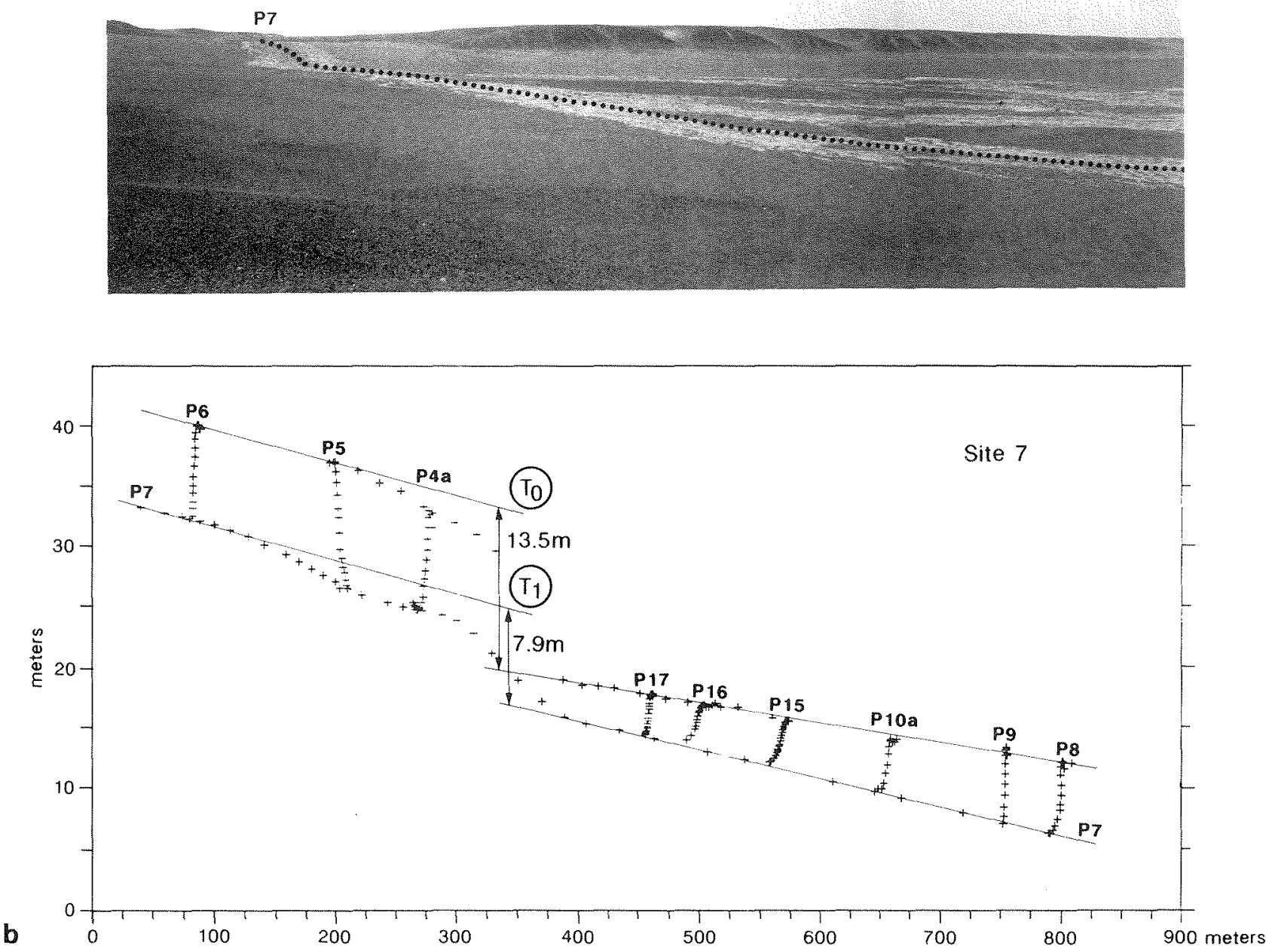

Fig. 20. (a) Southwest looking view of north facing fault scarp and flat foor valley at site 7. (b) N-S projection of profile P7 along the valley floor (T1) and of profiles of terrace riser between levels $\mathrm{T} 0$ and $\mathrm{Tl}$. Note that valley floor is offset at two places by fault scarps.

analyzed profile of terrace riser, the degradation coefficient is plotted as a function of the vertical of fset of the corresponding terrace level, normalized by the offet of uppermost level TO at the same site. The graph shows that, within our error bars, the degradation coefficient varies linearly with the normalized vertical offset of terraces. Since both are independent functions of time, this suggests that both, the coefficient of degradation and the normalized offset, might vary linearly with time. This would imply that both the rate of erosion and the rate of vertical uplift on faults have remained essentially constant since the deposition of the piedmont surface $\mathrm{T} 0$ in the region of Hotan. A linear dependency of degradation coefficient with time $(\tau=k T)$ is consistent with the diffusion model based on the assumption that the rate of down-slope transport of material is proportional to local slope of scarp [Nash, 1980; Hanks et al.,
1984; Andrews and Hanks, 1985]. Note that such a linear dependency of degradation coefficient with time has also been obtained using a similar approach for scarps along the northern front of the Tien Shan [Avouac et al., 1993].

Constant slip rate on faults and relative heights of surfaces T0, T1 and T2 determine ages of $10.2+3 \mathrm{ka}$ for terrace $\mathrm{T} 1$ and $6.8 \pm 3 \mathrm{ka}$ for terrace $\mathrm{T} 2$, given the age of $17 \pm 5 \mathrm{ka}$ inferred for the surface of the Qira fan (TO). Although the age of $\mathrm{T} 2$ cannot be correlated with any documented climatic event in the region, the fact that similar middle Holocene terraces have been observed on the northern front of the Tien Shan [Avouac et al., 1993] suggests that its formation and abandonment may have been driven by a climatic factor. The age of $\mathrm{Tl}$ is synchronous with the wet, warm pulses recorded at 12.5-10,000 years in lacustrine sediments of Western Tibet [Gasse ef al., 


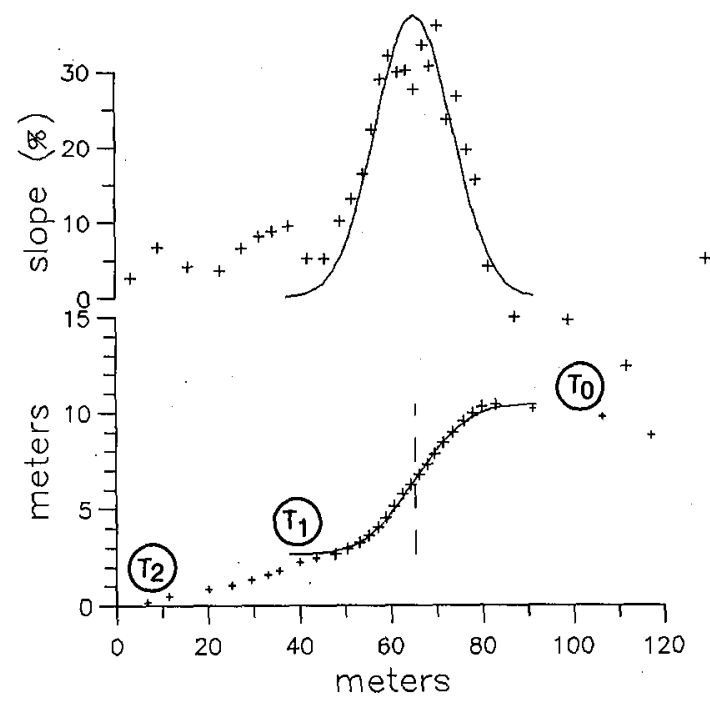

P31a
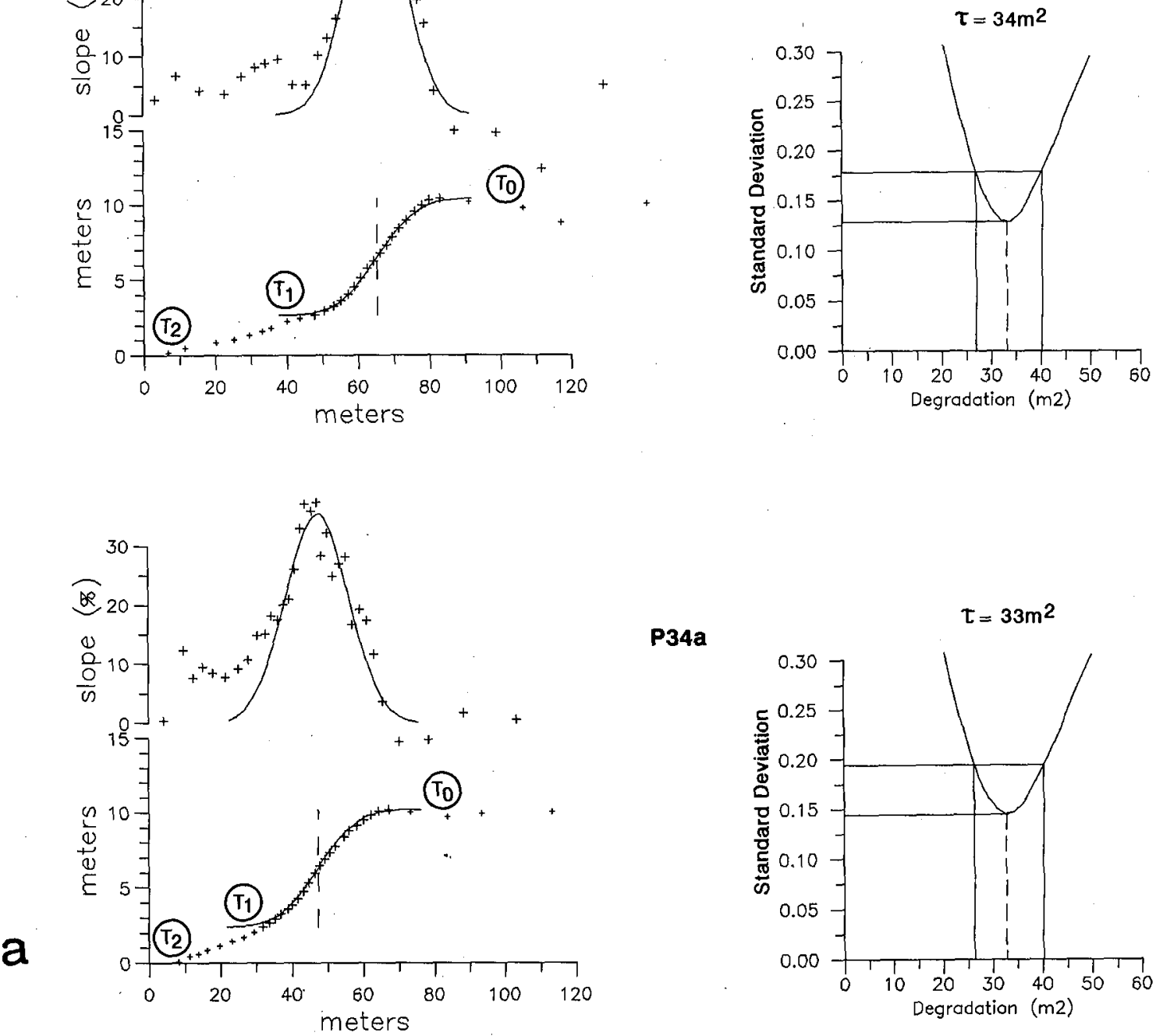

Fig. 21. (a) Analysis of profiles P31 a and P34a across terrace riser between levels T0 and T1. (b) Analysis of profiles P8 $1 \mathrm{~b}$ and P82b of terrace riser between levels T1 and T2. Plots and symbols are as in Figure 12.

1991]. Consequently, since the age of T1 corresponds to the abandonment of scarps whose degradation coefficient has been determined to be $33.3 \pm 4 \mathrm{~m}^{2}$ (Figure $23 \mathrm{~b}$ ), the mass diffusivity constant in the region of Hotan can be determined and is $3.3 \pm 1.4 \mathrm{~m}^{2} / 10^{3}$ years (Figure 25 ). This value is equal to the value determined for scarps formed in similar conditions in the Gansu corridor [Tapponnier et al., 1990]. Along the northern piedmont of the Tien Shan; however, Avouac et al. [1993] have determined a value of $5.5 \pm 2 \mathrm{~m}^{2} / 10^{3}$ years, slightly above the value determined here. A larger mass diffusivity constant is consistent with a higher rate of erosion resulting from a relatively more humid climatic environment. A broad classification of climatic zones in western China shows that southern Tarim and the Gansu corridor, at the northern front of the Qilian Shan are both in the arid area, whereas the northern piedmont of the Tien Shan is considered as semiarid [Beijing Map Publishing House, 1984; Dormös and Peng, 1988]. The values we found for $\mathrm{k}$ in western China are approximately 3 times larger than those obtained for similar scarps under semiarid climate in the western United States [Hanks et al., 1984; Hanks and Wallace, 1985]. Although our approach differs from that used for the western United States studies, this difference may be more likely due to different climatic conditions and alluvial material.

\section{Rates of Tarim Subsidence and Convergence Along the Northern Front of the Western Kunlun}

It is reasonable to assume that the Hotan-Qira fault was active prior to the aggradation of the present piedmont, as suggested by the large vertical offset $(5-9 \mathrm{~km})$ of the paleozoic basement underneath. The total offset recorded by the surface can thus be used to estimate the average vertical throw rate across the fault system. Our reconstruction of long topographic profiles transverse to the fault shows that the total offset of the piedmont surface is approximately $70 \pm 20 \mathrm{~m}$ (Figure $4 \mathrm{~b}$ ). If, 

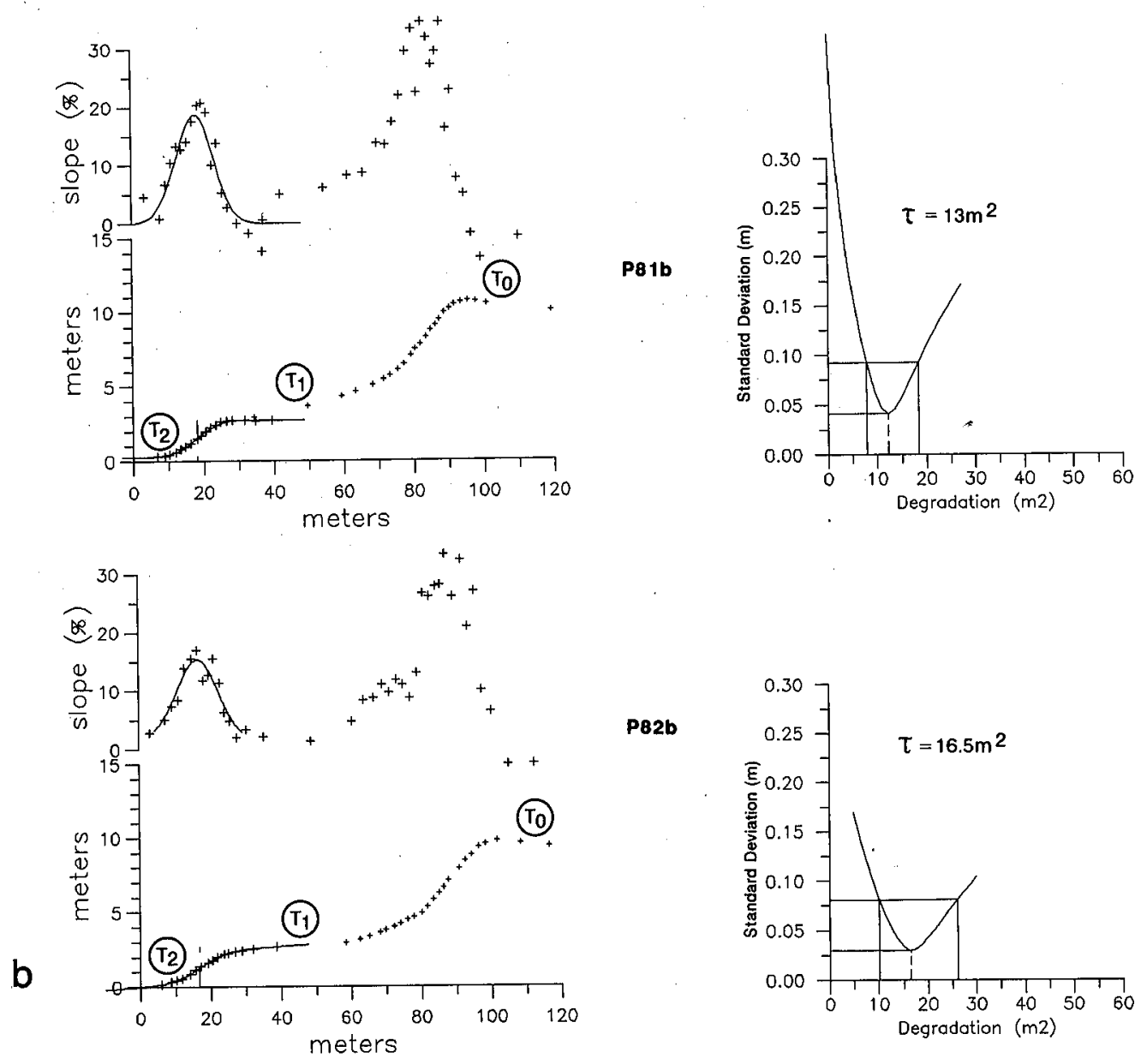

Fig. 21. (continued)

according to the discussion above, the age of the piedmont is $17 \pm 5 \mathrm{ka}$, the total vertical throw rate on the fault would be $4.1 \pm 2.4 \mathrm{~mm} / \mathrm{yr}$.

We have interpreted the Hotan-Qira fault as a crustal tear fault at the south-eastern edge of the Hotan flexural basin, thus being related to the Tarim subsidence due to the underthrusting of the Tarim basement under the Western Kunlun mountains (Figure 26a). Because additional vertical motion may occur on other faults, between the Hotan-Qira fault and the Kunlun northern front, the vertical throw rate determined on the Hotan-Qira fault represents a minimum estimate of the differential vertical motion between the mountain range and the Tarim slab. However, observation of satellite images of the Kunlun front shows no major active fault, south of the Hotan-Qira fault, suggesting that the rate deficiency due to such additional faults might be minor in this estimate. Gravity anomalies indicate that the western Kunlun range is undercompensated and Lyon-Caen and Molnar [1984] have attributed the undercompensation to the flexural rigidity of the underthrusting Tarim slab. In the case elastic forces which sustain the range remain constant through time, e.g., in a steady state underthrusting process, the uplift rate of the mountain range must result from isostatic adjustment only. Therefore the vertical throw rate of $4.1 \pm 2.4 \mathrm{~mm} / \mathrm{yr}$ resulting from underthrusting of the Tarim under the Kunlun would be partitioned into $3.5 \pm 2 \mathrm{~mm} / \mathrm{yr}$ of subsidence of the southern Tarim flexural basin and $0.6 \pm 0.4 \mathrm{~mm} / \mathrm{yr}$ of uplift of the
Kunlun range (assuming crustal and upper mantle densities of 2.8 and $3.3 \mathrm{~g} / \mathrm{cm}^{3}$, respectively).

If we assume that the Tarim basement underthrusts the Western Kunlun along a crustal ramp dipping $40^{\circ}-45^{\circ}$ to the south, such a process would absorb approximately $4.5 \pm 4$ $\mathrm{mm} / \mathrm{yr}$ of north-south convergence between the Tarim and western Tibet. Because a steeper crustal ramp is very unlikely, and because our estimate of the vertical movement between the Kunlun mountains and the Tarim slab is a minimum estimate, $4.5 \pm 3 \mathrm{~mm} / \mathrm{yr}$ must be considered as a lower bound of the actual crustal shortening rate taking place at the north front of the Western Kunlun range. As a lower bound, this value is consistent with the value of $6 \mathrm{~mm} / \mathrm{yr}$ derived from the velocity diagram displayed in Figure 26b [Avouac, 1991]. Using the geometric relationship between the two branches of the Altyn Tagh fault and the Gozha Co fault, rates of slip of $20 \mathrm{~mm} / \mathrm{yr}$ and $30 \mathrm{~mm} / \mathrm{yr}$ on the western and eastern branch of the Altyn Tagh fault [Armijo et al., 1989; Peltzer et al., 1989a] would imply approximately $7 \mathrm{~mm} / \mathrm{yr}$ of strike slip on the Gozha fault and $6 \mathrm{~mm} / \mathrm{yr}$ of thrusting in the Kunlun mountains [Avouac, 1991; Avouac and Tapponnier, 1993].

\section{APPENDIX A: Synthetic Fault Scarp Model}

In order to analyze cumulative fault scarps, we generate synthetic scarps following the sequence outlined in Figure A1. The model involves the succession of fault rupture events 
a

Site 5 , east

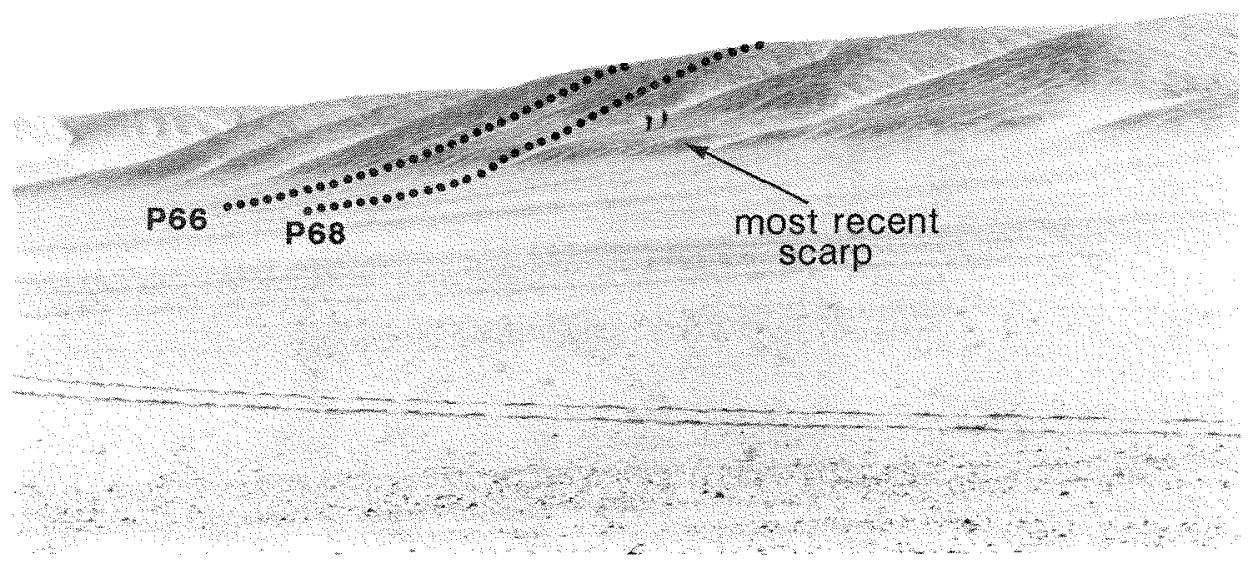

b
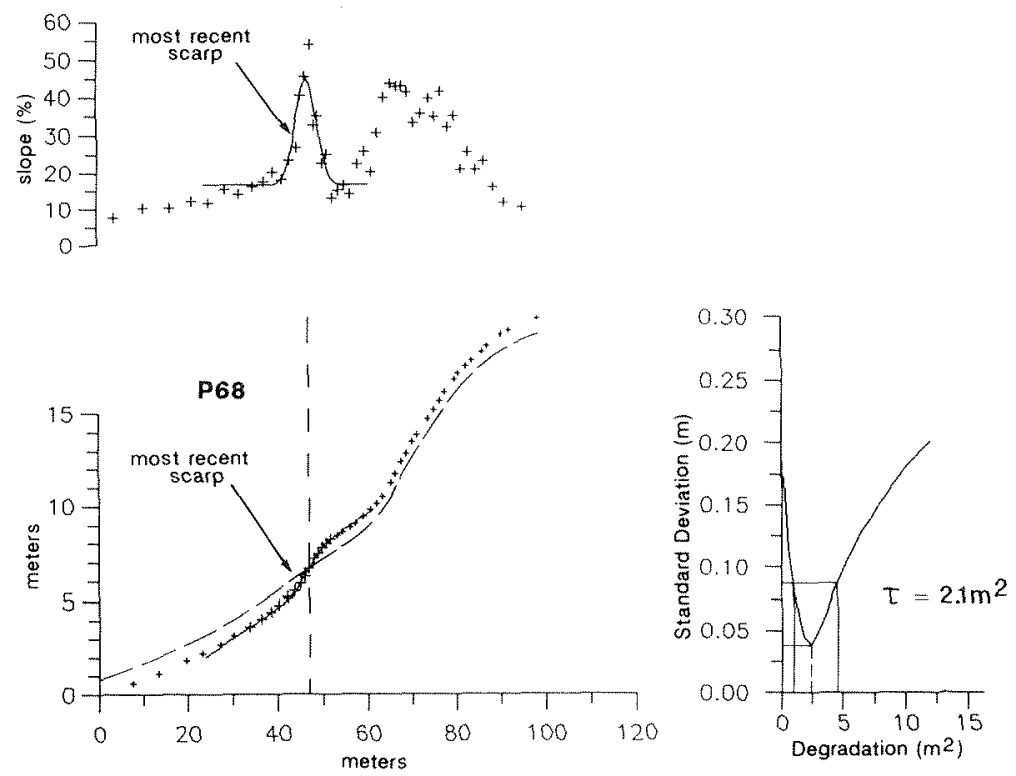

Fig. 22. (a) South looking view of fault scarp at site 5 (see location in Figure 14). Clear break in slope in basal part of fault scarp corresponds to $1.65 \mathrm{~m}$ of vertical offset and can be interpreted as most recent rupture event on fault. Solid circles indicate location of leveling profiles. (b) Analysis of part of profile P68 corresponding to most recent reactivation on fault. Plots and symbols are as in Figure 12. Dashed line in elevation profile plot is residual topography after best adjusted model for reactivation has been subtracted. (c) Elevation and slope distribution of profile P66. Note plateau at an angle close to the angle of repose of colluvial material in slope distribution profile.

inserted between regular dormancy intervals. Each increment is the result of an elementary vertical offset of amplitude $\Delta h$, followed by a gravitational phase during which the scarp tree face collapse forming a slope at the angle of repose of the colluvium material. In the field, we measured angles of repose of approximately $38^{\circ}$ (slope of $78 \%$ ) at the base of a terrace riser for which the gravitational phase was just completed. This angle corresponds to the angle of static friction of the colluviums. We noticed, however, that for almost all the scarps we have measured, the maximum slope angle never exceeded $31^{\circ}$ (slope of $60 \%$ ). This angle may correspond to the angle of dynamic friction and may better represent the initial scarp slope angle before diffusive erosion starts [Nash, 1980]. We have chosen a value of $\tan (\alpha)=0.6$ in the model. The scarp formation and the gravitational collapse are assumed to be instantaneous. Each event is followed by a period of dormancy $\Delta t$ during which the scarp degrades under the action of erosion. The effect of erosion is modeled as a Gaussian smoothing of the scarp elevation profile [Avouac, 1993]. Dormancy intervals are characterized by the quantity of erosion $\Delta \tau$ that scarps undergo 


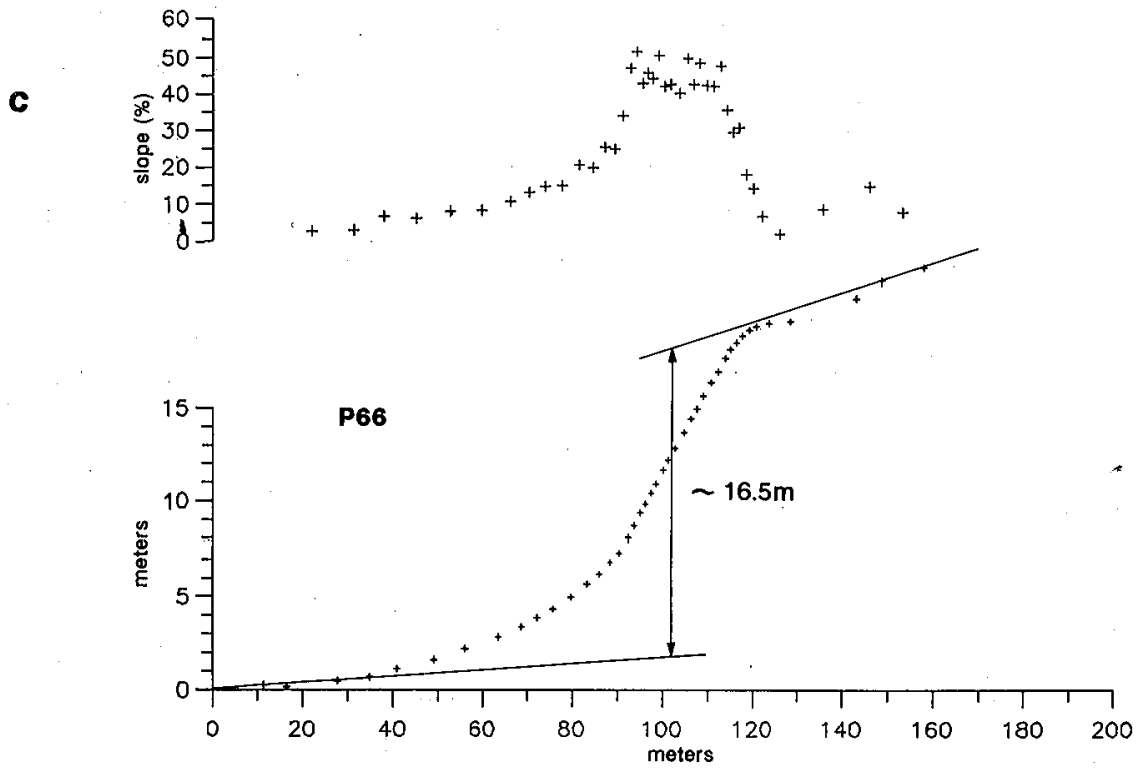

Fig. 22. (continued)

before the next fault rupture. In the erosion model, this quantity is measured by the width of the Gaussian curve used in the convolution of the scarp profile. $\Delta \tau$ is an elementary coefficient of degradation and is related to dormancy intervals duration $\Delta t$ by $\Delta \tau=k \Delta t, k$ being the mass diffusivity constant of the colluvium material under given climatic conditions. Figure A1 shows a series of two faulting events. Note that after the second event, most of the scarp slope is rejuvenated at the angle of repose of the colluvium. This effect which erases most of the memory of the previous event in the scarp morphology has a major influence on the final shape of a multievent scarp. Scarps which have been recently reactivated such as those at site 5 exhibit a steep, linear slope, forming a flat plateau on the slope profile (e.g., P66, Figure 22c). Reactivated profile P68 (Figure 22b) does not display such a plateau since reactivation

TABLE 4. Mean Vertical Offset of Terraces, and Inferred Vertical Throw Rates.

\begin{tabular}{lccccc}
\hline Site & $\begin{array}{c}\text { T0, } \\
\mathrm{m}\end{array}$ & $\begin{array}{c}\mathrm{T} 1, \\
\mathrm{~m}\end{array}$ & $\begin{array}{c}\mathrm{T} 2, \\
\mathrm{~m}\end{array}$ & $\begin{array}{c}\text { Single } \\
\text { Event, } \mathrm{m}\end{array}$ & $\begin{array}{c}\text { Rate, } \\
\mathrm{mm} / \mathrm{yr}\end{array}$ \\
\hline Site 1 & $10.4 \pm 1.0$ & & & & 0.61 \\
Site 2 & $10.5 \pm 0.7$ & & & & 0.62 \\
Site 3 & $8.9 \pm 0.7$ & $5.4 \pm 0.5$ & $3.5 \pm 0.5$ & $1.4 ?$ & 0.58 \\
Site 4 & $5.35 \pm 0.4$ & $3.1 \pm 1$ & & $1.3 ?$ & 0.35 \\
Site 5 & $16 \pm 0.7$ & $9.4 \pm 1.2$ & $6.5 \pm 0.6$ & $1.65 \pm .15$ & 0.95 \\
Site 6, east & $22.3 \pm 1.7$ & $13.5 \pm 1.2$ & & $1.8 ?$ & 1.30 \\
Site 6, middle & $21.3 \pm 2.7$ & $13.7 \pm 1.8$ & & & 1.25 \\
Site 6, west & $21.0 \pm 1.6$ & $13.7 \pm 1.3$ & $8.5 \pm 0.7$ & $1.58 \pm .3$ & 1.25 \\
Site 7 & $13.5 \pm 1.8$ & $7.8 \pm 1.0$ & & & 0.80
\end{tabular}

Mean values of offset are calculated from measurements in Table 1 for sites 1-4 and 6-mid (P44 and P45) and derived using graphical regression in Figure 15 for site 5, Figure $18 \mathrm{~b}$ for site 6-east, Figure $17 \mathrm{~b}$ for site 6 west, and Figure $20 \mathrm{~b}$ for site 7 . Uncertainty on mean offset value at each site is computed assuming gaussian distribution of errors on offset measurements. Characteristic standard deviation of $13 \%$ on individual offset measurements is estimated from longest series of measurements of same scarp (site 5, Table 1). Throw rates are calculated assuming age of Qira alluvial fan surface (T0) to be $17 \pm 5 \times 10^{3}$ years (see text). took place at the base of the older scarp. It is thus clear that the overall shape of a scarp profile will depend on the elapsed time since the last reactivation. Since, except at site 5, all the scarps we have surveyed do not display evidence of recent

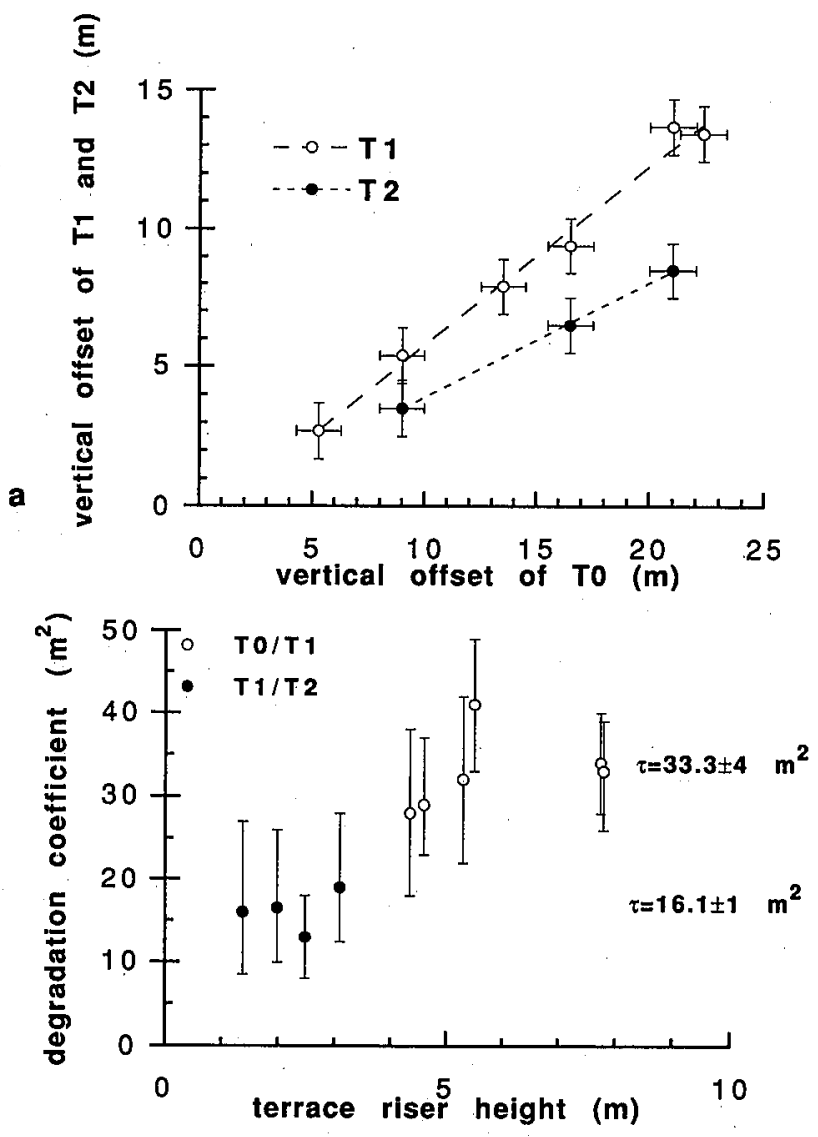

Fig. 23. (a) Plot of vertical offsets of terraces $T 1$ and $T 2$ as a function of vertical offset of terrace T0 at same site. (b) Plot of degradation coefficients derived from analyses of terrace risers T0-T1 and T1-T2 as a function of terrace riser height (Table 3 ). 

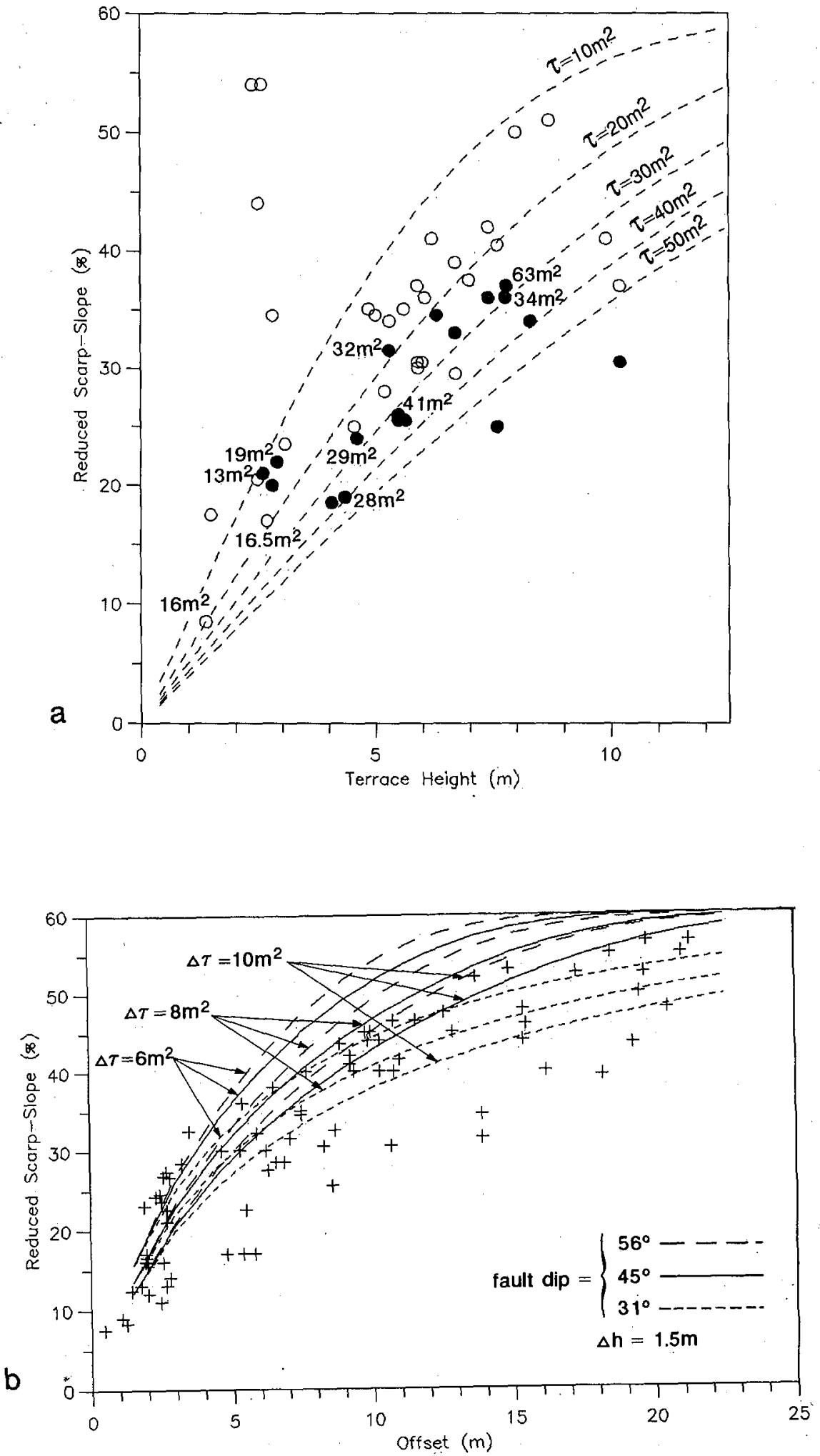

Fig. 24. (a) Plot of reduced scarp slope $(\tan \alpha-\tan \beta)$ as a function of terrace height. Solid circles are profiles across terrace riser $\mathrm{T} 0$ - T1 and open circles across T1-T2. Numbers indicate values of degradation coefficient when determined by best adjustment to synthetic profile (Table 3). Curves are error functions corresponding to various degradation coefficients and derived from diffusion model. (b) Same as Figure 24a for cumulative fault scarps. Scarps of site 5 are not displayed since they show evidence of recent reactivation (see discussion in Appendix A). Curves have been computed from a series of synthetic scarps generated with a fault scarp incremental model (Appendix A). Scarp slope for synthetic scarps is taken at end of dormancy periods. 
Age (ka)

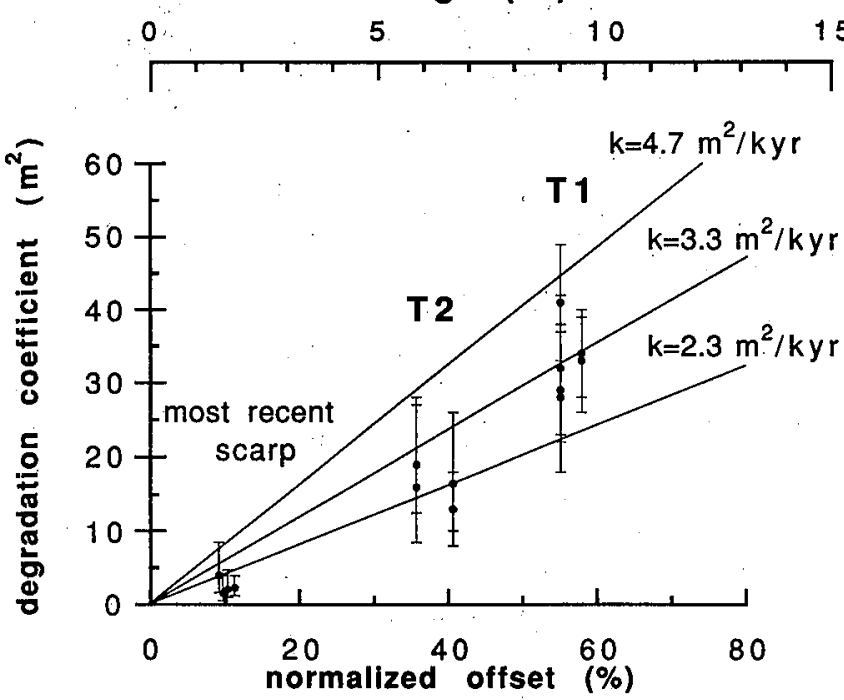

Fig. 25. Plot of degradation coefficients of terrace risers as a function of corresponding terrace total uplift, normalized by total uplift of terrace TO at same site. Time scale displayed on top of graph is based on assumption that terrace T0 and Qira fan emplaced at $17 \pm 5 \mathrm{ka}$. Data are consistent with degradation coefficient linearly dependent of age and mass diffusivity constant of $3.3 \pm 1.4 \mathrm{~m}^{2} / 10^{3}$ years. reactivation, we have assumed, for comparison with synthetic scarps, that elapsed time since last reactivation was close to dormancy interval $\Delta t$.

Figure A2 shows various elevation and slope profiles of a 10-m-high-scarp for different numbers of events $(N)$. The elapsed time since the first rupture is supposed to be the same in all cases. In the case of a single event scarp, the elapsed time corresponds to a degradation coefficient $\tau=40 \mathrm{~m}^{2}$. In each case, the incremental vertical throw $\Delta h$ is chosen such as $N \Delta h=10 \mathrm{~m}$, and the dormancy interval duration $\Delta t$, such as $N k \Delta t=40 \mathrm{~m}^{2}$. As expected, the figure shows important increases of the maximum slope of the scarp as the number of events increases. This is due to the multiple rejuvenation of the slope in the central part of the scarp. In the case of a large number of events, the maximum slope angle would approach the angle of repose of the colluvium material. The figure also shows that increasing the number of events above 10 or 15 would not change the overall shape of the scarp nor increase significantly its maximum slope.

Figure A3 shows the effect of the fault dip angle on the elevation and slope profiles of scarps. Maximum scarp slope angle appears to increase with fault dip angle and the largest variations are observed for dip angles lower than $45^{\circ}$. Cumulative slip increments on a fault with a low dip angle stretch the profile of the scarp by gradually moving apart the

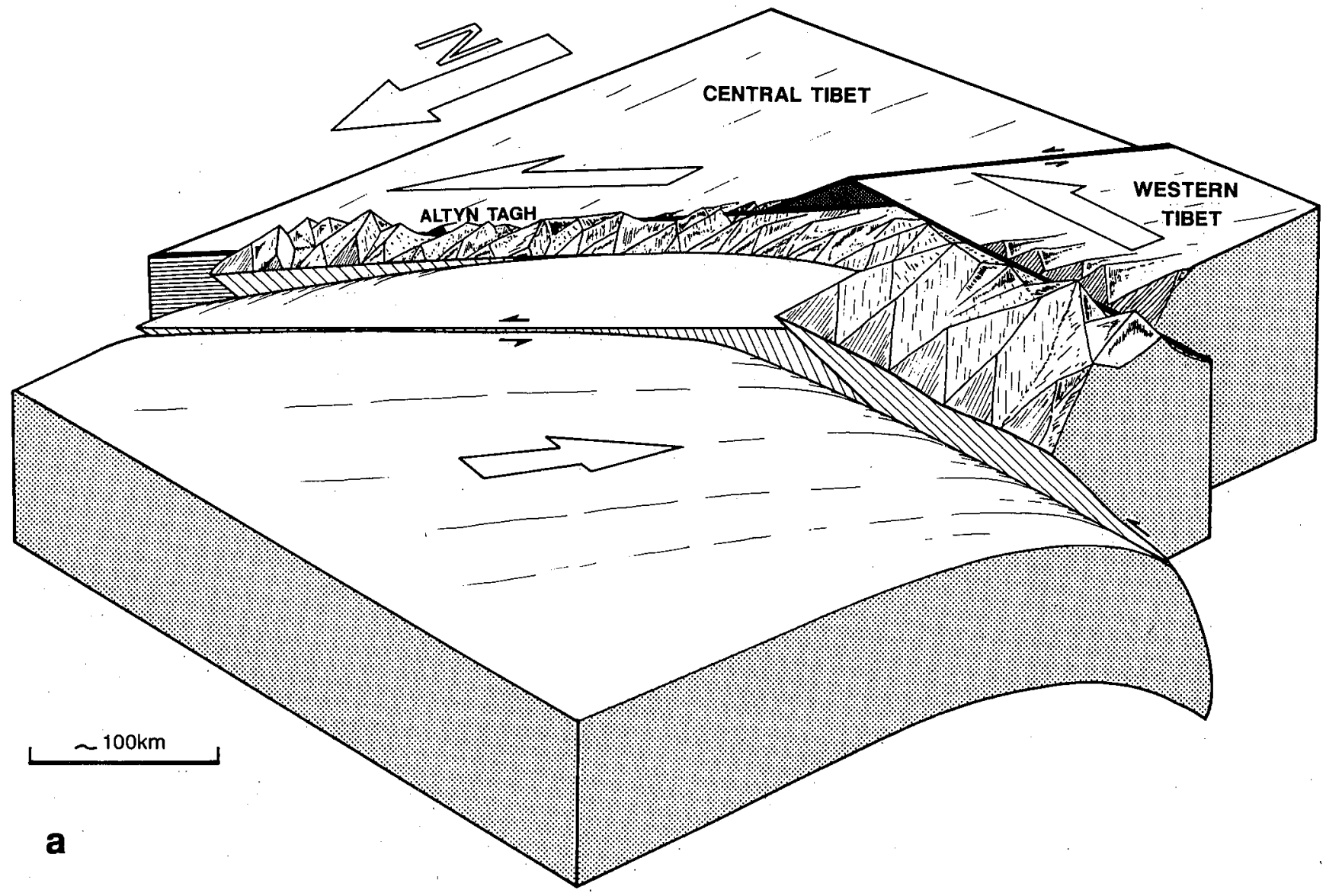

Fig. 26. (a) Idealized block diagram of crustal faulting in southern Tarim and western Tibet. Tarim basement underthrusts western Kunlun along deep crustal ramp which may join at depth with western segment of the Altyn Tagh fault. The HotanQira fault is viewed as tear crustal fault at southeast limit of subsiding flexural basin. (b) Simplified map view of fault triple junction in western Tibet and velocity diagram constrained by fault geometry and rate of slip on both west and east Altyn Tagh fault segments [after Avouac, 1991]. 


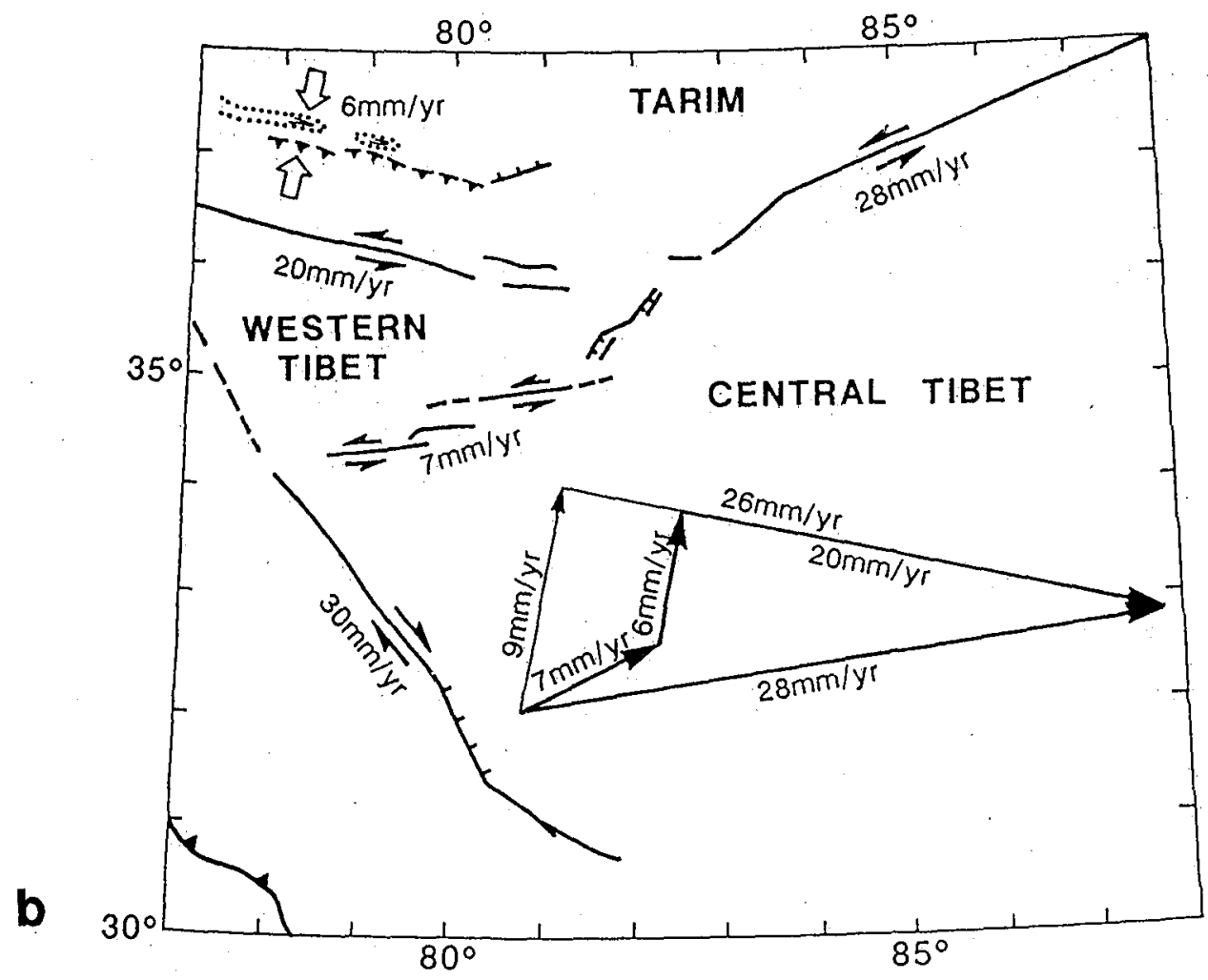

Fig. 26. (continued)

two sides of the eroded scarp. Low dipping faults then produce smoother and longer scarp profiles than steep faults. This effect is not apparent on scarps resulting from a single rupture since the initial shape of the scarp, after the gravitational phase, is controlled by the angle of repose of the colluvium material. This of course does not hold in the unlikely case of a fault dip angle smaller than the angle of repose of the material (approximately $30^{\circ}$ ).

Our fault scarp model is ideal and is based on a number of assumptions which may not apply to all fault scarps. In particular, we have implicitly assumed that all ruptures reached the surface along the same fault plane. Introducing a variable rupture abscissa into the model would increase the number of parameters and would render the problem underdetermined. The effect of distributing individual ruptures of a cumulative fault scarp over a finite length would be to form a longer scarp profile, and, as a consequence a smaller scarp slope. Then, depending on how individual ruptures are distributed with time over the finite length, the steep segment of such scarps may be at the base, in the center or at the crest. Our approach was thus to consider the entire set of scarp measurements on a scarp slope versus offset graph, and to compare our measurements with curves representing ideal distributions of scarps and generated using our synthetic scarp model. According to the discussion above, measured scarps should fall on or below a given curve; the upper envelope of the measured scarp distribution would thus characterize the various parameters of the model. Figures $\mathrm{A} 4 \mathrm{a}$ and $\mathrm{A} 4 \mathrm{~b}$ show different curves on slope offset graphs generated with various sets of parameters $\Delta h, \Delta \tau$ and fault dip angle. Curves appear to be relatively insensitive to variations of parameters $\Delta h$ and $\Delta \tau$, in the range of possible values for $\Delta h$, as long as their ratio remains constant. This means that, even if our estimate of the characteristic increment $\Delta h$ is biased by a factor of 2 , our analysis would constrain relatively well the vertical slip rate on the fault. Similarly, variations of the fault dip angle appear to have essentially no effect on the curves, except for low angle $\left(<45^{\circ}\right)$ dipping faults. In the present case of a system of normal faults, it is reasonable to assume that all faults have dip angles higher than $45^{\circ}$. Therefore errors in the determination of fault dip angle does not seem to bias our estimate of fault slip rate either.

Acknowledgments. The research described in this paper was carried out by the Institute de Physique du Globe de Paris (France) and the Jet Propulsion Laboratory, California Institute of Technology, respectively, under contra $t$ with the Centre National de la Recherche Scientifique and the national Aeronautics and Space Administration. We are grateful to Paul Tapponnier who discovered the Hotan fault on Landsat images and pinpointed the interest of the site. Numerous discussions with him were essential and enlightening. Special thanks goes to Pierre Gentelle for supporting one of us (J $>$ P $>$ A.) during the field campaign, and Liang Kuang Yi for the organization of the field program. We also benefitted from discussion with Tom Farr, Diane Evans, and Pierre Gentelle. Guy Aveline drafted the figures and maps. Comments by Thomas Hanks were very helpful. We thank Thomas Hanks and lark Burchfiel for reviewing the paper. This IPGP contribution 1267. 


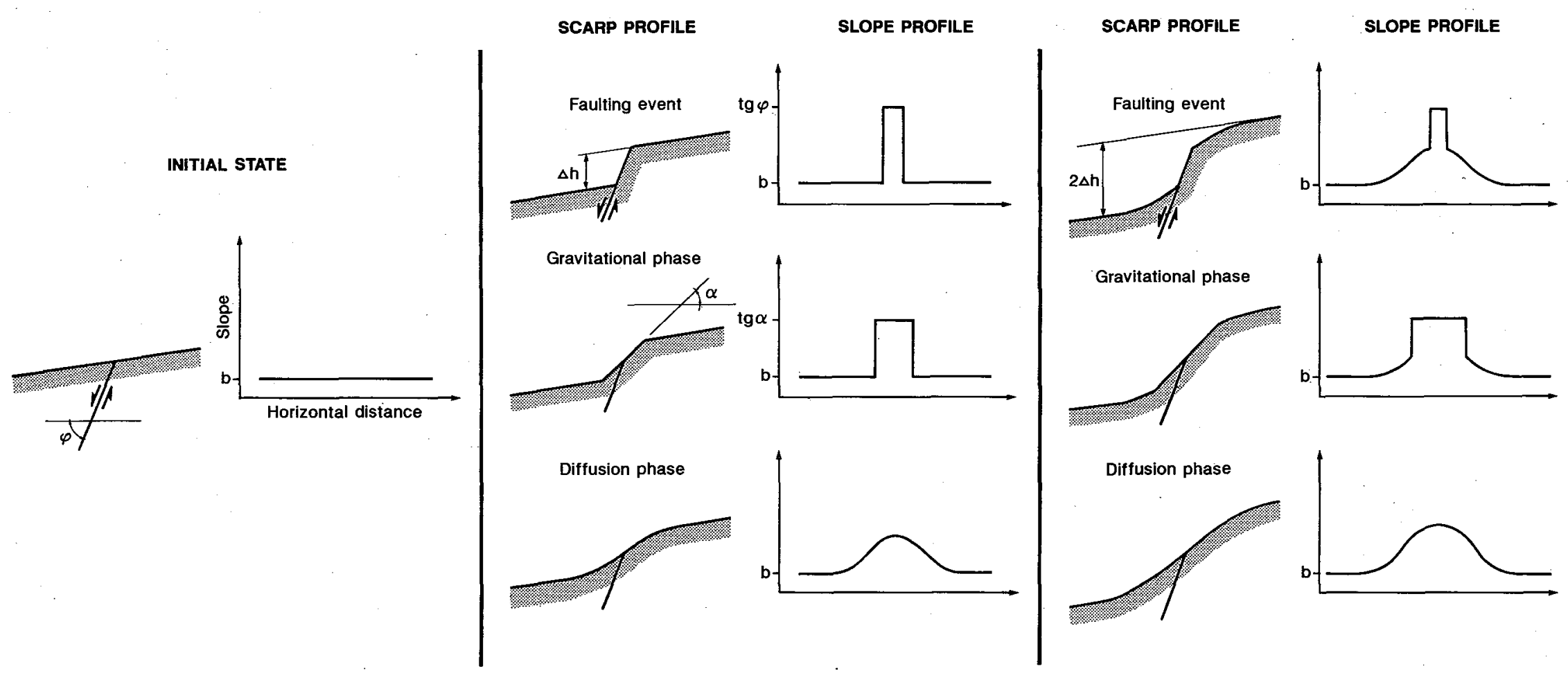

Fig. A1. Successive scarp geometries in fault scarp incremental model. Note that after second faulting event, scarp slope is rejuvenated at angle of repose over most of its length. 

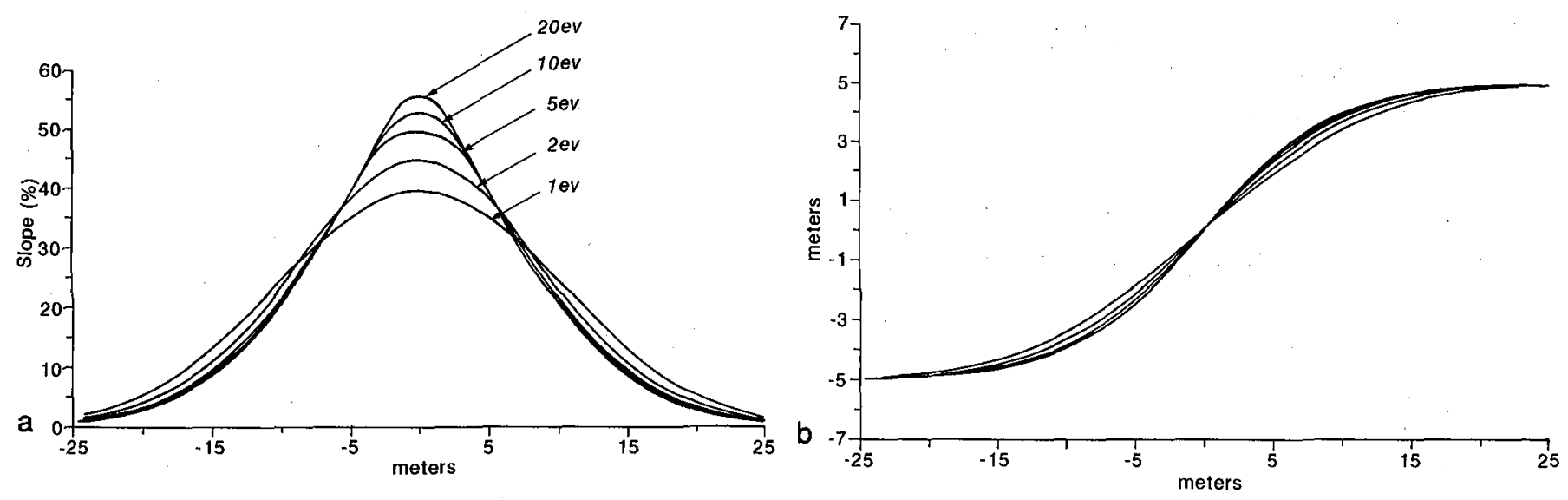

Fig. A2. Comparison of (a) scarp slope and (b) elevation profiles for scarps resulting from 1, 2, 5, 10, and 20 events. In four cases, final scarp height is $10 \mathrm{~m}$ and total elapsed time since first faulting event is the same. Elapsed time corresponds to a degradation coefficient of $40 \mathrm{~m}^{2}$ in the case of single event scarp.
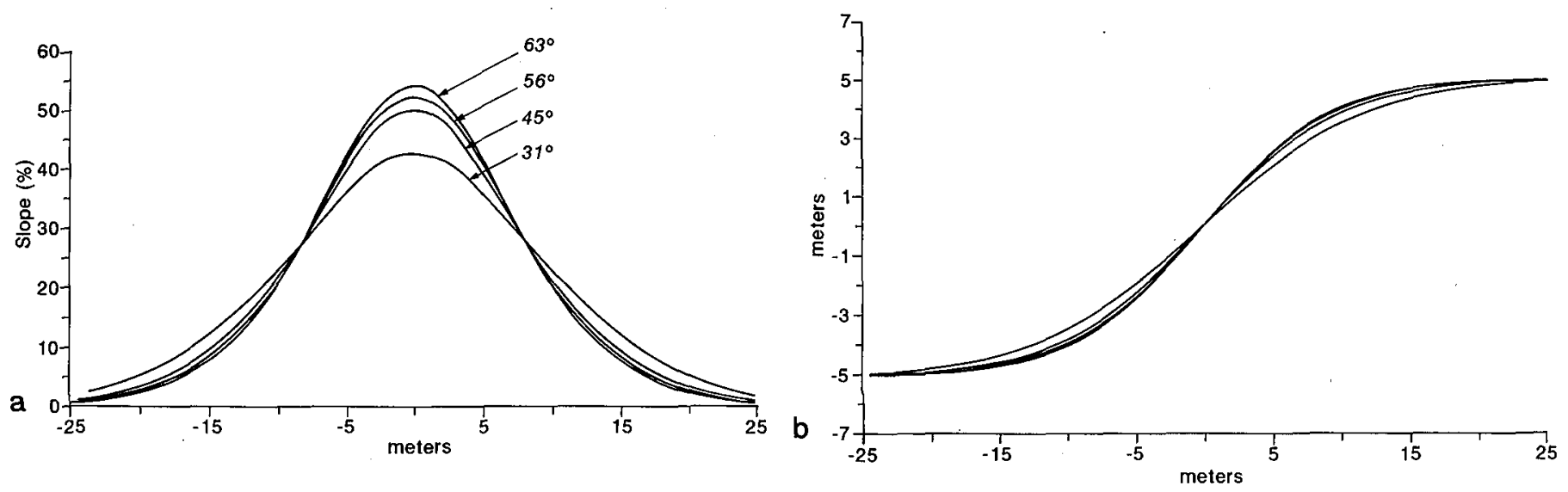

Fig. A3. Comparison of (a) scarp slope and (b) elevation profiles for scarp resulting from slip on fault planes dipping $31^{\circ}, 45^{\circ}$, $56^{\circ}$, and $63^{\circ}$. In each case, scarp results from five faulting events of $2-\mathrm{m}$ amplitude and dormancy intervals corresponding to degradation coefficient $\Delta \tau=8 \mathrm{~m}^{2}$.
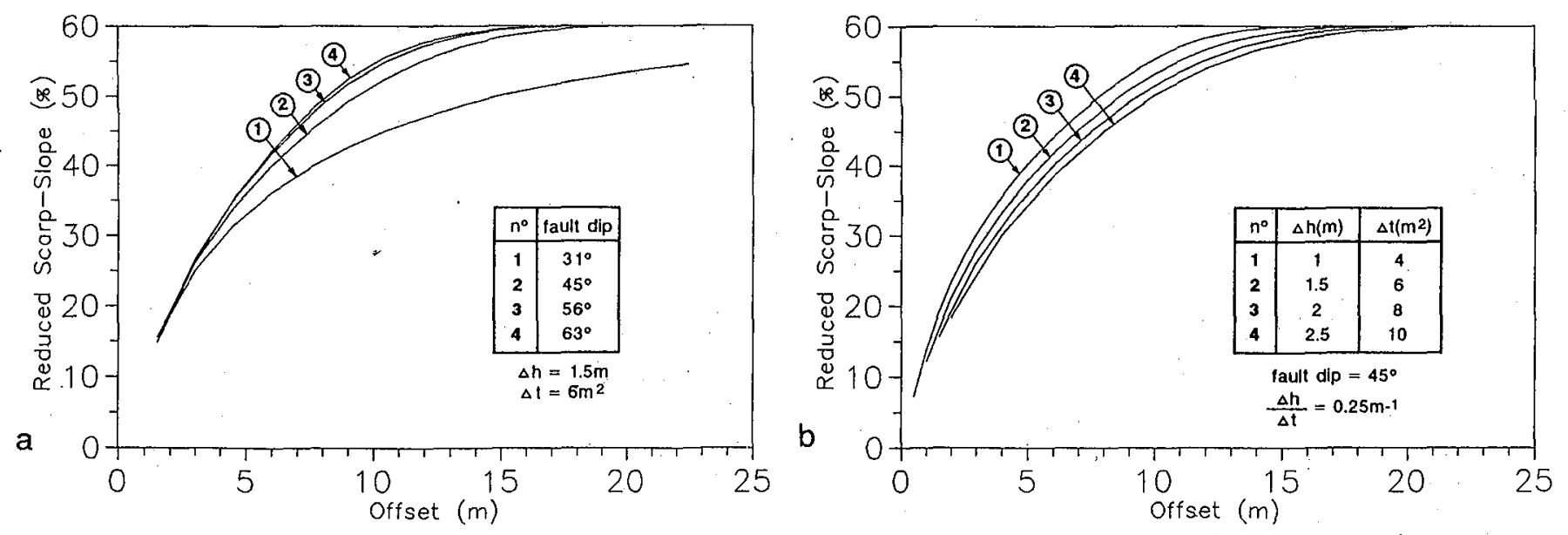

Fig. A4. Comparison of scarp slope versus offset curves obtained (a) with scarps resulting from slip on fault at constant average rate, with various sets of parameters $\Delta h, \Delta \tau$, and fault dip of $45^{\circ}$, and (b) with scarps resulting from slip on faults having different dips, and $\Delta h$ and $\Delta \tau$ constant. In Figures $A 4 a$ and $A 4 b$, value of ratio $\Delta h / \Delta \tau$ is $0.25 \mathrm{~m}^{-1}$. Using $k=3.5 \mathrm{~m}^{2} / \mathrm{s}$ for mass diffusivity constant, this corresponds to vertical slip rate of $0.88 \mathrm{~mm} / \mathrm{yr}$ on fault. 


\section{REFERENCES}

Andrews; D. J., and R. C. Bucknam, Fitting degradation of shoreline scarps by a nonlinear diffusion model, J. Geophys. Res., 92, 12857 $12867,1987$.

Andrews, D. J., and T. C. Hanks, Scarps degraded by linear diffusion: inverse problem for age, J. Geophys. Res., 90, 10193-10208, 1985.

Armijo, R., P. Tapponnier, and H. Tonglin, Late Cenozoic right-lateral strike-slip faulting in Southern Tibet, J. Geophys. Res., 94, 2787-2838, 1989.

Avouac, J. P., Application des methodes de morphologie quantitative à la neotectonique, modèle cinématique des déformations actives en Asie Centrale, thèse de doctorat, Univ. Paris VII, 1991.

Avouac, J. P., Analysis of scarp profiles: Evaluation of errors in morphologic dating, J. Geophys. Res., 98, 6745-6754, 1993.

Avouac, J.P., and P. Tapponnier, Kinematic model of active deformation in Central Asia, Geophys. Res. Lett., 20, 895-898, 1993.

Avouac, J.P., P. Tapponnier, M. Bai, H. You, and G. Wang, Active thrusting and folding along the northeastern Tien Shan, and rotation of Tarim relative to Dzungaria and Kazakhstan, J. Geophys. Res., 98, 6755-6804, 1993.

Bally, A. W., I. Ming Chou, R. Clayton, H.P. Heugster, S. Kidwell, L.D. Meckel, R.T. Ryder, A. B. Watts, and A. A. Wilson, Notes on sedimentary basins in China, Report of the American Sedimentary Basins Delegation to the People's Republic of China, August 17 September 8, 1985, U.S. Geol. Surv. Open File Rep., 86-327, 108 pp., 1986.

Bard, E., B. Hamelin, R. G. Fairbanks and A. Zindler, Calibration of the $14 \mathrm{C}$ timescale Over the past 30,000 years using mass spectrometric U-Th ages from Barbados corals, Nature, 345, 405-409, 1990.

Beijing Map Publishing House, Atlas of People's Republic of China, 1984.

Bureau of Geology and Mineral Resources of Xinjiang, Geological map of Xinjiang-Uygour Autonomous Region, scale 1/2000000, 1985.

Burov, E.V., M.G. Kogan, H. Lyon-Caen and P. Molnar, Gravity anomalies, the deep structure, and dynamic processes beneath the Tien Shan, Earth Planet. Sci. Lett., 96, 367-383, 1990.

China Cartographic Publishing House, Seismotectonic map of Xinjiang, lithospheric dynamics atlas of China, edited by Ma Xingyuan, Beijing, 1989.

Defense Mapping Agency, Operational Navigation Chart G-7, 1:1,000,000, St. Louis, Mo., 1980.

Dormös, M., and G. Peng, The climate of China, p. 360, SpringerVerlag, New-York, 1988.

Fairbanks, R., A 17,000 yr glacio-eustatic sea level record: Influence of glacial melting rates on the younger dryas event and deep ocean circulation, Nature, 342, 637-642, 1989.

Gasse, F., et al., 13,000 yr Climate record from western Tibet, Nature, $353,742-745,1991$.

Hanks, T. C., and J. Andrews, Effect of far-field slope on morphologic dating of scarplike landforms, J. Geophys. Res., 94, 565-573, 1989.

Hanks, T. C., and R. E. Wallace, Morphological analysis of the Lake Lahontan shoreline and beachfront fault scarps, Pershing County, Nevada, Bull. Seismol. Soc. Am., 75 (3), 835-846, 1985.

Hanks, T. C., R. C. Bucknam, K. R. Lajoie, and R.E. Wallace, Modification of wave cut and faulting-controlled landforms, $J$. Geophys. Res., 89, 5771-5790, 1984.

Hovermann, J., and E. Hovermann, Pleistocene and holocene geomorphological features between the Kunlun Mountains and the Taklimakan Desert, Die Erde, 6, 51-72, 1991.

Institute of Geophysics, The Catalog of Strong Shocks of China, Academia Sinica, Beijing, 1976.

Jakel, D., and J. Hofmann, Glacial and periglacial features in the Upper Keriya Valley (Kunlun Mountains), Die Erde, 6, 35-50, 1991.

Jakel, D., and Z. Zhu, Reports on the 1986 Sino-German Kunlun Shan Taklimakan-Expedition, Die Erde, 6, p. 202, 1991.

Lyon-Caen, H., and P. Molnar, Gravitiy anomalies and the structure of Western Tibet and the Southern Tarim basin, Geophys. Res. Lett., 11, 1251-1254, 1984.
Ma, X., Lithospheric dynamic map of China and adjacent seas with explanatory notes, scale 1:4,000,000, Geological Publishing House, Beijing, 1987.

Martinson, D. G., et al., Age dating and the orbital theory of the ice ages: Development of the high resolution 0 to $300,000 \mathrm{yr}$ chronostatigraphy, Quat. Res.,, N. Y., 27. 1-29, 1987.

Mayer, L., Dating Quaternary fault scarps formed in alluvium using morphologic parameters, Quat. Res., N. Y., 22, 300-313, 1984.

Molnar, P., and H. Lyon-Caen, Fault plane solutions of earthquakes and active tectonics of the Tibetan plateau and its margins, Geophys, $J$. Int., 99, 123-153, 1989.

Molnar, P., and Q. D. Deng, Faulting associated with large earthquakes and the average rate of deformation in central and eastern Asia, $J$. Geophys. Res., 89, 6203-6228, 1984.

Molnar, P., and P. Tapponnier, A possible dependence of tectonic strength on the age of the crust in Asia, Earth Planet. Sc. Lett., 52, 107-114, 1981.

Molnar, P., and P. Tapponnier, Cenozoic tectonics of Asia, Effects of a continental collision, Science, 189, 419-426, 1975.

Nash, D. B., Morphological analysis of degraded normal fault scarps, $J$. Geol., 88, 353-360, 1980 .

Nelson, M. R., R. McCaffery, and P. Molnar, Source parameters for 11 earthquakes in the Tien Shan, Central Asia, determined by $\mathrm{P}$ and $\mathrm{SH}$ waveform inversion, J. Geophys. Res., 92, 12629-12648, 1987.

$\mathrm{Ni}$, J., Contemporary teconics in the Tien Shan region, Earth Planet. Sci. Lett., 41, 347-355, 1978.

Norin, E., Geological reconnaissance in the Chinese Tien Shan, Reports from the scientific expedition to the northwestern provinces of China under the leadership of Dr. Sven Hedin, Publ. 29, (IV), Geol. 7, Tryckeri Aktiebolaget Thule, Stockholm, 1946.

Peltzer, G., P. Tapponinier, Y. Gaudemer, B. Meyer, S. Guo, K. Yin, C. Chen and H. Dai, Offsets of late Quaternary morphology, rate of slip and recurrence of large earthquake on the Chang Ma Fault, $J$. Geophys. Res., 93, 7793-7812, 1988.

Peltzer, G., P. Tapponnier, and R. Armijo, Magnitude of late Quaternary left-lateral displacements along the north edge of Tibet, Science, 246, 1285-1298, 1989a.

Peltzer, G., J. Avouac, and P. Tapponnier, Active Faulting in Southern Tarim basin, Xinjiang, China, (abstract), Eos Trans., AGU, 70, 43, $1989 \mathrm{~b}$.

Tapponnier ,P., and P. Molnar, Active faulting and Cenozoic tectonics of the Tien Shan, Mongolia and Baykal regions, J. Geophys. Res., 84, 3425-3459, 1979.

Tapponnier, P., and P. Molnar, Active faulting and tectonics of China, $J$. Geophys. Res., 82, 2905-2930, 1977.

Tapponnier, P., B. Meyer, J.P. Avouac, G. Peltzer, Y. Gaudemer, G. Shunmin, X. Hongfa, Y. Kelun, C. Zhitai, C. Shuahua, and D. Huagang, Active thrusting and folding in the Qilian Shan, and decoupling between upper crust and mantle in northeastern Tibet, Earth Planet. Sci. Lett., 97, 382-403, 1990.

Times Atlas of the World, Times Book, London, 1978.

Wallace, R. E., Profiles and ages of young fault scarps, north central Nevada, Geol. Soc. Am. Bull., 88, 1267-1281, 1977.

York, J., R. Cardwell, and J. Ni, Seismicity and Quaternary faulting in China, Bull. Seismol. Soc. Am., 66 (6), 1983-2001, 1976.

Zhu, Z., Aeolian landforms in Taklimakan Desert, in Desert and Arid Lands, edited by F. El-Baz, pp. 133-143, Martinus Nijhoff Dordrecht, Netherlands, 1984.

J.P. Avouac, Laboratoire de Détection Géophysique, CEA, B. P. 12 , 91680 Bruyère le Châtel, France.

G. Pelzer, Jet Propulsion Laboratory, California Institute of Technology, 4800 Oak Grove Drive, Pasadena, CA 91109.

(Received October 10, 1990; revised July 26, 1993; accepted July 30,1993 .) 